NBER WORKING PAPER SERIES

\title{
THE ROOTS OF HEALTH INEQUALITY AND THE VALUE OF INTRA-FAMILY EXPERTISE
}

\author{
Yiqun Chen \\ Petra Persson \\ Maria Polyakova
}

Working Paper 25618

http://www.nber.org/papers/w25618

\author{
NATIONAL BUREAU OF ECONOMIC RESEARCH \\ 1050 Massachusetts Avenue \\ Cambridge, MA 02138 \\ February 2019
}

We gratefully acknowledge support from the National Institute on Aging (R21AG052833), University of Chicago Becker Friedman Institute, Stanford Spectrum Pilot Grants for Population Health Sciences (NIH 5UL1TR001085), Stanford Institute for Research in the Social Sciences, and Stanford Institute for Economic Policy Research. We are grateful to Adam Altmejd, Marika Cabral, Alice Chen, Raj Chetty, Janet Currie, Liran Einav, Amy Finkelstein, Matt Gentzkow, Mark Hlatky, Jonathan Kolstad, Camille Landais, Adriana Lleras-Muney, Douglas Owens, Maxim Pinkovskiy, Luigi Pistaferri, Maya Rossin-Slater, Jesse Shapiro, Heidi Williams, and seminar participants at Stanford's Opportunity Lab, MIT, University of California at Berkeley, Columbia University, Stanford University, University of California San Diego, Hebrew University, Tel Aviv University, Ben-Gurion University, University of Munich, University of Regensburg, University of San Francisco, University of Southern California, University of Warwick, London School of Economics joint with IFS, Berlin Applied Micro Seminar, University of British Columbia, University of Chicago Booth, the NBER Summer Institute, AshEcon 2019, WEAI 2019, and NBER Health Care. We are especially grateful to Katja Hofmann and Felipe Kup for excellent research sssistance. The views expressed herein are those of the authors and do not necessarily reflect the views of the National Bureau of Economic Research.

NBER working papers are circulated for discussion and comment purposes. They have not been peerreviewed or been subject to the review by the NBER Board of Directors that accompanies official NBER publications.

(C) 2019 by Yiqun Chen, Petra Persson, and Maria Polyakova. All rights reserved. Short sections of text, not to exceed two paragraphs, may be quoted without explicit permission provided that full credit, including $(\odot$ notice, is given to the source. 
The Roots of Health Inequality and The Value of Intra-Family Expertise

Yiqun Chen, Petra Persson, and Maria Polyakova

NBER Working Paper No. 25618

February 2019, Revised June 2020

JEL No. D12,D83,G22,H1,H4,I13,I14

\section{ABSTRACT}

Do differences in health literacy contribute to the widely documented health-income gradient? In the context of Sweden, we document a strong relationship between exposure to health-related expertise - captured by the presence of a health professional in the family - and health. Exposure to expertise raises preventive health investments throughout the lifecycle, improves physical health, and prolongs life. Two quasi-experimental research designs - admissions lotteries into medical school and variation in the timing of medical degrees - support a causal interpretation of these effects. We estimate that unequal exposure to health-related expertise may account for up to 18 percent of the population-wide health-income gradient.

Yiqun Chen

615 Crothers Way

Stanford University

Stanford, CA 94305

ychen13@stanford.edu

Petra Persson

Department of Economics

Stanford University

579 Serra Mall

Stanford, CA 94305

and NBER

perssonp@stanford.edu
Maria Polyakova

Department of Health Research \& Policy

Stanford University

Redwood Building T111

150 Governor's Lane

Stanford, CA 94305

and NBER

maria.polyakova@stanford.edu 


\section{Introduction}

Poorer people have worse health at birth, are sicker in adulthood, and die younger than richer people. Indeed, mounting evidence across various disciplines reveals stark correlations between health throughout the course of life and a range of measures of socioeconomic status (SES) (see, e.g., Marmot et al. 1991, Case et al. 2002, Deaton 2002, Currie 2009, and Lleras-Muney 2018). There is less evidence, however, on the magnitude and direction of the causal links between SES and health. Some of the channels that have been proposed include differences in initial endowments at birth, in access to health care, and in health behaviors across the SES spectrum, as well as incomplete insurance of income losses in response to health shocks. ${ }^{1}$

In this paper, we investigate whether (unequal) exposure to health-related expertise is an underlying causal mechanism that contributes to the health-income gradient. Exposure to health-related expertise may build "health literacy" that can help sustain better health throughout one's life. ${ }^{2}$ If so, then a lifetime of unequal exposure to expertise across the income ladder could induce and sustain a socioeconomic gradient in health. The aim of this paper is take this idea to the data, in two steps: First, we investigate if access to health-related expertise improves health. Second, we quantify the potential contribution of this channel to health inequality.

To accomplish this, we face two empirical challenges. First, individuals may have access to many sources of health-related expertise, and this exposure is not randomly assigned. Thus, it is difficult to separate the impact of better access to expertise from other unobservable differences between individuals with and without such access. To address this, we zoom in on an environment where the institutional setting provides several sources of variation for causal identification. In particular, we use the presence of a health professional - a doctor or nurse - within the family as a measure of exposure to health-related expertise.

Second, as emphasized by Currie (2011), analyses of health inequality, while ubiquitous, suffer from a lack of comprehensive data on health outcomes, often relying on self-reported health rather than medical records, coupled with a lack of detailed measures of socioeconomic status. ${ }^{3}$ To overcome this, we use Swedish administrative population-wide tax records linked to birth and health records; these data are described in Section 2.

Beyond the availability of data, Sweden is a particularly attractive empirical context because its universal health insurance system allows us to shut down one often-hypothesized driver of health inequality: inequality in formal access to health care. Given this, we start by briefly examining whether there is any health-SES gradient

\footnotetext{
${ }^{1}$ See, e.g., Currie (2011), Aizer and Currie (2014), and Persson and Rossin-Slater (2018) on how early-life health disparities driven by differential in utero conditions or genetic capital may perpetuate economic inequality, and Black et al. (2007), Oreopoulos et al. (2008), Almond and Mazumder (2011), and Bharadwaj et al. (2018a,b) for more evidence on the causal relationship between early-life health and future economic or health outcomes. Further, on differences in health behaviors, see, e.g., Rehm et al. (2016) on dietary intake, Hiscock et al. (2012) on smoking, and Ogden et al. (2010) on obesity. The formation of these health behaviors is poorly understood (Hut and Oster 2018 provides the most recent example), and recent evidence emphasizes differences in education (e.g. Allcott et al. 2017), peer imitation (e.g. Fowler and Christakis 2008, Rosenquist et al. 2010, Rosenquist et al. 2011, and Salvy et al. 2012) or costs (e.g. Walker et al. 2010 and Allcott et al. 2017 and the broader literature on food deserts; Meckel 2017 on a food program for mothers).

${ }^{2}$ The US Institute of Medicine defines health literacy as "the degree to which individuals have the capacity to obtain, process, and understand basic health information and services needed to make appropriate health decisions." Throughout most of the paper, we maintain this broad interpretation of health literacy, as encompassing anything that helps individuals make better health investment decisions - for example, knowledge of what constitutes beneficial health behaviors, as well as knowledge of how to gain access to the best or most appropriate healthcare. Then, after estimating aggregate effects of exposure to expertise on health, we discuss potential underlying mechanisms.

${ }^{3}$ While Chetty et al. (2016) overcome this by linking mortality data to tax records, an analysis of inequality in health outcomes other than mortality requires data linking individual medical records to detailed measures of income.
} 
left in the setting that we study. Despite Sweden's universal health insurance and extensive social safety net, we document substantial health inequality, across the life cycle. In fact, at the end of life, health inequality is as pronounced in Sweden as it is in the United States. ${ }^{4}$ This underscores the importance of studying drivers of health inequality that go beyond the access to health insurance channel, and further motivates our analysis of the impact of access to expertise. ${ }^{5}$

In Section 3, we examine whether increased access to health-related expertise, captured by the presence of a health professional in the extended family, improves health. We trace health across the life cycle and examine two sets of outcomes: physical health and preventive health investments. We begin by comparing individuals in families with and without a health professional in the raw data. We show that, conditional on individual income rank at age 55, individuals with a doctor or nurse in the extended family are more likely to survive until age 80 and less likely to suffer from chronic lifestyle-related conditions. Further, children with a health professional in the extended family are substantially more likely to have undertaken a preventive investment that we observe HPV vaccination by age 20 - and less likely to have been exposed to tobacco in utero. ${ }^{6}$ These patterns in the raw data remain economically and statistically significant when we control non-parametrically for a wide range of observable demographics, in the spirit of the identification strategies pursued by Bronnenberg et al. (2015), Johnson and Rehavi (2016), and Frakes et al. (2019).

Comparing demographically equivalent individuals with and without a health professional in the extended family may still yield a biased estimate of the effect of intra-family expertise if unobservables are correlated with this exposure, however. To assuage this concern, we also pursue two quasi-experimental approaches to identify causal effects. First, we leverage the fact that some admissions to medical school in Sweden were adjudicated by lottery starting in 2002. Our identification strategy leverages this randomization, by comparing family members of applicants to medical school who won and lost an admissions lottery. Our results from the lottery analysis are consistent with our non-parametric findings and show far-reaching health benefits for the admitted applicants' extended family (including grandparents, parents, siblings, children, cousins, and in-laws). Among older relatives, access to intra-family expertise reduces the occurrence of lifestyle-related diseases and improves drug adherence. For example, eight years after the applicant's matriculation, older relatives are 4 (5) percentage points less likely to have had a heart attack (heart failure), and 27 percent more likely to adhere to medication that can prevent heart attacks. Among younger relatives, access to intra-family expertise also raises preventive investments. For example, adolescents are 22 percentage points more likely to be vaccinated against HPV by age 25 .

While the medical school lottery resembles an ideal experiment, this design only permits a relatively short follow-up period, as the lotteries were recent. This precludes studying outcomes such as mortality and the gradual onset of some lifestyle-related chronic conditions, as the parents of medical school applicants are relatively young (while grandparents are frequently already deceased). We therefore complement this analysis with a second quasi-

\footnotetext{
${ }^{4}$ Data from the United States used in this comparison is reported by the Health Inequality Project https://healthinequality.org/. Also see Sjogren and Hartman (2018) for an analysis of how mortality inequality has evolved over time in Sweden. A large body of research on early-life health has documented that poor children are born less healthy than their advantaged counterparts; also, see, e.g., Currie and Moretti (2007) and Royer (2009) for evidence of intergenerational correlations with early life health in the US.

${ }^{5}$ The idea of considering factors other than formal access to healthcare is consistent with the largely mixed findings of a voluminous literature (mostly in US settings) that has investigated the causal effect of health insurance - which lowers the price and ease of access to formal healthcare - on long- and short-run health outcomes (see, e.g., Sommers et al. 2017, and Finkelstein et al. 2018).

${ }^{6}$ We rank children by their parents' household income percentile before birth.
} 
experimental approach: event studies that compare individuals' health before and after their (often younger) family member receives either a medical degree or a law degree. ${ }^{7}$ We find striking differences in the health and mortality profiles of the two groups in the raw data, and our results are confirmed in a rich regression specification that reveals no differences in trends in health outcomes predating the arrival of a health professional or lawyer in the family. "Getting" a doctor in the family yields a 10 percent reduction in mortality 25 years after the doctor's matriculation, along with substantially lower rates of heart attacks, heart failure, diabetes, and lung cancer. These effects emerge gradually, which points to improved health investments over a long time period.

Despite the fact that the results from our three identification strategies are not directly comparable due to the different samples and time horizons, they deliver largely overlapping insights, which underscores their credibility. In sum, access to intra-family medical expertise improves physical health and raises investment in health capital, across the life cycle.

In Section 4.1, we examine the implications of these findings for health inequality. The insight that exposure to expertise improves health implies that differential exposure to expertise and resulting differences in health literacy across the SES spectrum, could generate inequality in health outcomes. To get a sense of the quantitative importance of this source of health inequality, we entertain two thought experiments. First, we ask how many "doctor equivalents" could explain the full difference in observed health outcomes at the top and bottom of the income distribution. Our back of the envelope calculation suggests that exposing low-SES individuals to the same amount of expertise as would be transmitted by two doctors in the family could fully close the gap. The second hypothetical question we pose is the inverse of the first: suppose that, on top of Sweden's universal health insurance, we could add "universal access to expertise," that is, we could deliver the full benefit of access to expertise to all citizens. Our calculation suggests that this would close a meaningful share - as much as 18 percent - of the mortality gradient. It is important to emphasize that both of these exercises are highly stylized and designed to give a sense of the quantitative importance of the channel that we identify.

There are two main interpretations of our results, which we discuss in Section 4.2. One is that access to expertise delivers benefits that could readily be delivered to all. Under this interpretation, our results in Sections 3 and 4.1 suggest that there may be a quantitatively important opportunity to improve population health and reduce health inequality through public policies that mimic intra-family transmission of expertise. A second interpretation is that access to expertise delivers benefits that are intrinsically scarce, and thus not scalable. Under this interpretation, our results identify a deeply rooted, persistent, and quantitatively important source of inequality. This is perhaps all the more surprising in a society like Sweden, where formal health care is public and universal, and inequality in general is relatively low.

While the data does not allow us to perfectly adjudicate between the two interpretations - and while our findings are important under either one - our results clearly establish impacts on outcomes that are not intrinsically scarce, as we discuss in Section 4.2. For example, health professionals accomplish an increase in their relatives' adherence to drugs and vaccines that are cheap and readily available, a reduction in tobacco exposure in utero,

\footnotetext{
${ }^{7}$ The comparison of morbidity and mortality profiles at older ages between parents of doctors and lawyers is motivated by the fact that doctors and lawyers are both high-social status professions with similar income distributions; we verify that the parents of lawyers and doctors also have similar income distributions in our data.
} 
and a reduction in lifestyle-related chronic diseases. Such benefits to health literacy do not come at the expense of others in a society and are, at least conceptually, readily scalable.

Our work builds on and contributes to several strands of the literature. While a broad literature studies the importance of the family as a source of insurance (see, e.g., Lee and Persson 2016, Autor et al. 2017, and Persson 2020) or shocks (e.g., Persson and Rossin-Slater 2018), a smaller body of work examines the importance of the family as a nexus for transmission of expertise, information, and norms. For example, Bell et al. (2018) analyze parent-child transmission of know-how and norms relevant to innovation, and Hvide and Oyer (2018) study parent-child communication of industry-specific knowledge. We instead focus on familial transfers of healthrelated expertise; further, we do not restrict attention to the the nuclear family, but analyze these processes in the broader extended family.

Our focus on health-related expertise relates the paper to the large and growing literature in many fields that analyzes the impact of information, broadly defined, on health behaviors, including the following most recent examples of studies: Hut and Oster (2018) analyze one particular but important health behavior - diet - and show that dietary habits fail to respond to an individual's own disease diagnosis or to governmental diet recommendations. Fadlon and Nielsen (2019) study how individuals respond to a family member experiencing a sudden health shock (non-fatal heart attacks or strokes), finding that spouses and adult children increase their consumption of preventive care (cholesterol-lowering medication) in response. Our results are consistent with theirs in that they underscore the importance of one's family for models of health behaviors. We explore a different mechanism, however: rather than salience of a health condition or the arrival of information about genetic disposition towards a disease, we analyze the role of spillovers from expert knowledge in the family. Our focus on expertise about health further relates to Johnson and Rehavi (2016) who show that female physicians are less likely to receive a C-section when they themselves give birth, suggesting that their expertise on the health costs of this procedure affects their own health care consumption; to Leuven et al. (2013) and Artmann et al. (2019) who study healthcare utilization among medical doctors and parents of medical doctors in the Netherlands, respectively, finding no differences in self-reported health among physicians themselves, or the frequency or cost of formal healthcare utilization among parents with physician-children; and to Frakes et al. (2019), who find no meaningful differences in the use of care between regular patients and physician-patients in the context of the US Military healthcare system. ${ }^{8}$

More generally, our findings contribute to the literature documenting a positive association between educational attainment and own health and health behaviors (see, e.g., Cutler and Lleras-Muney 2008, Cutler and Lleras-Muney 2010, Dayoub and Jena 2015, and Meghir et al. 2018). Further, Currie and Moretti (2003) document positive spillovers of maternal education on child health. ${ }^{9}$ We build on this literature by considering a precise type of education, a medical degree, and by analyzing spillovers across large family trees.

Finally, contrary to the papers cited above, on expertise broadly defined or on educational attainment in

\footnotetext{
${ }^{8}$ Similarly, Bronnenberg et al. (2015) and Janssen (2018) provide evidence on how expert knowledge affects individuals' willingness to pay for branded versus genetic pharmaceuticals.

${ }^{9}$ McCrary and Royer (2011) also establish a positive effect of maternal education on infant health. Further, Lundborg and Majlesi (2018) exploit a Swedish compulsory schooling reform to document spillovers in the opposite direction, from children's education to parental longevity. Also see Kuziemko (2014) on intra-family spillovers of education.
} 
particular, we quantitatively explore the implications of our findings for the broader question of the roots of health inequality, relating our work to a plethora of research on health inequality. ${ }^{10}$ Here, we make two distinct contributions. First, we deliver estimates of the health-income gradient and show that it steepens over time using comprehensive, non-self-reported data on both health outcomes and precise measures of income. ${ }^{11}$ Second, we provide quasi-experimental evidence on one particular causal mechanism underlying the health-income gradient, and show that it may play a quantitatively important role in sustaining health inequality. ${ }^{12}$

\section{Institutional setting, data, and facts}

\subsection{Healthcare in Sweden}

Swedish healthcare is a textbook case of a universal health insurance system. The government provides health insurance financed by tax revenue. Coverage includes inpatient care, primary and specialty outpatient care, and prescription pharmaceuticals. Patients incur little out of pocket cost, paying at most a small co-pay. ${ }^{13}$ Further, the public safety net reduces existing out of pocket obligations for some particularly vulnerable groups. Thus, in practice, individuals at any point in the income distribution have similar formal access to healthcare.

\section{$2.2 \quad$ Data}

Overall sample The data covers the universe of individuals born between 1936 and 2016 that were living in Sweden in 1961 or at some later point in time. For these individuals, we know the exact year and month of birth, as well as the year of death (recorded starting with 1961 and up until 2017), and whether the individual was born in Sweden. From Statistics Sweden we obtain a file that connects each individual in this sample to the individual's mother and father. Equipped with these data, we can connect all individuals born in 1936 or later to both their own parents, as well as to their siblings and descendants - children, nieces, nephews, and grandchildren. Similarly, for later-born cohorts, these data allow us to identify parents, aunts, uncles, and grandparents.

Socioeconomic information We merge these data to annual income tax records for the adult population (age 16-74) over a 27-year time period, 1990 - 2016. These records contain detailed, third-party reported information

\footnotetext{
${ }^{10}$ See, e.g., Adler et al. (1994) for a review of early evidence on a socioeconomic gradient in health and mortality and Currie (2011) for a review of health inequality early in life. See also, e.g., Fuchs (1992, 2004), Cullen et al. (2012), National Academies of Sciences, Engineering, and Medicine (2015), The Future of Children (2015), Cesarini et al. (2016), Currie and Schwandt (2016), Seligman et al. (2016), Almond et al. (2018), Dwyer-Lindgren et al. (2017), Fuchs and Eggleston (2018), and Thakrar et al. (2018).

${ }^{11}$ The fact that the gradient weakly steepens throughout the lifecycle is consistent with evidence (using less granular measures of socioeconomic status) from the United States by Case et al. (2002), from Canada by Currie and Stabile (2006), from the United Kingdom by Case et al. (2008), and from cross-country evidence by Chen et al. (2016).

${ }^{12}$ Our exercise relates to that of Aizer and Stroud (2010), who show that the arrival of novel information - in particular, the Surgeon General's recommendation, made in 1964, that women should refrain from smoking during pregnancy - induced women with higher education to respond but elicited little response among mothers with lower educational attainment, thus increasing inequality at birth. Our findings, in contrast, suggest that intra-family expertise elicits a weakly larger response at the lower end of the income distribution.

${ }^{13}$ Once a household's total out of pocket spending for prescription drugs reaches SEK $2300(\$ 247)$ over a twelve month period, the co-pay is zero for all subsequent prescription fills during the remainder of the twelve-month period. For the purposes of calculating a household's total out-of-pocket drug spending, a household is defined as one adult plus all children aged 18 or below that reside in the same abode. Out-of-pocket costs for medical care are capped in a similar vein.
} 
about labor income, financial income, government transfers, as well as self-reported information about selfemployment income. To define income rank, we use individual work and business income in our analysis. ${ }^{14}$ In the same database, we also observe educational attainment at an annual level, which allows us to know when individuals complete their degrees and which subject they studied.

Healthcare records To construct measures of health outcomes, health investments, and healtcare utilization throughout individuals' lives, we merge in information from inpatient records, specialist outpatient care records, prescription drug records, and cause of death records. Inpatient records cover years 1997 to 2016, specialist outpatient records years 2001 to 2016, and prescription drug records years 2005 to 2017. The inpatient records contain information on the universe of a patient's visits to the hospital, including cases where the individual is admitted and discharged on the same day. The outpatient data records all visits outside of primary care. ${ }^{15}$ For each inpatient admission and outpatient specialist visit, the data contain rich information on the date of the visit, the associated International Classification of Diseases (ICD-9 and ICD-10) diagnosis codes, procedure codes, and the length of stay (for inpatient admissions). Drug records contain the universe of an individual's prescription drug purchases made in pharmacies. For each prescription drug purchase, the data contain the drug name, the active substance, the average daily dose, and the drug's Anatomical Therapeutic Chemical (ATC) classification code. The ATC classification allows us to link drugs to diseases.

Birth records We further merge in medical birth records for the time period between 1995 to 2016, matching them to (parents') individual tax records. The birth records contain birth outcomes as well as variables from the electronic medical records related to pregnancy and delivery such as tobacco use during pregnancy and pregnancy risk factors (diabetes, kidney disease, epilepsy, asthma, hypertension, or urinary infection).

Educational records Finally, we merge in educational records for year 2007 and onwards. First, we add high school GPA. This allows us to find medical school applicants with top GPAs, who would be competitive for randomized admission spots. We also add information about whether an individual has taken the Swedish Scholastic Aptitude Test (SAT, in Swedish högskoleprovet). Second, we add college application information. As college admissions in Sweden are centralized, we can observe the full set of programs to which each individual applies in each application cycle. Third, we add college admission outcomes, allowing us to track who gets admitted into (undergraduate) medical programs.

\subsection{Inequality in health in our empirical setting}

Beyond the availability of data, Sweden is a particularly attractive empirical context because its universal health insurance system allows us to examine health inequality in the absence of large differences in formal access

\footnotetext{
${ }^{14}$ We examined several alternative measures of income, varying whether government transfers and investment income is included or excluded in the income measure. We did not find that our results were sensitive to these alternative specifications, as these variations tend to be rank-preserving. The average individual pre-tax work and business income (among individuals with a positive income) in the last year of our data (2016) is 298,597 SEK $(\$ 34,878)$ with a standard deviation of 256,047 SEK.

${ }^{15}$ Primary care is provided at municipal "Care centrals" (Vårdcentraler); data from these centers has historically not been collected, limiting our ability to analyze individuals' utilization of primary care, except for the case of care during pregnancy, which is recorded separately.
} 
to health care. The opposite side of the coin is that the very presence of universal health insurance, coupled with Sweden's generous social safety net, may eradicate socioeconomic differences in health, rendering it a bad candidate for analyses of health inequality. We therefore begin by briefly characterizing health inequality in our empirical setting.

Inequality in mortality To study inequality in mortality, we start with all individuals that are alive at age 55. These individuals are still several years away from retirement, allowing us to measure their work-related income, but are old enough to allow us to observe their deaths within our sample period. For each individual in this sample, we define an indicator for whether (s)he has died by age 80 - one of the key outcomes throughout our paper. Panel A of Figure 1 plots the share of individuals that died by age 80 against individual income rank at age $55 .{ }^{16}$ Despite Sweden's generous social safety net and equalized formal access to health care, there is a strong gradient in cumulative mortality at older ages conditional on surviving to age $55 .{ }^{17}$ At the very bottom of the income distribution, more than 40 percent have died by age 80; at the very top, the corresponding number is below 25 percent.

It is instructive to briefly put these numbers in relation to the income gradient in mortality that has recently been documented in the U.S.. Figure 2 plots one-year log-mortality against own income rank in both countries, for three combinations of age at death and age of income measurement for which we were able to construct estimates that can can be directly compared to those reported for the U.S. in Chetty et al. (2016). In the first two panels of Figure 2, we plot log-mortality at age 75 against income rank at age 61 in the U.S. and age 60 for Sweden (a year before the earliest retirement ages in the respective countries), separately for men (Panel A) and women (Panel B). ${ }^{18}$ We observe substantially lower mortality, at any point in the relative income distribution, in Sweden relative to the U.S., consistent with the notion that universal health insurance and a broad safety net may raise a society's overall level of well-being; however, the slopes of the mortality gradients are nearly identical in the two countries. The subsequent four panels of Figure 2 plot log-mortality at ages 60 and 40, by gender, against (gender-cohort-specific) income rank ventile measured two years earlier. While mortality inequality estimated at earlier ages is lower in Sweden than in the U.S. - especially age-40 inequality among women - the Swedish data reveals a pronounced mortality gradient at all three ages. ${ }^{19}$

Inequality in morbidity throughout the life cycle To measure inequality in health in adulthood, we define indicator variables that capture any occurrence, at the individual level, of four common and malleable

\footnotetext{
${ }^{16}$ We use work-related income defined as the sum of income from employment-related activities as well as (positive) business income from self-employment. To calculate the individual's income rank, we measure individual's income at age 55, and rank individuals within birth cohort and gender. We use cohorts born in Sweden between 1936 and 1937, for whom we observe both income at age 55 and survival until age 80 . The shape of the gradient remains the same if we use household income rank.

${ }^{17} \mathrm{We}$ investigate, but do not separately report, mortality by gender. Among men at the at the 5 th percentile of the income distribution at age 55, 48 percent are no longer alive by age 80 ; among men at the 95th percentile, the corresponding share is 25 percent. Female mortality is lower at all points in the income distribution, but we observe a very similar gradient. Women in the lowest 5 percent of the income distribution have a 11 percentage point lower probability of being alive than their most advantaged peers, 18 percent of whom are not alive by age 80 .

${ }^{18}$ For these comparisons, we adjust our income measure so that it corresponds to the U.S. (positive) Adjusted Gross Income (AGI) measure, as used in Chetty et al. (2016). In particular, we add capital-based income and non-disability government transfers; we continue excluding individuals with zero or negative income levels.

${ }^{19}$ See Adler et al. (1994) for a review of early evidence of a socioeconomic gradient in mortality across different countries and a discussion of possible drivers.
} 
chronic conditions that we can measure precisely in our data: heart attack, heart failure, lung cancer, and type II diabetes. ${ }^{20}$ Panel B of Figure 1 displays the share of individuals aged 55 or older that have a history of being diagnosed with at least one of these conditions, against individual income rank at age 55. The panel displays a steep gradient: individuals at the bottom ventile of the income distribution are more than twice as likely to have at least one of these conditions (20 percent) than individuals at the top ventile (10 percent). ${ }^{21}$

For younger adults, who do not have a high prevalence of the chronic conditions analyzed above, we examine a measure of preventive health investment that we observe in the data, HPV vaccination by age 20, depicted (among women) in Panel C of Figure 1. ${ }^{22}$ We now use a different x-axis: individuals' parental household income rank in the year before the individual's birth (i.e., 21 years earlier). ${ }^{23}$ The figure shows a sharp reverse gradient in this preventive health measure: only about 10 percent of women born into households at the bottom of the income distribution get vaccinated against HPV, while 40 percent of women with parents at the top of the income distribution do.

Even earlier in life, we observe steep gradients in the two most common childhood conditions: asthma and ADHD. Panel A of Appendix Figure A1 reports the gradient in asthma by age 5, showing a substantially higher prevalence among children growing up in lower-SES households. ${ }^{24}$ The gradient in ADHD (as measured by ADHD medication take-up) is similarly pronounced. Further, we create two measures of the prenatal environment: an indicator for whether the mother is using tobacco right before or during pregnancy and an indicator for whether the child experiences a risky birth. ${ }^{25}$ The gradient in tobacco use, depicted in Panel D of Figure 1, is remarkable, with more than 30 percent of mothers in the bottom income ventile using tobacco around the time of pregnancy, as compared to slightly above 5 percent of mothers at the top of the income distribution. Tobacco use and especially smoking is known to be associated with substantial risks to the fetus, including an increased risk of miscarriage, pre-term birth, and low birth weight (see, e.g., Centers for Disease Control and Prevention 2017). Similarly, as shown in Panel B of Appendix Figure A1, adverse events at birth are more likely at the bottom of the income distribution than at the top, despite the fact that mothers are almost eight years older at the top of the income distribution and the latent probability of a high risk pregnancy increases with maternal age, and despite the fact that mothers at the top of the income distribution are more likely to give birth to a baby with low birthweight. ${ }^{26}$

\footnotetext{
${ }^{20}$ The malleability and lifestyle attribution of many common chronic conditions have been well documented in the medical literature (see, e.g., Wannamethee et al. 1998, Knowler et al. 2002, and Djoussé et al. 2009).

${ }^{21}$ The income gradient is strongly pronounced in each of the four underlying conditions. Many slowly emerging chronic conditions are frequently under-diagnosed. If the rate of diagnosis conditional on disease is lower at the bottom of the income distribution, which appears probable, then we are likely underestimating the steepness of the gradients for the prevalence of lifestyle-related conditions.

${ }^{22}$ While many preventive investments are unobservable in the data, we observe this measure because our prescription drug records span a time period when the HPV vaccine was not incorporated into the Swedish Vaccination Programme (which provides free vaccines for all children); thus, we observe take-up of this vaccine in the data. Human Papillomavirus (HPV) has been linked to several types of cancer, including cervical cancer.

${ }^{23}$ To calculate parental household income rank at birth, we average two years of annual earnings of the child's mother and father, measured one and two years before the child's birth, respectively; sum them into household income; and rank households within each child's birth cohort.

${ }^{24}$ Asthma is affecting nearly ten percent of all children in the United States (Chorniy et al. 2018); and in Sweden, already at age five roughly 11 percent are affected by asthma.

${ }^{25} \mathrm{~A}$ risky birth is defined as whether the mother has any of the following conditions during pregnancy: chronic kidney diseases, diabetes, epilepsy, lung diseases, systemic lupus erythematosus (SLE), ulcerative colitis, hypertension, or urinary tract infections.

${ }^{26}$ The lowest rate of adverse birth events, however, occurs in the middle of the income distribution, where mothers are have access to more resources, but are still relatively young. In a similar vein, the share of low birthweight babies is the lowest in the middle of the income distribution.
} 
Finally, to track the evolution of the health gradient over the life cycle, we use a health measure that is relevant at all ages: the number of inpatient visits. Panel $\mathrm{C}$ of Appendix Figure A1 displays the gradient in the number of inpatient visits in the first five years of life. While we observe a pronounced gradient already at age 5 , it steepens substantially over the course of the life cycle, as illustrated in Panel D of the same figure, which displays the same outcome in the five years from 45 to 50 .

In sum, our empirical setting is characterized by substantial health inequality: Despite Sweden's broad social safety net, the health-SES gradient emerges early in life and gradually steepens throughout the life cycle. This underscores, first, the importance of studying the role of factors other than social insurance and formal access to healthcare in sustaining health inequality; and, second, that Sweden is a highly suitable setting to do so. Further, this motivates our subsequent analysis of the importance of informal access to health expertise as a "demandside" driver of inequality that cannot be ameliorated by social insurance policies that equalize the "supply-side" gap in access to formal healthcare.

\section{$3 \quad$ Exposure to expertise and health outcomes}

\subsection{Measuring exposure to health expertise}

We are interested in measuring whether exposure to health-related expertise affects individuals' investments into their health and their subsequent health outcomes. Exposure to expertise may affect individuals through multiple mechanisms, all of which the public health literature commonly refers to as "health literacy" (Kindig et al. 2004). Experts can transmit new knowledge about the costs and benefits of healthy behaviors and health investments; they can remind, nudge or corroborate existing knowledge, making it more salient and trustworthy; and they can help determine when to seek formal care and how to navigate the healthcare system.

While it is intuitive that exposure to any or all of these underlying mechanisms may lead to better health outcomes, investigating the causal role of exposure to health expertise, and the associated improvements in health literacy, on health is challenging. First, individuals receive streams of information and reminders relevant to their health from many different sources throughout their lifetime, and these flows may be hard to measure; second, exposure to expertise is typically not randomly assigned. To overcome these challenges, we zoom in on an environment where we can precisely measure individuals' exposure to expertise, and where the institutional environment provides several sources of variation for causal identification: the presence of a health professional (HP) in the family. The idea is simple. It is reasonable to think that health professionals are experts in the field of health that on average posses the highest degree of health literacy in a society. Family members of a health professional enjoy increased exposure to such expertise in daily informal interactions, which in turn should increase their own health literacy and thereby may improve health outcomes.

In this section, we analyze the aggregate impact of having a health professional in the family on the extended family's health; we then return to a discussion of interpretations in Section 4.2. 


\subsection{Non-parametric evidence}

We use the records of higher education to find individuals with health professional degrees - physicians and nurses - among the cohorts of working age adults in our analytic sample. We define two groups of individuals who may benefit from (differential degrees of) access to expertise: the health professionals' narrow and extended families, respectively. The narrow family is defined as the health professional's spouse, parents, parents-in-law, children, and children-in-law. The extended family further includes the health professional's siblings, aunts and uncles, grandparents, and cousins.

We start by documenting differences in health between individuals in families with and without a health professional. Panel A of Figure 3 revisits the mortality gradient from Panel A of Figure 1, but now plots it separately for individuals with and without a health professional in the extended family. ${ }^{27}$ We drop observations for individuals who are educated as health professionals themselves.

Panel A of Figure 3 reveals two clear patterns in the raw data. First, there is a visually detectable difference in the probability of being alive at age 80 , which persists throughout the income distribution: Conditional on income rank, individuals with an extended relative who is educated as a physician or a nurse are more likely to survive to age 80 . Second, this mortality difference is larger at the bottom of the income distribution.

We estimate the magnitude of the difference in cumulative mortality by age 80 at each income decile $d$ using the following OLS specification:

$$
Y_{i d}=\delta_{d} H P_{i}+\beta_{d} X_{i}+\epsilon_{i d}
$$

Here, $Y_{i d}$ is the mortality (or health) outcome of interest for individual $i$ in income decile $d, H P_{i}$ is an indicator variable that takes the value of 1 if individual $i$ has at least one medical professional in the family, and $X_{i}$ is a set of demographic controls that are included in some specifications. The coefficients of interest are $\delta_{d}$ that measure the average difference in the health outcome between individuals with and without a health professional in the extended family, for each age-55 income decile $d$. We report the results of this regression in Panel $\mathrm{B}$ of Figure 3. The dashed line reports the estimates of $\delta_{d}$ without any controls; thus, these estimates measure the raw vertical distance between the two lines in Panel A of Figure 3. We estimate that, on average, individuals who have at least one extended family member who is a doctor or a nurse are 5.9 percentage points less likely to have died by age 80 conditional on being alive at age 55 . This is a large difference relative to the average probability of having died by age 80 in the full sample, which is 31 percent, as it implies an 19 percent reduction in the probability of death. This is equivalent in magnitude to moving from the 70th to 100th percentile in the income rank distribution. Further, the difference varies by income rank, ranging from 7 percentage points on average in the lower half of the distribution to 4 percentage points in the upper half of the distribution.

Next, we examine whether these differences remain when controlling non-parametrically for a wide range of observable demographics, in the spirit of the identification strategies pursued by Bronnenberg et al. (2015),

\footnotetext{
${ }^{27}$ Recall that the $\mathrm{x}$-axis is the percentile of the individuals' age-55 work income rank, where work income includes wage income and self-employment income, but excludes government transfers and capital income. Our results are not sensitive to whether we include or exclude the other two sources of income. We use work income in our preferred specifications, as intuitively this is a broader measure of socio-economic status, pre redistribution programs. We restrict the sample to individuals with positive work income. As we condition on work income, we implicitly condition on being alive at age 55. Our results are also not sensitive to replacing individual income rank with household income rank.
} 
Johnson and Rehavi (2016), and Frakes et al. (2019). The solid line in Panel B of Figure 3, as well as Panel A of Table 1, report results from regression Equation (1) including the vector of observables $X_{i} \cdot{ }^{28}$ The pattern remains qualitatively the same across all income deciles: Individuals with a health professional in the family are less likely to have died by age 80 , and the difference is on average larger at the lower end of the income distribution.

We now revisit the prevalence of chronic conditions that are commonly considered to be linked to lifestyle decisions throughout the life-cycle. In Panel $\mathrm{C}$ of Figure 3, we report differences in the probability of having the following conditions: heart attack, heart failure, type II diabetes, and lung cancer, by whether or not an individual has a health professional in the extended family. The conditions are aggregated into a z-score index. The raw data again shows a visible separation in the prevalence of these chronic conditions between individuals with and without a health professional in their extended families. As the dashed line in Panel D suggests, the differences in the raw data are larger at the bottom of the income distribution. Moreover, less than 50 percent of the difference can be explained by our rich set of observables, leaving us with a clear pattern (solid line) of significantly lower prevalence of lifestyle-related conditions among older individuals with health professionals in their families. As Panel B in Table 1 documents, the difference remains on average larger at lower income levels.

Figure 4 reports similar analyses for younger ages. In Panels A and B we examine the probability of young women receiving the HPV vaccine by age 20. We observe large differences in the probability of this health investment between young adults with and without a health professional in the family, across all points in the income distribution. About two thirds of the difference persists when we control for observable characteristics, as can be seen in Panel C in Table 1 as well as in the solid line in Panel B of Figure 4.

Finally, Panels C and D of Figure 4 report the same analysis for the probability of being exposed to tobacco use in utero. We observe large differences in tobacco exposure rates for an unborn child in families with and without a health professional (including the mother of the child herself), especially at the lower deciles of the income distribution. ${ }^{29} \mathrm{~A}$ child with parents in the first two deciles of the income distribution who has a health professional in the family is up to 8 percentage points less likely to have been prenatally exposed to tobacco than a child who has no medical professional in the family. As Panel D of Figure 4 and Panel D in Table 1 document, the gap in tobacco exposure rates monotonically declines with income rank and gets close to a precise zero at the top of the income distribution. While a substantial portion of the differences can be attributed to differences in observable demographics, observables do not account for the full gap, leaving a significant discrepancy of up to nearly 5 percentage points (or 14 percent) at the lower end of the income distribution (Panel D in Table 1). Further, observable differences cannot fully explain the pattern of the gap decreasing monotonically in income rank.

Figures 5 and 6 examine the heterogeneity in our non-parametric results along the intensive margin of exposure to a health professional in the family. We examine two dimensions of heterogeneity: geographic proximity and

\footnotetext{
${ }^{28}$ The vector of controls includes fixed effects for: own income rank percentile, highest-earning relative's income percentile, year of birth, gender, individual's (discretized) educational attainment, and county of residence at age 55.

${ }^{29}$ Notably, we find even larger differences when we consider only (children of) expecting mothers that are healthcare professionals themselves. There is almost no gradient in the probability of tobacco exposure in utero among children of these mothers, with a level difference of up to minus 20 percentage points relative to the general population. Figure A2 in the Appendix illustrates this striking difference.
} 
proximity in the family tree. The left-hand side panels in Figures 5 and 6 report the estimated differences in health outcomes between: (i) individuals without any health professional relative versus those with a broad - but not a narrow - health professional relative (dashed lines); as well as (ii) individuals without any health professional relative versus individuals with a health professional in their narrow family (solid line). The reported differences in health at each point in the income rank distribution come from the OLS regressions with the full set of controls, as in Panels B and D of Figure 3, as well as the respective Panels in Figure 4. The right-hand side panels report the same coefficients, but now splitting the sample by geographically close (solid line) and far (dashed line) health professional relatives. We define two family members as being geographically close if they have lived in the same county for more than 50 percent of the time during which they are observed in the sample. ${ }^{30}$

For both older and younger relatives, we consistently find that the effects of a health professional in the family are substantially more pronounced if the health professional is a close relative. The differences are especially clear when zooming in on the lower part of the income distribution. For example, at the lower rungs of the income distribution, having a health professional relative far away in the family tree has little effect on the prevalence of lifestyle-related conditions after age 55 (Panel $\mathrm{C}$ of Figure 5), while the effect of having a close relative who is a health professional is pronounced. The results are more mixed for geographic proximity. Panel B of Figure 5 shows that the mortality effect is mainly driven by geographically close relatives at the lower rungs of the income distribution, while the geographic location of the health professional relative matters less at the higher end of the income distribution. For young children, family proximity and geographic proximity are often hard to separate, as children are likely to live in the same household as a close relative. In both cases, however, we find that HPV vaccination is more pronounced among young adults exposed to a health professional who is either a close family member or lives close by. For tobacco exposure, there is little difference on either of the intensive margins at the top of the income distribution, while the intensity of exposure appears more important at the bottom of the income distribution. These results suggest that the intensity of access to expertise is crucial for health production.

While we control flexibly for a wide range of individual characteristics in this analysis, akin to the identification strategies pursued by Bronnenberg et al. (2015), Johnson and Rehavi (2016), and Frakes et al. (2019), a remaining concern is that the presence of an HP in the family may be correlated with unobservables. We therefore use two additional identification strategies to quantify the causal impact on health and longevity of having a health professional in the extended family.

\subsection{Leveraging randomization in medical school admissions}

Our second research design exploits the fact that admission to medical school in Sweden, for a subset of years, contained an element of randomization. ${ }^{31}$ "Medical school" in the Swedish context refers to an undergraduate

\footnotetext{
${ }^{30}$ County ("län") is the top level geographic division in Sweden, with 21 counties as of 2019. The largest county (Stockholm) has 2.3 million individuals, while the smallest (Gotland) has about 59 thousand people.

${ }^{31}$ There are no tuition fees for post-secondary education in Sweden. To cover living expenses, most students are eligible for financial support (part loan/part grant) from The Swedish Board of Student Finance (CSN).
} 
major in medicine, as medical training starts directly in college and not in a post-graduate professional school. Students choose their undergraduate majors before starting higher education, apply to specific departments, and follow a curriculum recommended by the department.

University applications in Sweden are centralized and handled by a governmental agency, Universitets- och högskolerådet (henceforth UHR). All prospective students interested in studying for all degrees and at all universities apply through the same system. There are two university application cycles per year, for programs starting in the fall and spring semesters, respectively. In each application cycle, a prospective student submits a rank ordered list of programs to the UHR. The applicant is not required to apply only to programs in the same discipline. For example, an applicant may rank the medical school program at the Karolinska Institute in Stockholm as her first alternative, the medical school program at Gothenburg University as her second alternative, a program in business at Lund University as her third alternative, and so on.

One mechanism by which the centralized agency allocates applicants to programs is by ranking them by their high-school GPA. ${ }^{32}$ The applicant with the highest GPA gets her preferred choice, the second highest ranked applicant gets the highest available choice for which she qualifies, and so on. For competitive programs, in which demand exceeds supply, this process generates GPA admission cutoffs for each program, around which admission is effectively randomized.

The high school GPA ranges from 0.0 to 20.0. Since the inception of this grading system in 1997, grade inflation has been substantial (see, e.g., Diamond and Persson 2016). The share of students graduating from high school with a GPA of 20.0 increased from less than 0.1 percent in 1997 to 0.8 percent in 2008 (Vlachos 2010), an increase of more than 800 percent. As a consequence, many university programs saw their GPA admission cutoffs steadily increase over time. For medical school programs, which generally have the highest cutoffs of any programs in Sweden, this process eventually led to the cutoff hitting the 20.0 mark at all medical schools.

Figure 7 displays the maximum, minimum, and median GPA cutoffs for admissions to Sweden's six medical schools from 1998 to 2017. Prior to the fall 2002 application cycle, the admission cutoffs were gradually increasing over time, with slightly higher cutoffs in the fall than in the spring (reflecting the fact that more students apply right after graduating high school in the preceding summer). Starting in the fall of 2002 and during the subsequent fifteen application cycles (until the spring of 2010), both the highest and the lowest cutoffs were 20.0. Thus, admission to any medical school in the country necessitated the highest possible GPA of 20.0, and admission was randomized by the UHR within this group. ${ }^{33}$ Our primary identification strategy leverages this randomization, by comparing applicants to medical school with a GPA of 20.0 who were admitted and not admitted to medical school. ${ }^{34}$

\footnotetext{
${ }^{32}$ The GPA quota is one of several quotas allocating applicants. Another quota allocates applicants to slots based on their scores on the Swedish SAT, a non-mandatory test administered by the Swedish Council for Higher Education. In addition, small quotas are reserved for students with five years of work experience and, in some universities, for students admitted based on interviews, respectively. A student automatically competes in all quotas for which she is eligible. We observe whether a student took the Swedish SAT, and thus competed in the second admissions category, and control for it in all regressions. While we do not directly observe whether a student has five years of work experience, we can restrict the sample to applicants who graduated less than five years before applying to medical school. See footnote 38 for further discussion of this.

${ }^{33}$ Strictly speaking, the admission procedure has two rounds. The first round allocates admissions offers by lottery and assigns applicants who are not offered admission to a waitlist. In the second round, any declined offers go to the waitlisted applicants. In practice, this distinction is immaterial in medical school admissions as there is near-universal take-up of admission offers.

${ }^{34}$ Randomization is not common, but is present in multiple higher education settings across different countries. See, e.g., Ketel et
} 
While the randomization of applicants with 20.0 into admission resembles a perfect RCT, one aspect of the institutional context complicates our analysis: Applicants who are not admitted on their first attempt have the option to re-apply in subsequent application cycles. ${ }^{35}$ The possibility of re-application implies that individuals that are not admitted in a particular cycle may still eventually gain admission and become physicians; thus, even conditional on a GPA of 20.0, being lotteried in or out is not a "sharp" allocation of students to medical schools. At the same time, not all students who are declined admission in their first application round choose to reapply. Thus, being admitted on the applicant's first application cycle (which is effectively random) affects the probability of eventually matriculating into a medical program.

Given this, we exploit admission on the student's first application attempt as an instrument for whether an individual becomes a medical student and ultimately graduates with a medical degree. We proceed by estimating the following two stage least squares (2SLS) relationship (and the associated intent to treat (ITT) relationship):

$$
\begin{gathered}
Y_{j(i)}=\delta M D_{i}+\beta_{1} x_{j(i)}+\kappa_{1} X_{i}+\epsilon_{1} \\
M D_{i}=\gamma A_{i}+\beta_{2} x_{j(i)}+\kappa_{2} X_{i}+\epsilon_{2}
\end{gathered}
$$

In Equation (2), $Y_{j(i)}$ is the incidence of a health outcome of interest for applicant $i$ 's family member $j$ (we consider all members of the extended family), measured over a period of six to eight years, which is the maximum time horizon that we observe in our sample, as we detail below. For individuals who matriculate into a medical program, this time horizon captures the period of medical education, which typically lasts for 6 years, and the first two years after medical school completion. $M D_{i}$ is an indicator variable that takes the value of 1 if applicant $i$ matriculated into a medical program. $X_{i}$ and $x_{j(i)}$ are vectors of observable demographics of applicant $i$ and his or her family member $j(i)$.

The demographic covariates for the applicant and family member are not necessary for identification but improve precision. They include year of birth fixed effects, a gender dummy, and an indicator for whether the individual was born in Sweden. All regressions also include fixed effects for the type of relative that $j(i)$ is to applicant $i$ (grandparent, parent, child, aunt or uncle, sibling, sibling's child, or cousin), and for family member $j(i)$ 's own level of education.

Further, we control for two variables that mechanically affect the probability of admission (to $a$ program): the number of medical schools the individual $i$ applies to in the first application round, and whether the applicant took the Swedish SAT. ${ }^{36}$ The identifying assumption is that, conditional on the number of medical school applications and whether the student took the Swedish SAT, admission is randomly assigned.

The coefficient of interest in Equation (2) is $\delta$, which measures the effect on health outcomes of having a

al. (2016) on the economic return to medical school admission lotteries in the Netherlands, as well as Stasz and von Stolk (2007) on the overview of lottery use in multiple countries.

${ }^{35}$ While waiting for the next application cycle, applicants may try to increase their admission chances, either by taking the scholastic aptitude test and attempting admission through the alternative quota, or by working.

${ }^{36}$ Sweden has six medical schools during the time period for which we observe admissions data, with a seventh added in 2010 (in Örebro), and an individual competes for admission at all schools to which she applies. In a similar vein, taking the SAT allows the applicant to compete for admission in a second admissions category. As the exact randomization algorithm used by the UHR is not known, this control variable also accounts for the possibility that the test influences how ties are broken in the GPA category. 
family member get medical training. This coefficient may be biased if individuals whose relatives are in worse (or better) health systematically select into medical training. To address this concern, we instrument for $M D_{i}$ with $A_{i}$ as specified in Equation (3). $A_{i}$ takes the value of 1 if student $i$ was admitted to medical school in the first application cycle. The resulting estimate of $\delta$ measures the effect of having a family member initiate medical school for the group of compliers (LATE). Here, the compliers are family members of applicants who went to medical school because they won admission on their first application attempt, but who would not have received medical education had they lost this first lottery. The standard errors are clustered at the family level.

Our baseline sample of applicants includes all applicants to medical school in Sweden for whom we can track health outcomes for at least six (and at most eight, since our application data starts in fall of 2007) years after their last medical school application who had a GPA of exactly 20.0. ${ }^{37}$ Our sample of family members includes all their grandparents, parents, parents-in-law, spouses, own children, aunts and uncles, siblings, siblings' children, and cousins.

Table 2 displays the mean of observable baseline demographics as well the probability of matriculating into medical studies for two groups of applicants in our baseline sample: those who were admitted (188 applicants) and those who were not admitted (555 applicants) in their first application cycle. First, we see a large difference in matriculation into medical school. Among applicants admitted in the first application cycle, 96 percent matriculated into a medical program. Among those who were not admitted in their first cycle (but could reapply), the corresponding figure is 59 percent, giving us a large and precise first stage of 37 percentage point difference in the matriculation probability.

The accepted and rejected students were equally likely to be women ( 57 percent in the accepted group) and had an equal number of siblings (1.82 in the accepted group). They had similar ages, although the accepted group is statistically (but not economically) significantly older (19.67 in the accepted group vs. 19.48 in the rejected group). ${ }^{38}$ Accepted and rejected applicants were equally likely to be born in Sweden, and to have parents that were born in Sweden. Both groups had similar parental household income and father's income, both measured before the applicant's high school graduation and before the first medical school application cycle. A similar share of applicants had lost their father, or mother, or one of the grandparents by the year before the first application to medical school in the admitted and non-admitted groups (in the admitted group, 1 percent of fathers, 1 percent of mothers, 57 (48) percent of paternal (maternal) grandfathers, and 32 (30) percent of paternal (maternal) grandmothers were deceased prior to the student's application).

In sum, 15 out of 16 observables are balanced across the admitted and non-admitted groups, and the t-test comparisons are far from any conventional significance levels with the lowest p-value of 0.33 (for whether the father was born in Sweden) for all observables except age. We conclude that the evidence in Table 2 is consistent

\footnotetext{
${ }^{37}$ Because our health care records end in 2016, this includes applicants whose last medical school application happens in the spring 2010 application cycle or earlier.

${ }^{38}$ The difference in age stems from the institutional nuances of the admission system: Applicants can strengthen their applications by gaining five years of work experience; so, if there is a big time gap between the first and subsequent applications for some applicants who chose this route for their applications, we may in a small number of cases mis-classify the first application cycle and capture individuals who gained work experience before re-applying. The differences in age shrinks substantially when we zoom in on small subsamples where we can more conservatively define the first application cycle and focus on high school graduates from the same year. The sample of these individuals, however, is too small to perform our analysis. Hence, we keep the sample in Table 2, and control for the year of birth non-parametrically in our regressions.
} 
with an essentially random breaking of ties in medical school admission decisions for this group of highest GPA students. We thus proceed to use the first application cycle admission decision as an instrument for whether an individual matriculates into medical school. We report results (ITT and LATE estimates) separately for older and younger relatives of the medical school applicants, as the sets of relevant health outcomes and health investments differ.

Health of older relatives Table 3 reports our estimates of the effect of an individual gaining a medical education on the health outcomes of relatives aged 50 and above. For each relative, we track health outcomes starting in year $t+1$ after the applicant's last medical school application and until $t+8$, which is the maximum time horizon that we observe in our sample.

We study two sets of outcomes. First, to capture physical health, we return to the common lifestyle-related conditions analyzed above. Second, we study outcomes that capture preventive health investments. Intuitively, we want to capture beneficial health behaviors that individuals have agency over and that thus may respond to increased health literacy within the time period that we observe (and potentially before they translate into improvements in physical health). While many of the most obvious candidate health behaviors, such as diet or exercising habits, are not observable in the data, our medical and prescription drug records allow us to precisely capture several other important preventive investments in older age: the use of (three types of) drugs that reduce the risk of cardiovascular disease; the use of diabetes drugs; take-up of Vitamin D (among women, for whom this vitamin is recommended in old age); the use of asthma medication; (absence of) the occurrence of preventable hospitalizations; and (absence of) addiction to alcohol or drug substances. In a final step, we also aggregate all the specific outcomes into a single health index. All outcomes are scaled in per 1,000 individuals terms to aid in interpretation.

Columns (1), (2), and (3) report the intent to treat (ITT) effects (with and without controls), and the local average treatment effect (LATE), respectively. In columns (4) and (5) we report two different benchmarks that are useful for interpreting the ITT and LATE coefficients. Column (4) reports a simple mean among family members of applicants who loose the lottery on their first application attempt. In column (5) we report the complier mean among control compliers. Within our control group, we observe individuals that decide not to attempt another medical school application when they loose the lottery. Conceptually, this group of individuals includes (untreated) compliers and never takers. From Table 2, we see that only 4 percent of individuals that win the lottery do not matriculate into a medical school, so the share of never-takers in our data is extremely low. In that case, family members of individuals who loose the lottery and do not re-apply are predominantly compliers. Computing the mean of outcomes among the family members of these individuals allows us to directly estimate the mean of potential outcomes under no treatment for compliers. This is what we report in Column (5).

Physical health. We first examine the effect on physical health. We find that 42 out of 1,000 individuals in the control group have a heart attack during our observation period. Among individuals whose relative wins the medical school lottery, the rate declines by 19 out of 1,000 people - a remarkable decrease of 45 percent (ITT). Exposure to a health professional among compliers leaves this group with only 23 per 1,000 individuals 
with a heart attack. Importantly, as we are measuring the effects over a relatively short time frame, we cannot ascertain whether this decline is permanent or represents a short-run delay of this acute cardiovascular event. ${ }^{39}$ We find similarly large effects on the probability of being diagnosed with heart failure: a decline of 27 per 1,000 individuals (ITT), or 54 per 1,000 among compliers (LATE), off of the mean of 74 per 1,000 cases in the control group and 83 among control compliers. We do not find any evidence of a reduction of type II diabetes or lung cancer. $^{40}$

Preventive investments. Turning to preventive investments, we first study the effects on adherence to medication for the most common chronic conditions. We measure adherence as the probability of purchasing medication conditional on having any condition that may warrant the need for this medication. ${ }^{41}$ We consider three common cardiovascular drugs: statins (for lowering cholesterol levels), blood thinners (for reducing the chance of blood clots), and beta blockers (used for prevention and treatment in multiple cardiovascular conditions). Individuals in the treatment group, i.e., relatives of individuals who win the medical school lottery in their first application attempt, are substantially more likely to adhere to these medications. The effects are economically large for all three outcomes, and statistically precise for statins and blood thinners. For example, on average 247 out of 1,000 individuals in the control group purchase blood thinners, while in the treatment group it is 29 more people per 1,000 - a 12 percent increase (ITT). The effect of having a relative matriculate into medical school (on the compliers) is in turn larger, with 73 more people taking the blood thinning medication, which represents a 27 percent increase off of the control complier mean (LATE). The relative increases are qualitatively similar for the other two cardiovascular drugs: 32 percent and 7 percent increases in adherence to statins and beta blockers, respectively (LATE). Further, older family members of lottery winners are 20 percent (ITT) more likely to adhere to diabetes medication conditional on having the disease. Female older relatives also take prescription strength (rather than over-the-counter) vitamin D (vitamin D deficiency is common with aging, especially among women) at higher rates: 27 out of 1,000 untreated compliers take the vitamin, while 49 per 1,000 more do so among treatment compliers (LATE). We find positive but noisy differences in adherence to asthma medication. We find no systematic evidence of a decline in what we measure as preventable hospitalizations for older adults, but find some evidence of a decreased probability of addiction to alcohol or drug substances.

Health index. To address the issue of inference with multiple outcomes and to improve statistical power, we aggregate all eleven measures into a "health index," following the approach in Kling et al. (2007). We first orient all outcomes in the same qualitative direction (for example, for statins more is "good," while for addiction less is "good"). We then construct a z-score for each outcome (subtracting the control group mean and dividing by the control group standard deviation) and take an unweighted average across all outcomes. ${ }^{42}$ The result suggests

\footnotetext{
${ }^{39}$ In general, our estimates are not inconsistent with the results of related clinical trials; however, the direct comparison is hard to achieve for two key reasons: first, our timeline is actually long in the world of clinical trials, hence only few trials have been run over a comparable time period; second, nearly all large-scale clinical trials test the effect of one medication at a time, so that the composite effect of higher exposure to several cardiovascular medications at a time - which we are documenting further down in this Section - is unknown.

${ }^{40}$ Given that lung cancer is a very rare condition, we do not have statistical power to detect a difference in our small sample; we nonetheless include it, for completeness, given that it is included in our non-parametric analysis.

${ }^{41}$ In addition to the controls discussed above, the subset of regressions where the outcome captures individuals' drug purchases also includes controls for the presence of asthma, type II diabetes, heart failure, ischemic heart diseases, stroke, hyperlipidemia, or hypertension.

${ }^{42}$ The index is on average equal to zero in the control group, by construction, since we are normalizing the z-score to the control
} 
that, among older adults, exposure to a family member who matriculates into medical school yields a large and statistically precise improvement in health.

Overall, the point estimates in our analysis are consistent with the idea that older relatives of a physician are in better health and that they undertake more - cheap and simple - investments into their health, than similar individuals in families without a physician in training or early in her career.

Health of younger relatives Table 4 reports estimated effects of exposure to health expertise on the health outcomes of younger relatives. ${ }^{43}$ We measure health outcomes starting in year $t+1$ after matriculation and until year $t+6 .{ }^{44}$ For younger individuals, who do not have a high prevalence of the chronic conditions analyzed above and among whom severe health issues are much less common - we focus on physical health issues that are common in childhood and early adulthood, as well as on preventive health investments that are important during this time period (and that our data allows us to capture): HPV vaccination, not using hormonal contraceptives, having substance addiction, experiencing injury or poisoning that require a hospitalization, the number of inpatient stays, and occurrence of respiratory infections, intestinal infections, and chronic tonsil diseases. ${ }^{45}$

Columns (1), (2), and (3) again report intent to treat (ITT) effects without and with covariates, and the local average treatment effect (LATE), respectively. Among female relatives aged 10 to 25, we estimate a large and positive effect on take-up of the HPV vaccine. While 119 out of 1,000 individuals are vaccinated in the control group (174 among compliers), our estimates imply increases of 56 per 1,000 (ITT) and 218 per 1,000 (LATE) an increase of more than 100 percent among compliers. ${ }^{46}$ We estimate similarly large effects for the avoidance of hormonal contraception. While 644 out of 1,000 young women aged between 10 to 20 do not use hormonal contraception in the control group, 135 women (21 percent more) refrain from this form of contraception among those with a lottery winner (in the first application attempt) in the extended family (ITT).

We further find large effects of being exposed to a health professional in the family on the probability of having an injury or poisoning that warrants a visit to a hospital (in inpatient or outpatient specialist care). The rate of substance addiction that warrants a visit to a hospital or specialist care among young individuals in the control group is 19 per 1,000; the corresponding number in the treatment group is significantly lower at 11 per 1,000 - a decline of 58 percent (ITT).

Our estimates for inpatient stays paint a similar picture. We find that younger relatives of those who win the lottery have a third of the number of inpatient stay days. ${ }^{47}$ We do not capture any differences in the rates

\footnotetext{
group mean.

${ }^{43}$ Recall that these include the health professional's siblings, cousins, own children, or siblings' children.

${ }^{44}$ We take a shorter time window for younger relatives. There are fewer younger than older relatives in the sample, while they experience adverse health events much less frequently. A shorter follow-up window allows us to increase the sample size, and unlike for the chronic conditions of the older relatives, for the conditions of the younger relatives, we would expect the effects to appear faster.

${ }^{45}$ We consider not using hormonal contraceptives as a positive health investment, since we find overwhelming evidence of physicians themselves substituting away from hormonal birth control. Concerns about the side effects of these medicines that have been documented in the clinical literature may drive this observation, although we cannot pin down the exact underlying mechanism with certainty.

${ }^{46}$ Interestingly, even in the families of compliers, we still only estimate an about 40 percent take up of this routinely recommended vaccine.

${ }^{47}$ For the count of inpatient stays, we drop 27 observations (99th percentile) with very high counts of inpatient stays that are clear outliers in the distribution. Our point estimates are larger and slightly more precise when we include these observations, but excluding outliers gives us a more conservative estimate of the marginal effects given the high sampling variance.
} 
of severe injuries or poisoning (which are experienced by about a quarter of individuals in the sample), and we also do not find that being exposed to a health professional lowers the rates of respiratory infections, intestinal infections, or chronic tonsillitis.

Overall, we conclude that for younger generations, having a new doctor-in-training in the family has positive effects on health: We see a larger probability of preventive investments, a lower prevalence of addiction, and fewer inpatient days. Finally, we summarize our eight measures into a health index, constructed in the same way as for the older family members. The health index estimate suggests that, among younger family members, informal exposure to a health professional yields economically and statistically significant improvements in health.

\subsection{The event of a family member becoming a health professional}

While the Swedish medical school lotteries resemble an RCT and thus represent a near-ideal setting to examine causal effects, the short follow-up period precludes us from studying the long-run impact of exposure to expertise on older adults. We therefore complement this research design with event studies that exploit the timing of the arrival of a health professional in the family. Consistent with the analysis in Section 3.3, we define the event of a family member matriculating into medical school as the start of exposure to expertise. ${ }^{48}$ Which families experience this event is not random. However, we can still assess whether having a doctor in the family impacts the health of family members by observing how the trends in health evolve over time for families that experience this event relative to the trends in health in (similar) families that do not.

In particular, we compare the families of individuals trained as medical doctors to the families of individuals trained as lawyers. Both types of families have similar socio-economic status, with income distributions that are skewed towards the top ventiles (although family members are present at all points in the income distribution). Moreover, admittance into law school - a similarly prestigeous education - also requires a high GPA.

We need two key identifying assumptions that appear plausible in our context. First, we require that access to health expertise arrives to families after an individual starts medical training. We use the first medical doctor (and the first lawyer) arriving into a family as the time of arrival of medical (or legal) expertise. Second, for our results to be consistent with a causal interpretation, we need to assume that individuals do not decide to undertake medical training based on the trend in the health of their extended family members. In other words, we need the counterfactual trend in morbidity and mortality of health professionals' family members to be parallel to that of lawyers. These assumptions appear plausible given the long timeline that typically accompanies the decision to pursue a medical degree and the slow process of chronic disease development.

Before turning to a formal regression specification, we investigate whether the assumptions we require for identification, as well as the hypothesized effects, are supported by the raw data. Figure 8 documents raw differences in the probability of adverse health outcomes between individuals with a child who received a medical degree versus a law degree. In Panel A, we plot mortality. In particular, we take the five cohorts of individuals born in Sweden between 1936 to 1940, and select individuals who have at least one child with a medical or law degree. We exclude individuals who are health professionals themselves (either a doctor or a nurse) or who have

\footnotetext{
${ }^{48}$ We do not require that the medical profession is pursued after college, though in practice the vast majority pursue medicine.
} 
a health professional spouse. ${ }^{49}$ In this sample, we compute the share of individuals that died by each calendar year starting with year 1980 (i.e., starting when the individuals are aged 40 to 45). We keep individuals in the sample even if they die, so the figure records cumulative mortality. Panel B confirms that individuals in our two samples have identical average age. (This is what we would expect absent any dramatic-and unlikely-differences in the probability of having a lawyer or a doctor child across the 1936 to 1940 cohorts.) In earlier years, mortality rates are visually identical between the two groups. Around 1995 (ages 55 to 60), however, a diversion emerges between the mortality trends of lawyer-parents (hollow circles) and doctor-parents (filled triangles). Throughout the years 1997 to 2017, parents of doctors are dying at a slower rate than parents of lawyers. The difference becomes economically and statistically significant over time, converging to a difference of 269 per 1,000 individuals having died among lawyers' parents by 2017, as compared to 238 per 1,000 individuals among doctors' parents. The difference of 31 per 1,000 lives (or 14 percent) is statistically significant at less than 1 percent level. ${ }^{50}$

In Panels $\mathrm{C}$ to F, we repeat a similar exercise for the four chronic, lifestyle-related conditions: heart attacks, heart failure, type II diabetes, and lung cancer. As our medical claims data starts much later than our mortality data, we track individuals starting in year 1997 (up until 2016). To be able to observe individuals prior to older age when the onset of conditions is already likely to have had started (and to increase precision), we increase the sample size by pooling the cohorts from 1936 to 1961. This cohort choice implies that we track individuals' chronic diagnoses from the age of 36 to 81 . We observe remarkably similar patterns across all of these conditions. As with mortality, in the early years of our data, the prevalence of chronic conditions is indistinguishable among individuals with a lawyer and a doctor child. Eventually, significant differences emerge, however, with parents of doctors having a persistently lower prevalence of all four chronic conditions. By the end of our sample period, in 2016, parents of doctors will have had 3 per 1,000 fewer heart attacks ( 7 percent fewer compared to the base of 42 heart attacks per 1,000 individuals in the lawyer-child sample); 4 per 1,000 fewer cases of heart failure (10 percent fewer relative to the base of 40 per 1,000 among lawyer-parents); 8 per 1,000 fewer cases of type II diabetes (11 percent fewer relative to 76 per 1,000 among lawyer-parents), and finally 2 per 1,000 fewer cases of lung cancer (18 percent fewer relative to the lawyer-parents baseline of 11 per 1,000 cases). All of these differences are again economically large and highly statistically precise.

These sharp patterns in the raw data support our event study approach, as they suggest that the deviation in the trend of chronic condition incidence and mortality happens long after individuals' children are likely to decide to start their (undergraduate) degrees in law or medicine. Further, we observe non-trivial differences in the incidence of chronic conditions and mortality between these two groups of parents at older ages, despite their largely similar socio-economic standing (as illustrated in Appendix Figure A4).

We now turn to a more formal analysis of these patterns and estimate the following event study-style specification:

$$
Y_{i t}=\alpha_{i}+\sum_{\tau} \sigma_{\tau} D_{\tau, i t} * D o c_{i}+\sum_{\tau} \kappa_{\tau} D_{\tau, i t}+\gamma_{t}+\beta * X_{i t}+\epsilon_{i t}
$$

\footnotetext{
${ }^{49}$ For lawyer-parents we further exclude those who had a child that became a nurse, while for the physician-parents, we exclude those who had a child that became a nurse before another child became a doctor.

${ }^{50}$ Note that in Sweden, it is extremely rare for individuals to reside with their children, even at a very old age; the social norm is that parents live alone and, if this is no longer possible, move into a long-term care facility (which is part of the municipal social insurance system). Thus, our results do not reflect an in-house caregiver effect.
} 
In this specification, $Y_{i t}$ is the health outcome of interest for individual $i$ at time $t$. While for simplicity we considered only parent-child links when graphing the raw data above, we now expand our analysis to the full set of relatives and consider health outcomes of parents, parents-in-law, as well as aunts and uncles of a medical doctor or a lawyer. The individual fixed effects $\alpha_{i}$ measure time-invariant unobserved determinants of individual $i$ 's health. Year fixed effects $\gamma_{t}$ non-parametrically control for general time trends in population health and allow us to account for secular trends in healthcare delivery and medical innovation. $X_{i t}$ is a set of time-varying demographic controls, in which we include the entire vector of age fixed effects to account for the fact that age is one of the most important determinants of health.

The set of $\kappa_{\tau}$ :s are event time fixed effects and separately capture the evolution of health in event time. The coefficients of interest are $\sigma_{\tau}$ that measure the impact of the first health professional arriving into the family on the family members' health relative to the arrival of a lawyer into the family. $\tau$ measures the number of years since the arrival of the health professional relative to time $t$. The range of $\tau$ 's varies by outcome, depending on the availability of data. We do not impose a time break and allow the data to flexibly reveal any changes in the health patterns around the time when a family member starts training as a physician (or a lawyer). We normalize $\sigma_{-1}$ to zero, so that all other $\sigma_{\tau}$ 's are interpreted as changes in health relative to one year before the young family member matriculates into a medical or a law program. For a subset of families with a health professional (or lawyer) in the family, we do not observe the time at which they acquire their medical (or legal) degrees. Rather than excluding these individuals from the sample, we impute the timing of their degrees using high school completion year. ${ }^{51}$

Figure 9 illustrates our results. We consider two main long-run outcomes: mortality and chronic conditions at older ages. For each health outcome, we plot the estimated $\sigma_{\tau}$ :s against $\tau$. Coefficient estimates for negative $\tau$ :s allow us to assess whether the data are consistent with the assumption that individuals are not sorting into the medical profession based on trends in familial health. Our estimates strongly support this assumption, which is also consistent with our observations in the raw data on parental mortality and morbidity.

Panel (A) illustrates the impact of having a family member trained as a physician on the probability of death. ${ }^{52}$ We observe a clear slow-down in the relative mortality rate among relatives of doctors (as compared to the relatives of lawyers) that starts emerging around year 8 after the young relative matriculates into college. The mortality gap then steadily widens for two decades. As Column (1) in Table 5 reports, the point estimates suggest a 1.7 percentage point decrease in the probability of death by event time 25 , which corresponds to a 10 percent decline off the mean among relatives of lawyers, which is 17 percent. $^{53}$

Panel (B) of Figure 9 captures the impact on the aggregated incidence of lifestyle-related chronic conditions.

\footnotetext{
${ }^{51}$ For all individuals for whom we observe the year in which they acquire a medical (or law) degree, we count back 6 (or 5 ) years to define the matriculation year, as these are the common lengths of the undergraduate medical and legal programs. In event studies that examine mortality, we consider cohorts born in 1936 to 1940. In 17 percent of cases for doctor-relatives and 21 percent of cases for lawyer-relatives, we do not observe the exact year in which the relative acquired a medical or a legal degree. For these observations, we impute the age of matriculation as the year of high school graduation. In the analysis of chronic conditions, we observe the exact graduation date in 97 percent and 96 percent of cases, and impute the rest using high school graduation year.

${ }^{52}$ The outcome is an indicator taking the value of 1 if the individual has died by time $t$, and the value zero otherwise (i.e., if the individual is still alive in time $t$ ). The outcome thus captures the timing of death.

${ }^{53}$ Some individuals in our sample are observed only for a subset of event years. When we restrict the sample to a balanced panel (59 percent of the sample), we get nearly identical results - a 10 percent effect on the probability of death at event year +25 in the balanced panel and 10.2 percent effect in our baseline specification with the full sample.
} 
We plot the same "lifestyle" index that we examined in the non-parametric analysis, which is a z-score incorporating the following conditions: heart attack, heart failure, type II diabetes, and lung cancer. Consistent with the observations in the raw data and our lottery-based results, we observe a significant divergence in health between relatives of doctors and lawyers that emerges around year 5 post college matriculation. The divergence widens for two decades post college matriculation, as can also be seen in Column 1, Panel B of Table 5.

We report separate event study results for the four chronic conditions underlying the lifestyle index in Appendix Table A1, and graphically in Appendix Figure A5. We observe that differences emerge at around year 9 post matriculation in the probability of having a heart attack and at around year 5 for congestive heart failure. The differences persist and expand over time. We observe a similarly pronounced divergence in the incidence of type II diabetes and lung cancer. Fifteen years after matriculation, relatives of doctors are 1 percentage point (23 percent) less likely to have a diabetes diagnosis and 20 percent less likely to have lung cancer. These long-run patterns are consistent with the idea that responses to exposure to expertise include the formation of healthier behaviors and the adoption of new preventive measures, and that these long-run processes yield cumulative health benefits that grow important over time.

We further examine the heterogeneity of our event study effects by income and proximity, both geographically and in the family tree. Columns (2) to (7) in Table 5 report the results. As in the non-parametric analysis, we find that individuals with income in the lower half of the distribution are more affected (we find a 35 percent higher relative impact on mortality in the fist half of the income distribution) by exposure to expertise. ${ }^{54}$ Further, family members that live closer to the health professional geographically benefit more. We do not find substantial heterogeneity in the impact on mortality with respect to proximity along the family tree, though the impact on chronic conditions is stronger among individuals with health professionals that are closer family members.

\section{Exposure to expertise and health inequality}

\subsection{Quantifying the implications for the health-income gradient}

Section 3 documents positive average treatment effects of increased exposure to health-related expertise on a set of important health investments and physical health outcomes. These effects do not accrue only at the top of the income distribution, but are similar, or even more pronounced, in the first half of the income distribution. We now use these findings to assess whether differences in health literacy across the income distribution could account for a quantitatively meaningful share of the health-income gradient.

To fix ideas about magnitudes, we perform two hypothetical counterfactual exercises. First, we ask how big the difference in health literacy measured in "doctor equivalents" would have to be between those at the top half and bottom half of the income distribution in order to fully account for the observed gradient in mortality. Second, we create a "universal access to expertise" counterfactual, asking how the health-income gradient would

\footnotetext{
${ }^{54}$ To be able to conduct the heterogeneity analysis by income and geography, we switch our sample to younger cohorts; in particular, 1946 to 1955. This is because, while our mortality records go far back, the information on income and geography is available only for a more recent time period. The difference in samples accounts for the differences in relative and point estimates across the specifications.
} 
change if we could expose everyone in society to the benefits of health-related expertise that we document in Section 3.

First counterfactual: measuring the health-income gradient in "doctor-equivalents" We consider a stylized setting that divides individuals in our sample into two groups - those in the top and bottom halves of the income distribution, respectively. In the data, the average probability of dying by age 80 , conditional on having survived until age 55, is 35 percent in the first half of the income distribution and 27 percent in the second half of the income distribution. These two data moments are plotted as a solid line in Panel A of Figure 10. From our estimates of treatment effects in Table 1 and Table 5 , we have that exposure to a physician in the family leads to a 10 percent decline in mortality (on average). If the health benefits from exposure to expertise scaled linearly with each doctor in the family, it would take a difference of 2.1 "doctor-equivalents" on average between families at the top and the bottom of the income distribution to account for the full difference in mortality. ${ }^{55}$

Naturally, the levels of intra-family exposure that we observe in the data are much lower - in practice, exposure to doctors happens not only through family members, but also through friends, neighbors, and colleagues. What's more, health literacy does not only stem from relatives who are health professionals, but from a range of sources, all of which are likely to be more readily available at the top of the income distribution (Kindig et al. 2004). The gradient in exposure between the first and second half of the income distribution that we observe in the data, however, is striking: While individuals at the top half of the income distribution have on average 0.26 physicians in the family, those at the bottom have on average 0.05 , or five times fewer, doctors in the family. To get 2 more "doctor-equivalents" at the top of the income distribution, keeping the gradient the same, we would need to have at least 2.5 "doctor-equivalents" at the top of the income distribution on average and 0.5 at the bottom. Another way to summarize these magnitudes, staying for simplicity with exposure to physicians per se, is as follows. If individuals in the top half of the income distribution on average know one doctor, while only every fifth individual knows a doctor at the bottom of the income distribution, then this difference alone could account for a third of the health-income gradient.

Second counterfactual: universal access to expertise Our second counterfactual, illustrated in Panel B of Figure 10, captures the reverse thought experiment: Suppose that, on top of Sweden's universal health insurance, we could add "universal access to expertise," that is, we could deliver the full benefit of exposure to expertise to all citizens. Then, how much would the health gap between the top and bottom halves of the income distribution decline? This counterfactual requires two inputs: (i) the impact of expertise on health at different points in the income distribution, estimated in Section 3; and (ii) the baseline distribution of health literacy in society today, i.e., in the absence of any policy intervention. It is straightforward to see why we need (i), and our finding that the beneficial effects of exposure to expertise are weakly larger at the lower end of the income distribution already suggests that a policy that makes everyone exposed to expertise could close part of the health-SES gradient - even if (ii) were uniform across the SES spectrum. If, in addition - as documented in the

\footnotetext{
${ }^{55}$ The "doctor-equivalents" required to fully close the gap would naturally be higher if the effect of an extra physician on health literacy and the effect of extra heath literacy had decreasing marginal returns, as is likely to be the case in practice.
} 
public health literature ${ }^{56}$ - individuals at the lower end of the income distribution have lower health literacy, then this would further reinforce the impact of policies that provide exposure to expertise on overall health inequality (as a larger share of individuals at the lower end of the income distribution would move from low health literacy to high health literacy).

Following several studies in public health that have documented a tight linkage between multi-dimensional survey measures of health literacy and formal education in Europe (see, e.g., Sorensen et al. 2015), we use the share of individuals with a college degree as a proxy measure of health literacy. ${ }^{57}$ For the cohorts born in 1936 and 1937 - which are the ones for whom we can observe mortality by age 80 conditional on being alive at age $55-7$ percent of individuals had a college degree in the lower half of the income distribution, while 31 percent had a college degree in the top half of the income distribution. ${ }^{58}$ The large difference in formal education across the income distribution would imply that health literacy is substantially scarcer at the lower end of the SES spectrum than at the top.

In Figure 10, we combine our findings into a back-of-the-envelope calculation of the potential effect of providing universal access to expertise on the mortality-income gradient. We make the following two assumptions: First, we assume a uniform treatment effect of access to expertise on mortality of 10 percent across the income distribution. This is our aggregate estimate from the event study (which is consistent with the estimate from our non-parametric analysis); thus, it is a conservative estimate of the impact on mortality at the lower end of the income distribution. Second, we assume that the baseline level of health literacy follows the same distribution as the college share, so that we start from a situation in which 7 percent of individuals in the first half of the income distribution have a sufficient degree of health literacy, while 31 percent do at the top. Under these two assumptions, we compute the counterfactual mortality levels at the top and the bottom halves of the income distribution, respectively, under a policy that gives universal access to expertise, and that thus eradicates differences in health literacy across the SES spectrum.

To compute counterfactual mortality at the bottom (top) half of the income distribution, we start with observed mortality by age 80 . We then let our hypothetical policy move the percentage of individuals that have access to expertise by 93 (69) percentage points (to 100 percent), and let these "treated" individuals experience a 10 percent reduction in mortality. ${ }^{59}$ This calculation suggests that the mortality-income gap would shrink substantially under universal access to expertise: from the observed mortality gap of 0.076 between the top

\footnotetext{
${ }^{56}$ Appendix C.1 summarizes the public health literature on health literacy, which supports the notion that individuals at the higher rungs of the income ladder have more health literacy and have more exposure to health-related expertise. Intuitively, they likely have had a longer formal education, have access to more informed friends and relatives, a higher ability to search for information on their own, and possibly more "mental bandwidth" to remember to take prescribed medications or to decipher the intricacies of the administrative steps that are needed to navigate health care and health insurance systems, among many other channels (Mullainathan and Shafir 2013).

${ }^{57}$ Using data of the European Social Survey we have ourselves verified the strong association between measures of health literacy that were available for Sweden in the 2004 and 2014 waves and education. As a sanity check on the ESS survey data, we also verify that individuals without a college degree report being in worse health Appendix Table A2 reports these results.

${ }^{58}$ The gap in formal education is pronounced in younger cohorts as well. In a pooled sample across all cohorts for whom we can observe formal education levels, 16 percent of individuals have a college degree in the bottom half of the income distribution, and 44 percent in the top half.

${ }^{59}$ The resulting formula for counterfactual mortality is: observed mortality within the income group times the treatment effect (1-0.1), divided by $\left(1-0.1^{*} 0.07\right)$ for the first half of the income distribution, and divided by (1-0.1*0.31) for the second half. The denominator term re-scales the numerator to account for the differences in the baseline levels of access to expertise and hence the share of individuals that gets treated.
} 
and bottom halves of the income distribution, to 0.063. This corresponds to a 18 percent reduction in the mortality-SES gradient.

Our two thought experiments have important implications for health inequality, as they suggest that asymmetry in the quality and ease of access to health-related expertise across the socio-economic distribution can, in theory, generate and sustain a quantitatively important share of the health-SES gradient - even in the presence of equalized formal access to healthcare and a generous social safety net. Yet it is important to emphasize that both of these are highly stylized exercises designed to give a sense of the quantitative importance of the channel that we identify, and not explicitly linkable to policy (this, we briefly return to in the discussions below).

\subsection{Mechanisms}

There are two (broad) interpretations of the health rents to expertise that we document in Section 3. First, access to expertise may deliver benefits that are intrinsically zero-sum and that simply stem from having access to someone "inside" the health care system. For example, a better understanding of "how to work the healthcare system" may result in faster appointments with better physicians. Such benefits, which we will refer to as a form of "social capital," would come at the expense of individuals who lack informal access to expertise, and thus to the health care system. Indeed, if someone gets a faster appointment, then someone else must wait longer. In other words, benefits that are intrinsically zero-sum are inherently non-scalable (holding constant the quality and quantity of healthcare providers). Under this interpretation of our results, none of the inequality reduction associated with the "universal expertise"- counterfactual that we calculated above would be attainable. Instead, our findings would imply that differential access to informal expertise is a persistent and deeply rooted source of inequality in our empirical setting - despite Sweden's universal health insurance, universal pharmaceutical drug insurance, and a broad social safety net. What's more, our calculations in Section 4.1 would underscore that this source of inequality is quantitatively important, accounting for as much as 18 percent of Sweden's health-SES gap.

A second interpretation is that access to expertise deliver benefits that are not zero-sum, and that hence may be scalable. Health professionals may, for example, use some combination of information provision, reminders, nudges, and social pressure to accomplish an improvement in their relatives' health behaviors. Such improvements could, for instance, include smoking cessation, an improved diet or exercising regime, better adherence to prescribed drugs, increased take-up of immunizations and flu shots, and an increased proclivity to doing annual check-ups and preventive health care visits. Such benefits to informal expertise would not come at the expense of individuals who lack informal access to expertise. Indeed, one individual getting vaccinated or quitting smoking does not preclude another individual from undertaking the same health investment. Under this interpretation, there may be an opportunity to scale (some of) the benefits from exposure to expertise to others, and thus to achieve some reduction in health inequality.

Under either interpretation, our central finding - that health rents to exposure to expertise are substantial and contribute to inequality - is important. ${ }^{60}$ In reality, both mechanisms may be at play to some extent. While

\footnotetext{
${ }^{60}$ Yet another alternative interpretation is that our results could be driven by an income effect. As we are able to test this
} 
our data does not allow us to do an exact decomposition, our results allow us to convincingly rule in the second interpretation; moreover, we are able to speculate about the quantitative importance of the first.

Conceptually scalable benefits Among older adults, we studied a number of chronic cardiovascular and metabolic conditions that are commonly attributed to a combination of lifestyle (e.g., diet, exercise, smoking) and adherence to medications preventing these conditions (rather than to any expensive clinical interventions, which potentially may be in shortage in the Swedish health care system). Improvements in these physical health outcomes are not zero-sum: one patient avoiding a heart attack, for example, does not raise another patient's heart attack risk. In a similar vein, the preventive investments that we analyzed are inherently not zero-sum: one patient's improved adherence to prescribed medications preventing chronic cardiovascular disease, diabetes, or asthma does not preclude another patient from undertaking the same beneficial behavior change. The drugs that we examined are all cheap and easily obtainable - they are off patent and included on the national prescription drug insurance formulary. Hence, increased consumption of these drugs among family members of health professionals likely stems from a combination of better information about the benefits of these drugs; more trust in this information; as well as reminders, nudges, and "nagging" about drug adherence - rather than from any costly and scarce interventions. ${ }^{61}$

Among younger individuals, our results also allow us to rule in benefits to health expertise that are not inherently scarce. For example, one child avoiding tobacco exposure in utero is costless (if not cost-saving) to society. Similarly, one patient obtaining the HPV vaccine does not preclude another patient from getting the same (low-cost) vaccine. Further, we documented a reduction in the number of inpatient stay days among young family members of health care professionals; under any non-scalable mechanism, we would have expected the reverse. What's more, if anything, the rates of addiction and infection are likely to be diagnosed at higher rates conditional on true disease prevalence in families with links to the healthcare system; despite this, we consistently find either negative effects or noisy zeros.

In sum, many of the outcomes that respond to exposure to expertise are inherently not zero-sum. Instead, they likely reflect decisions that individuals make in their everyday lives, and that everyone in the society could make without imposing a meaningful social cost - lifestyle choices concerning diet and exercise, tobacco use (or cessation) during pregnancy, vaccine take-up, and adherence to cheap and readily available drugs. These are outcomes for which "connections" to the healthcare system likely matter very little. ${ }^{62}$

Another way to shed light on the importance of the scalable benefits channel would be to vary the extent of medical information held by a family member, without varying whether the family member is an "insider" in the health care system. In this spirit, the comparison of our results to the investigation in Artmann et al. (2019) - which uses medical school lotteries in the Netherlands to examine how doctors affect their parents' health -

interpretation directly using the lottery sample, and do no find evidence in support of income effects in the Swedish context, we do not pursue this alternative interpretation further.

${ }^{61}$ Notably, in the lottery analysis, our results "show up" while physicians are still in training, and hence cannot prescribe these medications themselves. This rules out "ease-of-prescribing"-effects.

${ }^{62}$ These findings are consistent with the fact that, in our lottery analysis, the "treated" group is exposed to a young physician either in medical school, or in the first two years after finishing medical training - who likely has few connections and can mostly influence the health of family members by transmitting new or better explained information. 
yields another suggestive piece of evidence in support of the "scalable benefits" interpretation of our results. In the Dutch setting, more than $40 \%$ of lottery losers go on to pursue professions that likely lead to high health literacy. ${ }^{63}$ This stands in contrast to the Swedish context, where individuals not admitted to medical school through the GPA-based admission mechanism most frequently decide to pursue professions related to business, economics, and engineering. This suggests that there is a greater difference in basic medical information between lottery winners and losers in Sweden than there is in the Netherlands (while winners in both settings end up "inside" the health care system). Consistent with this, we find larger treatment effects on outcomes capturing scalable benefits in the Swedish context. ${ }^{64}$

Zero-sum, and thus conceptually non-scalable, benefits To get a sense of how the "social capital" channel could operate and how likely it is to be quantitatively significant in the Swedish context, we discuss several examples of this channel on outcomes that we can capture in the data that reflect expensive or (in our setting) potentially rationed health care services.

First, we investigate whether family members of health professionals obtain more expensive heart attack treatments. The underlying idea is as follows. There are two common invasive therapies, one of which is substantially more expensive than the other, and one non-invasive (drug) therapy, which is the cheapest; under the "social capital" hypothesis, connected patients may be more likely to get a relatively expensive treatment option (holding severity of the condition constant). ${ }^{65}$ We find no evidence of differences in the probability of getting an invasive (versus non-invasive) heart attack treatment across patients with and without a health professional in the extended family. Further, we find no difference in the intensity of invasive treatment conditional on getting an invasive (i.e. surgery rather than drugs) treatment.

Second, we investigate whether family members of health professionals have systematically longer stays in the hospital after childbirth (conditioning on a wide range of characteristics capturing postpartum maternal health and the child's health at birth). Despite the fact that the duration of postpartum care is generally rationed in the Swedish healthcare system - mothers are discharged as early as six hours after childbirth, while mothers in the U.S. are legally entitled to stay for up to 48 hours, depending on the state - we do not find any differences in the length of stay across patients with and without a health professional in the family.

Third, we examine the importance of the access to care channel for cancer treatment, as existing literature has documented that connections appear relevant for the choice and speed of cancer treatments Fiva et al. (2014). Here, we do find a smaller time window between the first diagnosis of breast cancer and breast cancer surgery among family members of health professionals. Interestingly, however, there is no pronounced income gradient in the prevalence of cancers, nor in mortality attributable to cancer. ${ }^{66}$ This suggests that, at the population level,

\footnotetext{
${ }^{63}$ Specifically, $18.2 \%$ pursue professions in biomedical science, movement science, therapeutics, and rehabilitation; $10.1 \%$ pursue psychology; $7.7 \%$ pharmacy and $6.8 \%$ other health occupations.

${ }^{64}$ Further, when comparing individuals with a much larger distance in medical expertise - physicians and lawyers - the same large positive treatment effect of expertise emerges in the Dutch setting.

${ }^{65}$ The two invasive therapies are coronary artery bypass grafting (CABG) and percutaneous coronary intervention (PCI), with the former being a more expensive open heart surgery.

${ }^{66}$ In fact, if anything, we observe an inverse SES-gradient in cancers, which likely is driven by competing risks with cardiovascular diseases as well as more screening at the upper end of the income distribution. The exception is lung cancer; however, it accounts for a very small share of all cancers.
} 
the access to care channel does not generate substantial differences in cancer-related outcomes across the income distribution.

In sum, the broader picture that emerges is that, while some non-scalable benefits may be at play in our empirical setting, our results allow us to argue that there exists an effect of exposure to expertise that does not run through social capital, that may be scalable, and that is currently being left on the table. ${ }^{67}$

\section{Discussion and Conclusion}

Growing evidence across various disciplines reveals stark correlations between health capital throughout the course of life and a range of measures of socioeconomic status. Yet, the mechanisms underlying these associations are poorly understood. A common explanation (and a ubiquitous focus of policy discussions) for the existence and persistence of the health-SES gradients is the difference in formal access to healthcare. Our evidence suggests that this explanation can only be one piece of the puzzle when it comes to understanding the origins of SES gradients (as crucially distinct from levels) in health. We document that strong socioeconomic gradients in mortality and morbidity across a range of ages and conditions persist in Sweden, a country that boasts universal formal access to healthcare and a well-developed social safety net. This fact motivates us to examine a mechanism other than access to health insurance and formal healthcare that may perpetuate socio-economic gradients in health. Specifically, we investigate whether exposure to health-related expertise over the course of an individual's life can build health literacy that improves health, and whether differences in such exposure across the SES spectrum contributes to health inequality.

To create a quantifiable metric of health literacy, we zoom in on an environment where we can precisely measure individuals' exposure to health-related expertise: the presence of a health professional in the family. Using non-parametric evidence, event studies, and exploiting "admissions lotteries" into medical school, we find that access to expertise improves physical health and boosts preventive health investments among younger as well as older generations. Our back of the envelope calculations based on these estimates suggest that differences in this exposure across the SES spectrum can account for as much as 18 percent of the mortality gradient.

One view of our results is that they emphasize the limits of government intervention. Sweden equalizes the supply-side of health, providing cheap and universal access to inpatient and specialized care, prenatal care, primary care, prescription drugs, and vaccines; and yet substantial inequality remains. Our results indicate that this remaining inequality could in part stem from demand-side factors: decisions that individuals make outside of the healthcare system, such as whether to undertake beneficial lifestyle investments, whether to adhere to prescribed (and cheap) drugs, whether to take up vaccines, and whether to cease tobacco use during pregnancy.

A more positive interpretation of our findings is that they suggest that a policy that were able to "mimic" what health professionals do for their family members would have the potential to make a substantial dent in population health and reduce health inequality. Indeed, our analysis suggests that exposure to expertise at least

\footnotetext{
${ }^{67}$ Our results are consistent with the idea that historically, the "extensive" margin of disease prevention through changes in social and individual investments into health - that we hypothesize can be affected by access to health expertise - has had a substantially more pronounced effect on population health than the "intensive" margin of moving from a lower to a higher quality of care provider, or getting care faster within a given system (Cutler and Lleras-Muney 2008).
} 
partially improves health through "low-tech" (and hence, cheap) and nonrivalrous determinants of health, such as adherence to medication, vaccination, and cessation of tobacco use. At least conceptually, these benefits are scalable at the population level.

It is thus worthwhile to consider the specific features of intra-family communication, and whether a policy maker may be able to replicate (some of) those. If intra-family health professionals simply transfer (common) knowledge to their family members, then incorporating health literacy as a standard part of school curriculum along with information provision campaigns may be effective. ${ }^{68}$ To the extent that the power of intra-family communication about health stems from trust or detailed knowledge about the health history and habits that come with a relationship that spans a long period of time, however, effective policies may need to strive to mimic the depth of these relationships. ${ }^{69}$ Elements of such a policy could include nurse outreach programs with a strong emphasis on the continuity of care (yielding long-term relationships), coupled with a strengthening of the role of a trusted and easily accessible - both in terms of geographic location and the administrative hurdles - general practitioner who knows patients, and potentially their whole family, over a long period of time. Further, Alsan et al. (2018) suggests that healthcare professionals that resemble the patient (in their case, same-race providers) may gain more trust. Finally, given the heterogeneous effects across the income distribution, such programs specifically targeted at the poor may have the largest potential to reduce health inequality. Understanding the patterns that underlie the intra-family transmission of expertise in health (and other) domains, and the potential replicability of this transmission by public policies, remains an important area for future work.

\footnotetext{
${ }^{68}$ Notably, health literacy instruction in sexuality and the family planning domain has become an standard part of secondary school curriculum in many countries. A multitude of studies has documented that the existence of this instruction and what is being taught in the classroom has significant effects on behavior. We are not aware of settings where broader health literacy instruction that could transmit information ranging from which food to eat to how to make an appointment with a doctor is systematically included in the national secondary school curriculum. A number of pilot interventions, however, have been implemented across different countries.

${ }^{69}$ Such an idea hypothesizes that repeated interactions between patients and healthcare providers improve the efficiency of healthcare delivery, which resonates with the idea that repeated interactions between healthcare providers of a team improve their productivity (Chen 2019).
} 


\section{References}

Adler, Nancy E, Thomas Boyce, Margaret A Chesney, Sheldon Cohen, Susan Folkman, Robert L Kahn, and S Leonard Syme, "Socioeconomic Status and Health: The Challenge of the Gradient," American Psychologist, 1994, 49 (1), 15-24.

Aizer, Anna and Janet Currie, "The Intergenerational Transmission of Inequality: Maternal Disadvantage and Health at Birth," Science, 2014, 344 (6186), 856-861.

- and Laura Stroud, "Education, Knowledge and the Evolution of Disparities in Health," Working Paper 15840, National Bureau of Economic Research March 2010.

Allcott, Hunt, Rebecca Diamond, and Jean-Pierre Dubé, "The Geography of Poverty and Nutrition: Food Deserts and Food Choices Across the United States," Working Paper 24094, National Bureau of Economic Research December 2017.

Almond, Douglas and Bhashkar Mazumder, "Health Capital and the Prenatal Environment: The Effect of Ramadan Observance during Pregnancy," American Economic Journal: Applied Economics, 2011, 3 (4), 56-85.

_ , Janet Currie, and Valentina Duque, "Childhood Circumstances and Adult Outcomes: Act II," Journal of Economic Literature, 2018, 56 (4), 1360-1446.

Alsan, Marcella, Owen Garrick, and Grant C Graziani, "Does Diversity Matter for Health? Experimental Evidence from Oakland," Working Paper 24787, National Bureau of Economic Research June 2018.

Artmann, Elisabeth, Hessel Oosterbeek, and Bas van der Klaauw, "Do Doctors Improve the Health Care of Their Parents? Evidence from Admission Lotteries," University of Amsterdam mimeo, September 2019 .

Autor, David, Andreas Ravndal Kostol, Magne Mogstad, and Bradley Setzler, "Disability Benefits, Consumption Insurance, and Household Labor Supply," Working Paper 23466, National Bureau of Economic Research June 2017.

Bell, Alexander M, Raj Chetty, Xavier Jaravel, Neviana Petkova, and John Van Reenen, "Who Becomes an Inventor in America? The Importance of Exposure to Innovation," Quarterly Journal of Economics, 2018, 134 (2), 647-713.

Bharadwaj, Prashant, Juan Pedro Eberhard, and Christopher A. Neilson, "Health at Birth, Parental Investments, and Academic Outcomes," Journal of Labor Economics, 2018, 36 (2), 349-394.

_ , Petter Lundborg, and Dan-Olof Rooth, "Birth Weight in the Long Run," Journal of Human Resources, 2018, $53(1), 189-231$. 
Black, Sandra E., Paul J. Devereux, and Kjell G. Salvanes, "From the Cradle to the Labor Market? The Effect of Birth Weight on Adult Outcomes," Quarterly Journal of Economics, 2007, 122 (1), 409-439.

Bronnenberg, Bart J., Jean-Pierre Dube, Matthew Gentzkow, and Jesse M. Shapiro, "Do Pharmacists Buy Bayer? Informed Shoppers and the Brand Premium," Quarterly Journal of Economics, 2015, 130 (4), 1669-1726.

Case, Anne, Darren Lubotsky, and Christina Paxson, "Economic Status and Health in Childhood: The Origins of the Gradient," American Economic Review, 2002, 92 (5), 1308-1334.

_ , Diana Lee, and Christina Paxson, "The Income Gradient in Children's Health: A Comment on Currie, Shields and Wheatley Price," Journal of Health Economics, 2008, 27 (3), 801-807.

Centers for Disease Control and Prevention, "Tobacco Use and Pregnancy," 2017. Accessed March 18, 2018. https://www.cdc.gov/reproductivehealth/maternalinfanthealth/tobaccousepregnancy/index.htm.

Cesarini, David, Erik Lindqvist, Robert Östling, and Björn Wallace, "Wealth, Health, and Child Development: Evidence from Administrative Data on Swedish Lottery Players," Quarterly Journal of Economics, 2016, $131(2), 687-738$.

Chen, Alice, Emily Oster, and Heidi Williams, "Why is Infant Mortality Higher in the United States than in Europe?," American Economic Journal: Economic Policy, 2016, 8 (2), 89-124.

Chen, Yiqun, "Team-Specific Human Capital and Team Performance: Evidence from Doctors," 2019. Accessed October 19, 2019. https://web.stanford.edu/ ychen13/jmp_ychen.pdf.

Chetty, Raj, Michael Stepner, Sarah Abraham, Shelby Lin, Benjamin Scuderi, Nicholas Turner, Augustin Bergeron, and David Cutler, "The Association between Income and Life Expectancy in the United States, 2001-2014," Journal of the American Medical Association, 2016, 315 (16), 1750-1766.

Chorniy, Anna, Janet Currie, and Lyudmyla Sonchak, "Exploding Asthma and ADHD Caseloads: The Role of Medicaid Managed Care," Journal of Health Economics, 2018, 60, 1-15.

Cullen, Mark R., Clint Cummins, and Victor R. Fuchs, "Geographic and Racial Variation in Premature Mortality in the U.S.: Analyzing the Disparities," PLOS One, 2012, 7 (4), 1-13.

Currie, Janet, "Healthy, Wealthy, and Wise: Socioeconomic Status, Poor Health in Childhood, and Human Capital Development," Journal of Economic Literature, 2009, 47 (1), 87-122.

_ , "Inequality at Birth: Some Causes and Consequences," American Economic Review, 2011, 101 (3), 1-22.

- and Enrico Moretti, "Mother's Education and the Intergenerational Transmission of Human Capital: Evidence from College Openings," Quarterly Journal of Economics, 2003, 118 (4), 1495-1532.

_ and _ , "Biology as Destiny? Short- and Long-Run Determinants of Intergenerational Transmission of Birth Weight," Journal of Labor Economics, 2007, 25 (2), 231-264. 
_ and Hannes Schwandt, "Mortality Inequality: The Good News from a County-Level Approach," Journal of Economic Perspectives, 2016, 30 (2), 29-52.

_ and Mark Stabile, "Child Mental Health and Human Capital Accumulation: The Case of ADHD," Journal of Health Economics, 2006, 25 (6), 1094-1118.

Cutler, David and Adriana Lleras-Muney, "Education and Health: Evaluating Theories and Evidence," in Robert F. Schoeni, James S. House, George A. Kaplan, and Harold Pollack, eds., Making Americans Healthier: Social and Economic Policy as Health Policy, New York: Russell Sage Foundation, 2008.

_ and _, "Understanding Differences in Health Behaviors by Education," Journal of Health Economics, 2010, $29(1), 1-28$.

Dayoub, Elias and Anupam B Jena, "Chronic Disease Prevalence and Healthy Lifestyle Behaviors among US Health Care Professionals," Mayo Clinic Proceedings, 2015, 90 (12), 1659-1662.

Deaton, Angus, "Policy Implications of the Gradient of Health and Wealth," Health Affairs, 2002, 21 (2), $13-30$.

Diamond, Rebecca and Petra Persson, "The Long-Term Consequences of Teacher Discretion in Grading of High-Stakes Tests," Working Paper 22207, National Bureau of Economic Research April 2016.

Djoussé, Luc, Jane A Driver, and J Michael Gaziano, "Relation between Modifiable Lifestyle Factors and Lifetime Risk of Heart Failure," JAMA, 2009, 302 (4), 394-400.

Dwyer-Lindgren, Laura, Amelia Bertozzi-Villa, Rebecca W Stubbs, Chloe Morozoff, Johan P Mackenbach, Frank J van Lenthe, Ali H Mokdad, and Christopher JL Murray, "Inequalities in Life Expectancy among US Counties, 1980 to 2014: Temporal Trends and Key Drivers," JAMA Internal Medicine, 2017, 177 (7), 1003-1011.

Fadlon, Itzik and Torben Heien Nielsen, "Family Health Behaviors," American Economic Review, 2019, 109 (9), 3162-3191.

Finkelstein, Amy, Neale Mahoney, and Matthew J. Notowidigdo, "What Does (Formal) Health Insurance Do, and for Whom?," Annual Review of Economics, 2018, 10 (1), 261-286.

Fiva, Jon H, Torbjørn Hægeland, Marte Rønning, and Astri Syse, "Access to Treatment and Educational Inequalities in Cancer Survival," Journal of Health Economics, 2014, 36, 98-111.

Fowler, James H and Nicholas A Christakis, "Dynamic Spread of Happiness in a Large Social Network: Longitudinal Analysis over 20 Years in the Framingham Heart Study," BMJ, 2008, 338 (7685), 23-28.

Frakes, Michael, Jonathan Gruber, and Anupam Jena, "Is Great Information Good Enough? Evidence from Physicians as Patients," Working Paper 26038, National Bureau of Economic Research July 2019. 
Fuchs, Victor R., "Poverty and Health: Asking the Right Questions," The American Economist, 1992, 36 (2), $12-18$.

_ , "Reflections on the Socio-Economic Correlates of Health," Journal of Health Economics, 2004, 23 (4), 653 661.

_ and Karen Eggleston, "Life Expectancy and Inequality in Life Expectancy in the United States," SIEPR Policy Brief, April 2018.

Hiscock, Rosemary, Linda Bauld, Amanda Amos, Jennifer A. Fidler, and Marcus Munafò, "Socioeconomic Status and Smoking: A Review," Annals of the New York Academy of Sciences, 2012, 1248 (1), $107-123$.

Hut, Stefan and Emily Oster, "Changes in Household Diet: Determinants and Predictability," Brown University mimeo, January 2018.

Hvide, Hans K. and Paul Oyer, "Dinner Table Human Capital and Entrepreneurship," Working Paper 24198, National Bureau of Economic Research January 2018.

Janssen, Aljoscha, "Switching Costs, Quality Misconceptions and Behavioral Pricing in the Pharmaceutical Market," mimeo, Stockholm School of Economoics, 2018.

Johnson, Erin M. and M. Marit Rehavi, "Physicians Treating Physicians: Information and Incentives in Childbirth," American Economic Journal: Economic Policy, 2016, 8 (1), 115-141.

Ketel, Nadine, Edwin Leuven, Hessel Oosterbeek, and Bas van der Klaauw, "The Returns to Medical School: Evidence from Admission Lotteries," American Economic Journal: Applied Economics, 2016, 8 (2), $225-254$.

Kindig, David A, Allison M Panzer, Lynn Nielsen-Bohlman et al., Health literacy: A prescription to end confusion, National Academies Press, 2004.

Kling, Jeffrey R, Jeffrey B Liebman, and Lawrence F Katz, "Experimental Analysis of Neighborhood Effects," Econometrica, 2007, 75 (1), 83-119.

Knowler, William C, Elizabeth Barrett-Connor, Sarah E Fowler, Richard F Hamman, John M Lachin, Elizabeth A Walker, and David M Nathan, "Reduction in the Incidence of Type 2 Diabetes with Lifestyle Intervention or Metformin.," New England Journal of Medicine, 2002, 346 (6), 393-403.

Kuziemko, Ilyana, "Human Capital Spillovers in Families: Do Parents Learn from or Lean on their Children?," Journal of Labor Economics, 2014, 32 (4), 755-786.

Lee, Samuel and Petra Persson, "Financing from Family and Friends," The Review of Financial Studies, 2016, 29 (9), 2341-2386. 
Leuven, Edwin, Hessel Oosterbeek, and Inge de Wolf, "The effects of medical school on health outcomes: Evidence from admission lotteries," Journal of Health Economics, 2013, 32 (4), 698 - 707.

Lleras-Muney, Adriana, "Mind the Gap: A Review of The Health Gap: The Challenge of an Unequal World by Sir Michael Marmot," Journal of Economic Literature, 2018, 56 (3), 1080-1101.

Lundborg, Petter and Kaveh Majlesi, "Intergenerational Transmission of Human Capital: Is it a One-Way Street?," Journal of Health Economics, 2018, 57, 206-220.

Marmot, Michael G, Stephen Stansfeld, Chandra Patel, Fiona North, Jenny Head, Ian White, Eric Brunner, Amanda Feeney, and G Davey Smith, "Health Inequalities among British Civil Servants: the Whitehall II Study," The Lancet, 1991, 337 (8754), 1387-1393.

McCrary, Justin and Heather Royer, "The Effect of Female Education on Fertility and Infant Health: Evidence from School Entry Policies Using Exact Date of Birth," American Economic Review, 2011, 101 (1), $158-95$.

Meckel, Katherine, "Is the Cure Worse than the Disease? Unintended Consequences of Fraud Reduction in Transfer Programs," UCLA mimeo, September 2017.

Meghir, Costas, MÃrten Palme, and Emilia Simeonova, "Education and Mortality: Evidence from a Social Experiment," American Economic Journal: Applied Economics, 2018, 10 (2), 234-56.

Mullainathan, Sendhil and Eldar Shafir, Scarcity: Why Having Too Little Means So Much, New York: Times Books, 2013.

National Academies of Sciences, Engineering, and Medicine, The Growing Gap in Life Expectancy by Income: Implications for Federal Programs and Policy Responses, Washington, DC: The National Academies Press, 2015.

Ogden, Cynthia L., Molly M. Lamb, Margaret D. Carroll, and Katherine M. Flegal, "Obesity and Socioeconomic Status in Adults: United States, 2005-2008," NCHS Data Brief, December 2010, 50, 1-8.

Oreopoulos, Philip, Mark Stabile, Randy Walld, and Leslie L. Roos, "Short-, Medium-, and Long-Term Consequences of Poor Infant Health: An Analysis Using Siblings and Twins," Journal of Human Resources, 2008, $43(1), 88-138$.

Persson, Petra, "Social Insurance and the Marriage Market," Journal of Political Economy, 2020, 128 (1), $252-300$.

- and Maya Rossin-Slater, "Family Ruptures, Stress, and the Mental Health of the Next Generation," American Economic Review, 2018, 108 (4-5), 1214-1252.

Rehm, Colin D., José L. Peñalvo, Ashkan Afshin, and Mozaffarian Dariush, "Dietary Intake among US Adults, 1999-2012," Journal of the American Medical Association, 2016, 315 (23), 2542-2553. 
Rosenquist, J Niels, Joanne Murabito, James H Fowler, and Nicholas A Christakis, "The Spread of Alcohol Consumption Behavior in a Large Social Network," Annals of Internal Medicine, 2010, 152 (7), $426-433$.

_ , _ _ , and _ , "Social Network Determinants of Depression," Molecular Psychiatry, 2011, 16 (3), 273-281.

Royer, Heather, "Separated at Girth: US Twin Estimates of the Effects of Birth Weight," American Economic Journal: Applied Economics, 2009, 1 (1), 49-85.

Salvy, Sarah-Jeanne, Kayla de la Haye, Julie C. Bowker, and Roel C.J. Hermans, "Influence of Peers and Friends on Children's and Adolescents' Eating and Activity Behaviors," Physiology \& Behavior, 2012, 106 (3), 369-378.

Seligman, Benjamin, Gabi Greenberg, and Shripad Tuljapurkar, "Equity and Length of Lifespan are Not the Same," Proceedings of the National Academy of Sciences, 2016, 113 (30), 8420-8423.

Sjogren, Anna and Laura Hartman, "Hur Ojamlik Ar Halsan I Sverige," IFAU Rapport, 2018.

Sommers, Benjamin D., Atul A. Gawande, and Katherine Baicker, "Health Insurance Coverage and Health - What the Recent Evidence Tells Us," New England Journal of Medicine, 2017, 377 (6), 586-593.

Sorensen, Kristine, on behalf of the HLS-EU Consortium, Juergen M. Pelikan, on behalf of the HLS-EU Consortium, Florian Roethlin, on behalf of the HLS-EU Consortium, Kristin Ganahl, on behalf of the HLS-EU Consortium, Zofia Slonska, on behalf of the HLS-EU Consortium, Gerardine Doyle, on behalf of the HLS-EU Consortium, James Fullam, on behalf of the HLSEU Consortium, Barbara Kondilis, on behalf of the HLS-EU Consortium, Demosthenes Agrafiotis, on behalf of the HLS-EU Consortium, Ellen Uiters, on behalf of the HLS-EU Consortium, Maria Falcon, on behalf of the HLS-EU Consortium, Monika Mensing, on behalf of the HLSEU Consortium, Kancho Tchamov, on behalf of the HLS-EU Consortium, Stephan van den Broucke, on behalf of the HLS-EU Consortium, Helmut Brand, and on behalf of the HLSEU Consortium, "Health literacy in Europe: Comparative results of the European health literacy survey (HLS-EU)," European Journal of Public Health, 04 2015, 25 (6), 1053-1058.

Stasz, Cathleen and Christian von Stolk, "The Use of Lottery Systems in School Admissions," RAND Corporation, January 2007.

Thakrar, Ashish P., Alexandra D. Forrest, Mitchell G. Maltenfort, and Christopher B. Forrest, "Child Mortality in the US and 19 OECD Comparator Nations: A 50-Year Time-Trend Analysis," Health Affairs, 2018, 37 (1), 140-149.

The Future of Children, "Policies to Promote Child Health," Princeton University and The Brookings Institution, 2015, 25 (1), 1-197. 
Vlachos, Jonas, "Betygets Värde: En Analys Av Hur Konkurrens Påverkar Betygss Vättningen Vid Svenska Skolor," 2010.

Walker, Renee E., Christopher R. Keane, and Jessica G. Burke, "Disparities and Access to Healthy Food in the United States: A Review of Food Deserts Literature," Health \& Place, 2010, 16 (5), 876-884.

Wannamethee, S Goya, A Gerald Shaper, Mary Walker, and Shah Ebrahim, "Lifestyle and 15Year Survival Free of Heart Attack, Stroke, and Diabetes in Middle-Aged British Men," Archives of Internal Medicine, 1998, 158 (22), 2433-2440. 
Figure 1: Income Gradients in Mortality and Morbidity over the Lifecycle

A. Died, by Age 80

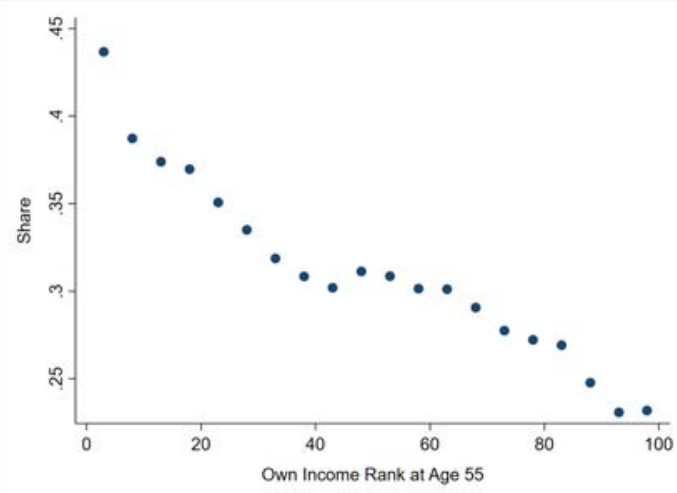

C. HPV Vaccine, by Age 20

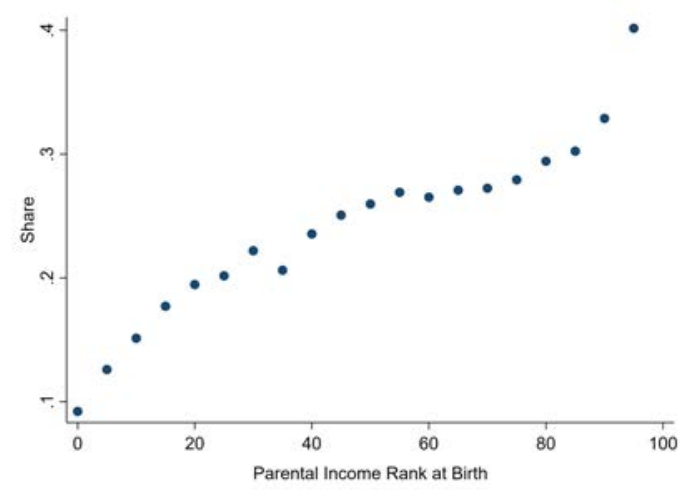

B. Lifestyle-Related Conditions, Age 55+

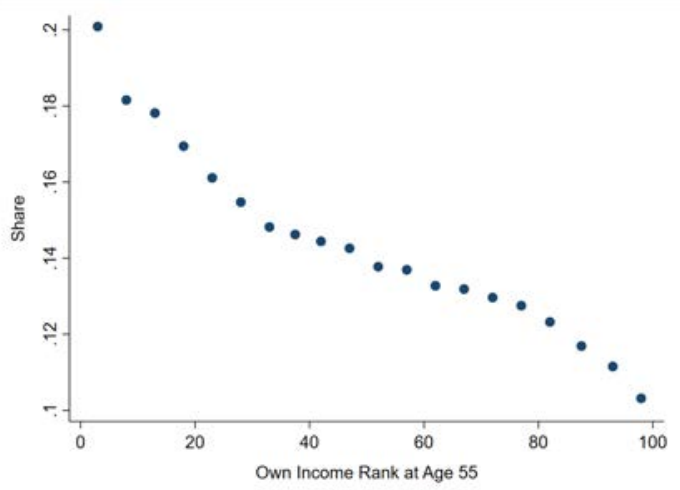

D. Tobacco Exposure, in utero

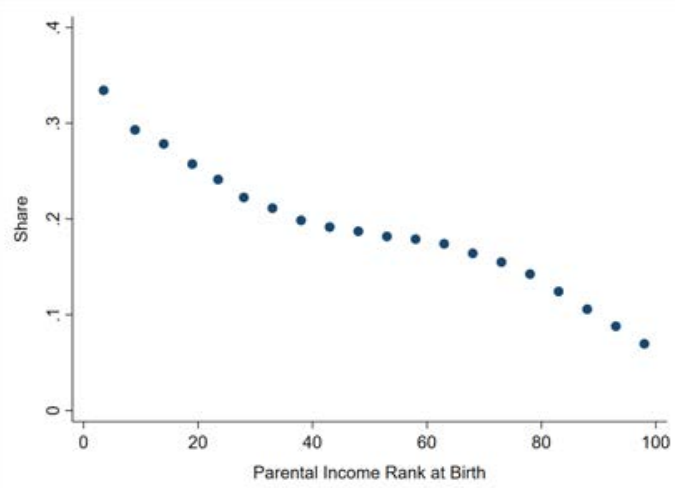

Figures show the share of individuals with the specified health condition (vertical axis) by ventile of own income rank at age 55 or parental income rank at birth (horizontal axis). Individuals with zero or negative (parental) work-related income are excluded. Own income rank is assigned based on each individual's own income at age 55 relative to other people in the same gender-birth cohort. Parental income ranks at birth are assigned based on the average of parents' incomes in the two years before the child was born relative to other parents with children in the same birth cohort. Panel B is defined as having diagnosis codes for any of the following conditions after age 55: heart attack, heart failure, lung cancer, or type II diabetes. Panel A restricts the sample to birth cohorts 1936-1937; panel B restricts the sample to individuals born between 1936-1961 and alive at age 55 and year 1997 (first year of inpatient claims). Panel C restricts the sample to females born between 1995-1997 and alive at age 20. Tobacco exposure in utero in panel D measures whether the mother used any type of tobacco within 3 months before or during pregnancy; the sample is restricted to children born in 1995-2016. 
Figure 2: Income Gradients in Mortality in the US and Sweden

A. Mortality at Age 75 , Men

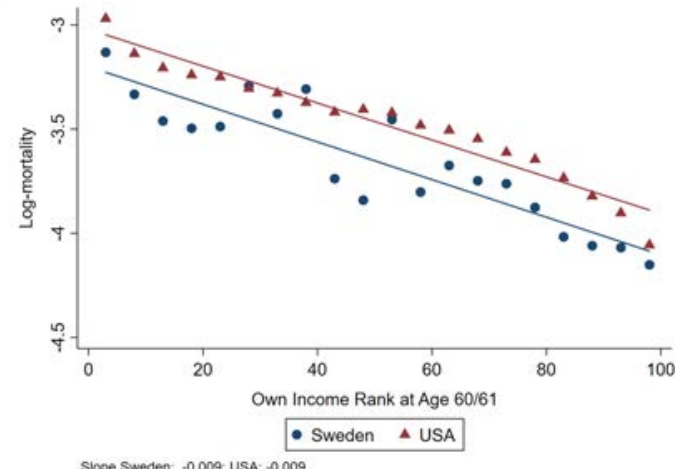

C. Mortality at Age 60, Men

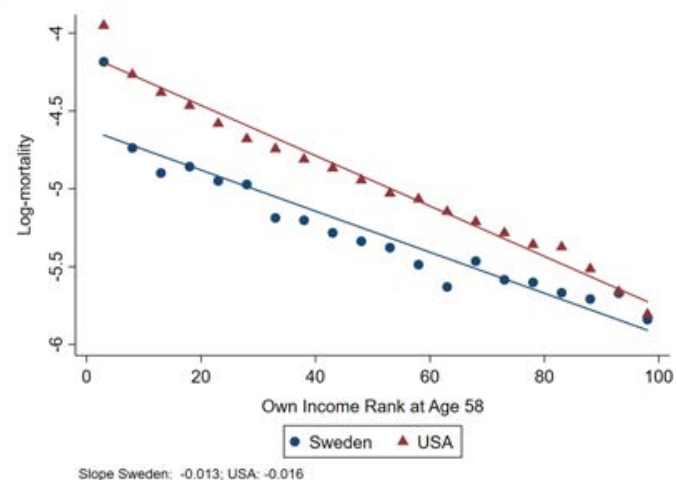

E. Mortality at Age 40, Men

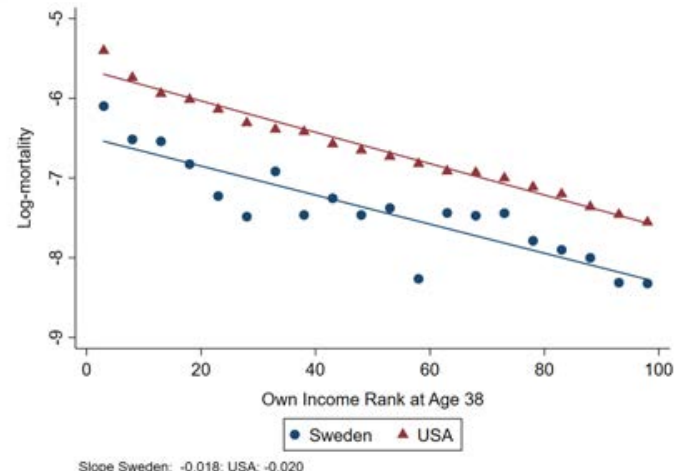

B. Mortality at age 75 , Women

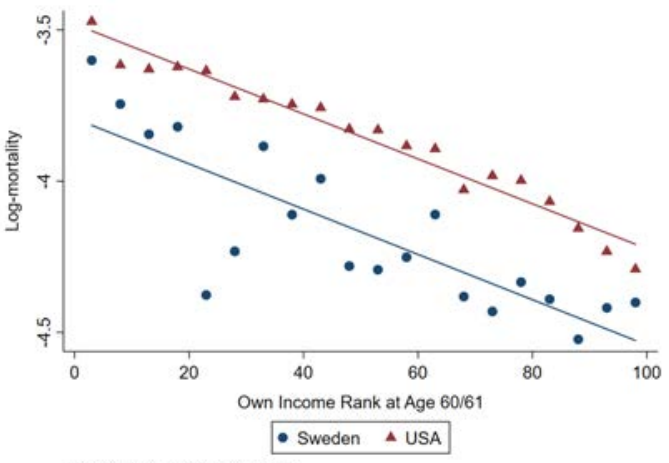

D. Mortality at Age 60, Women

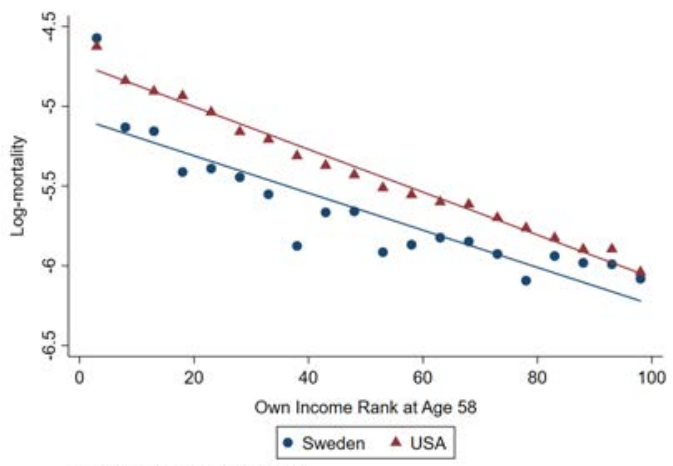

F. Mortality at Age 40, Women

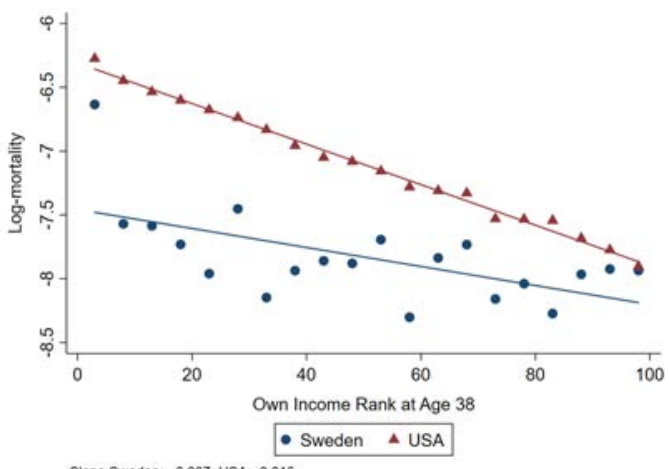

Figures compare mortality rates by income rank ventile between Sweden and the US. We report mortality at age 40,60 and 75 conditional on ventiles of income rank at age 38,58, and 60 (Sweden) or 61 (US), respectively. US mortality data is derived from the data reported by the Health Inequality Project https://healthinequality.org/. The sample for Sweden is restricted to the same birth cohorts as in the US data. Income is measured as the equivalent of the US adjustable gross income (includes work-related income, self-employment income, and capital income). We exclude individuals with zero or negative income from the analysis. The note in each panel reports the estimated slope of a linear regression of log-mortality rate on income rank percentile, separately by country and gender. We cannot reject the statistical equivalency of the slopes measuring the mortality gradient for men at age 40 and at age 75 ( $p$-values 0.46 and 0.87 , respectively), as well as for women at age 75 ( $p$-value 0.96 ). We reject the equivalency for the mortality gradient for men at age 60 and for women at age 40 ( $p$-value 0.00$)$, and for women at age 60 at the $10 \%$ significance level ( $p$-value 0.05 ). 
Figure 3: Health Professional in the Family and Health at Older Ages: Non-Parametric Evidence

A. Died, by Age 80

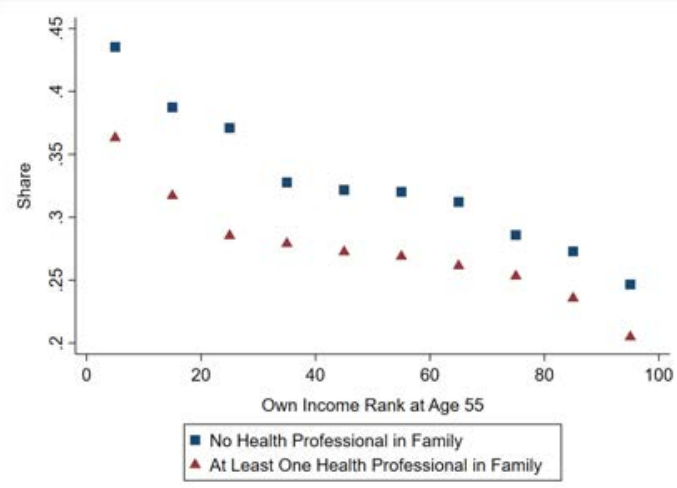

C. Lifestyle-Related Conditions, Age 55+

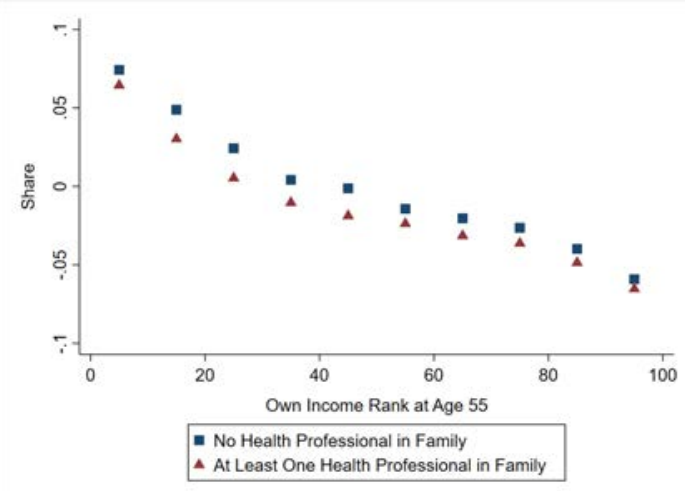

B. Died, by Age 80

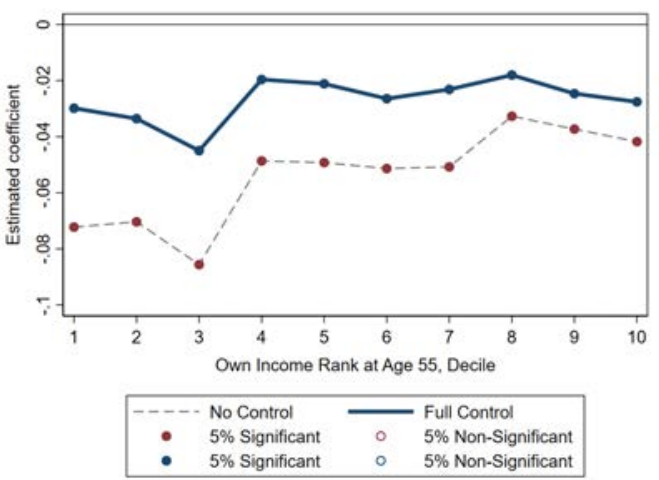

D. Lifestyle-Related Conditions, Age 55+

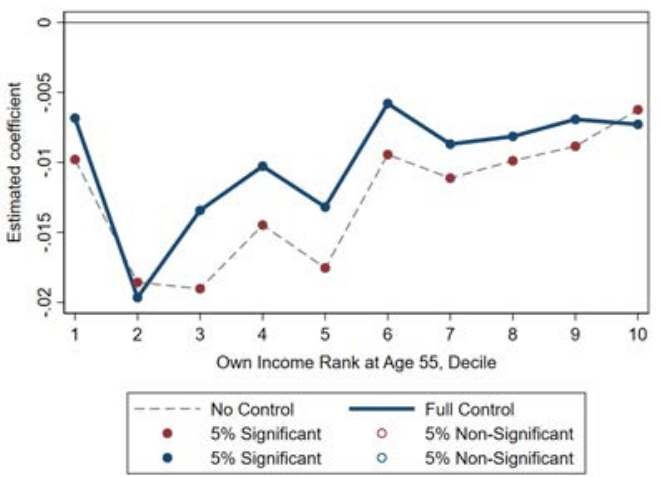

Panels A and C plot the share of individuals with the specified health condition by decile of own income rank at age 55. The outcome in Panel C is a z-score index of four underlying conditions: heart attack, heart failure, type II diabetes, and lung cancer; the index is constructed as specified in the text. We start with the same data samples as defined in Figure 1. The samples are split by whether an individual has a health professional in the family. Individuals are assigned to the sample "with a health professional" if at least one member of their broad family (spouse, sibling, cousin, child, child-in-law, niece/nephew, grandchild) has a university degree in medicine or nursing. We exclude individuals who hold a degree in medicine or nursing themselves. Panels B and D report coefficients from OLS regressions of each outcome on the dummy indicating whether the person has a health professional in the family, with (solid line) and without (dashed line) covariates. Coefficients are reported as filled circles if they are estimated with at least $5 \%$ statistical significance level, and as hollow circles otherwise. The covariates include fixed effects for individual's own income rank percentile and income rank percentile of the highest-earning relative, year of birth fixed effects, gender dummy, fixed effects for discretized education levels, fixed effects for the county of residence at age 55 . Standard errors are clustered at the family level. 
Figure 4: Health Professional in the Family and Health at Younger Ages: Non-Parametric Evidence

A. HPV Vaccine, by Age 20

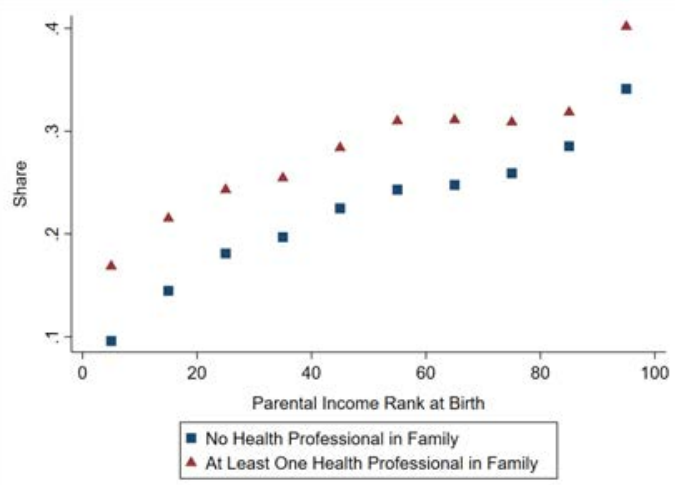

C. Tobacco Exposure, in utero

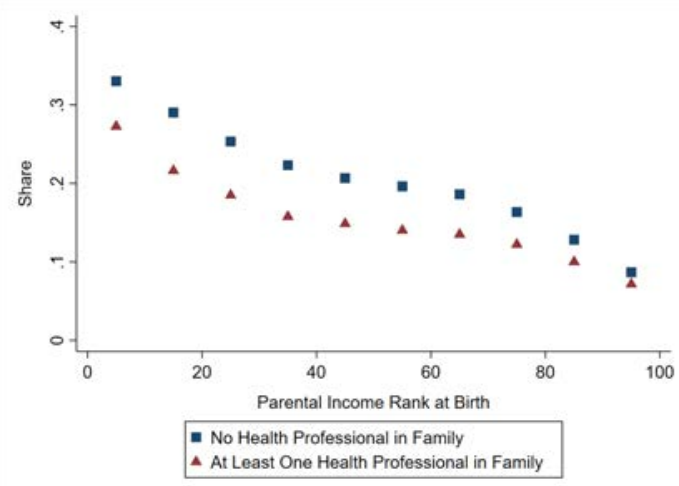

B. HPV Vaccine, by Age 20

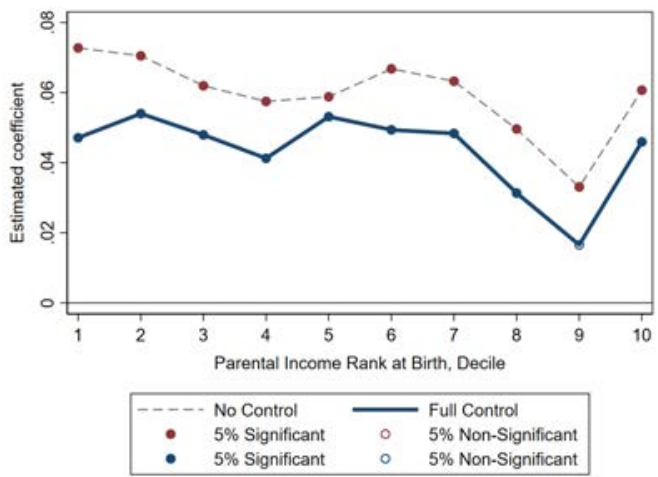

D. Tobacco Exposure, in utero

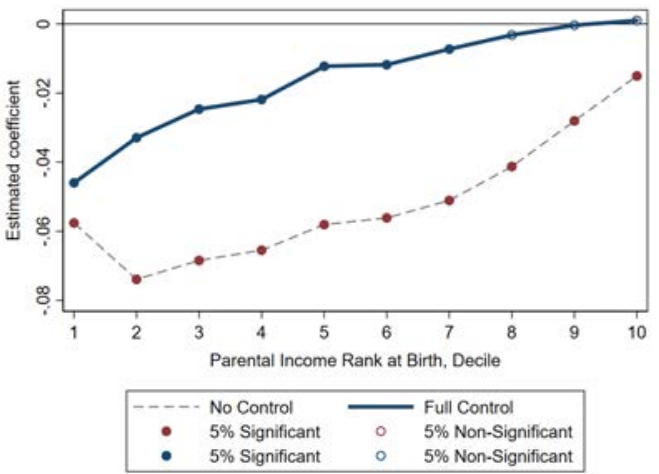

Panels A and C plot the share of individuals with the specified health condition by decile of parental income rank at birth. We start with the same data samples as defined in Figure 1. The samples are split by whether an individual has a health professional in the family. Individuals are assigned to the sample "with a health professional" if at least one member of their broad family (sibling, cousin, parent, aunt/uncle, grandparent) has a university degree in medicine or nursing. Panels B and D report coefficients from OLS regressions of each outcome on the dummy indicating whether the person has a health professional in the family, with (solid line) and without (dashed line) covariates. Coefficients are reported as filled circles if they are estimated with at least $5 \%$ statistical significance level, and as hollow circles otherwise. The covariates include fixed effects for parental income rank percentile and income rank percentile of the highest-earning relative, year of birth fixed effects, gender dummy, fixed effects for mother's county of residence before birth; covariates in Panel D further add fixed effect for birth order, mother's education, and maternal age. Standard errors are clustered at the family level. 
Figure 5: Health Professional in the Family and Health at Older Ages: Heterogeneity

\section{A. Died by Age 80}

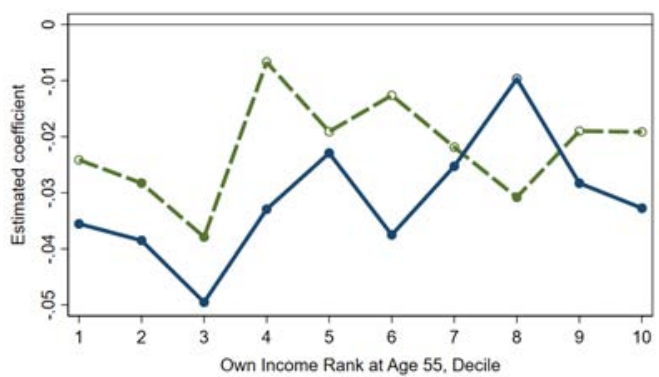

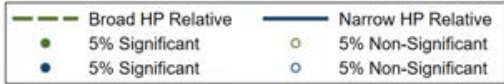

C. Lifestyle-Related Conditions, Age 55+

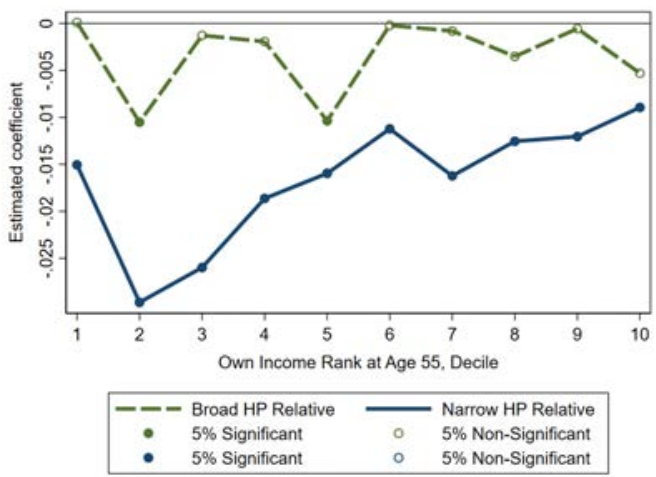

B. Died by Age 80

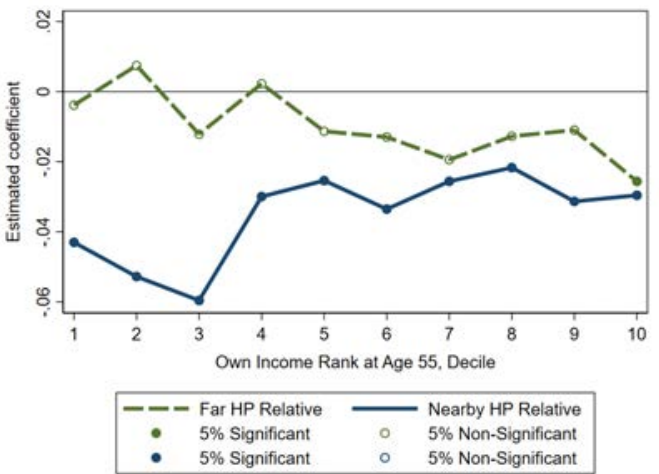

D. Lifestyle-Related Conditions, Age 55+

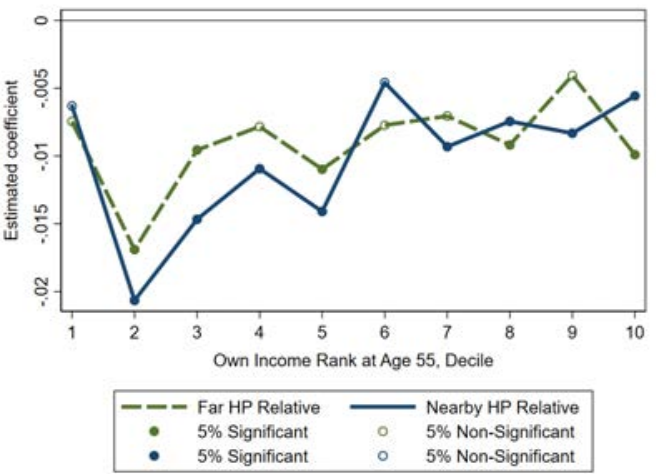

Figures replicate the analyses in Panels B and D (specifications with the full set of covariates) of Figure 3 for sub-samples of the data. Panels A and C re-estimate conditional differences in mortality and the prevalence of lifestyle-related conditions separately for individuals that have a broad, but no narrow, health professional in the family (dashed line), and for individuals that have a narrow health professional (solid line), relative to individuals that have no health professionals. A broad family tie is defined as having a health professional, who is a sibling, cousin, niece/nephew, or a grandchild. A narrow family tie is defined as having a health professional, who is a child, child-in-law, or a spouse. Panels B and D split the same based on geographic proximity. An individual is defined to have a nearby health professional relative (solid line) if both reside in the same county in the same year for more than 50 percent of the years that are observed between 1991 and 2016. The individual is defined to have a far health professional relative otherwise (dashed line). In all regressions, the comparison group is the set of individuals without any health professional relative. Coefficients are reported as filled circles if they are estimated with at least $5 \%$ statistical significance level, and as hollow circles otherwise. 
Figure 6: Health Professional in the Family and Health at Younger Ages: Heterogeneity

A. HPV Vaccine, by Age 20

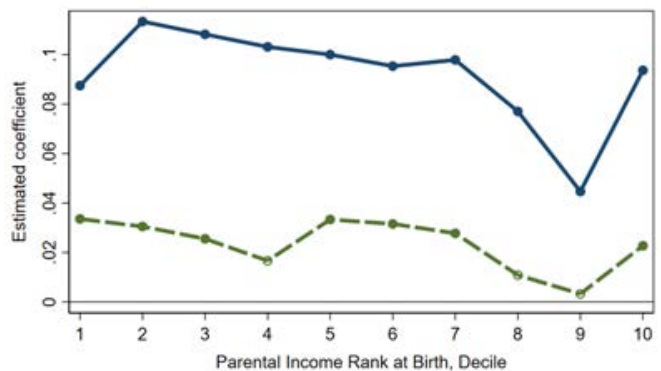

\begin{tabular}{|c|c|c|c|}
\hline - & Broad HP Relative & & Narrow HP Relative \\
\hline • & $5 \%$ Significant & o & $5 \%$ Non-Significant \\
\hline$\bullet$ & Significant & 。 & $5 \%$ Non-Significant \\
\hline
\end{tabular}

C. Tobacco Exposure, in utero

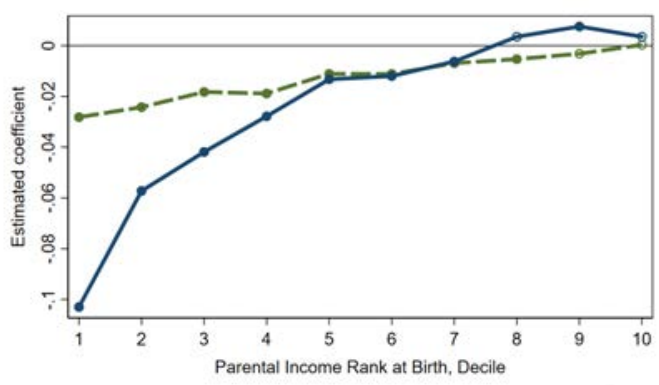

\begin{tabular}{|c|c|}
\hline lative & — Narrow HP Relative \\
\hline $\begin{array}{l}\text { - } \quad 5 \% \text { Significant } \\
\text { - } 5 \% \text { Significant }\end{array}$ & $\begin{array}{l}\text { 5\% Non-Significant } \\
5 \% \text { Non-Significant }\end{array}$ \\
\hline
\end{tabular}

B. HPV Vaccine, by Age 20
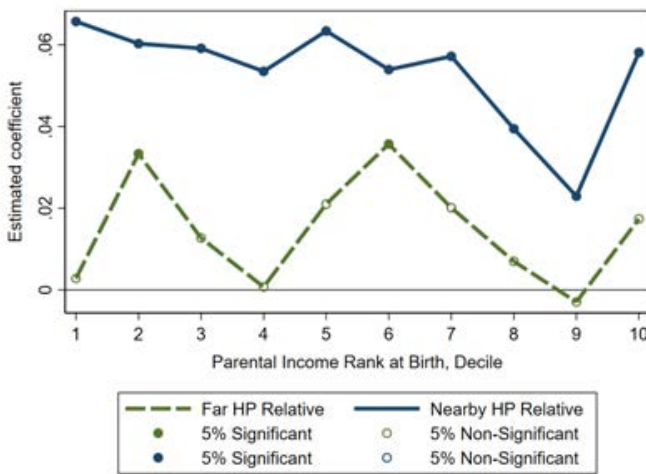

D. Tobacco Exposure, in utero

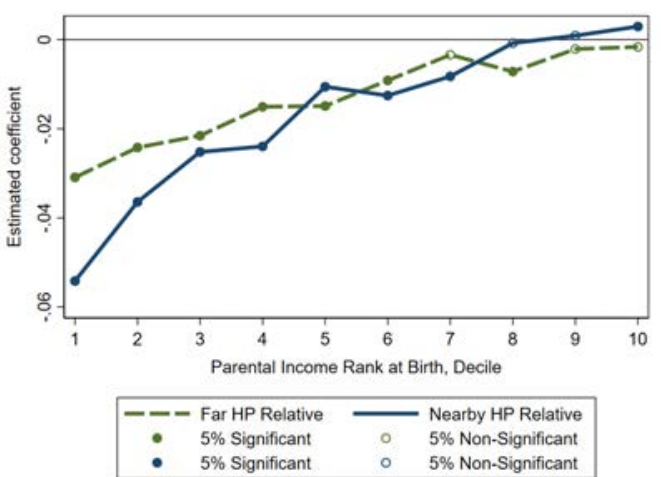

Figures replicate the analyses in Panels B and D (specifications with the full set of covariates) of Figure 4 for sub-samples of the data. Panels A and C re-estimate conditional differences in HPV vaccination and tobacco exposure in utero separately for individuals that have a broad, but no narrow, health professional in the family (dashed line), and for individuals that have a narrow health professional (solid line), relative to individuals that have no health professionals. A broad family tie is defined as having a health professional, who is a sibling, cousin, aunt/uncle, or a grandparent. A narrow family tie is defined as having a health professional mother or father. Panels B and D split the same based on geographic proximity. An individual in Panel B is defined to have a nearby health professional relative (solid line) if the individual's parents reside in the same county in the same year for more than 50 percent of the years that are observed between 1991 and 2016. A child in Panel D is defined to have a nearby health professional relative (solid line) if in the year of birth, a health professional relative lived in the same county as the mother. The individuals are defined to have a far health professional relative otherwise (dashed line). In all regressions, the comparison group is the set of individuals without any health professional relative. Coefficients are reported as filled circles if they are estimated with at least $5 \%$ statistical significance level, and as hollow circles otherwise. 
Figure 7: GPA Cutoffs for Admission into Medical Programs

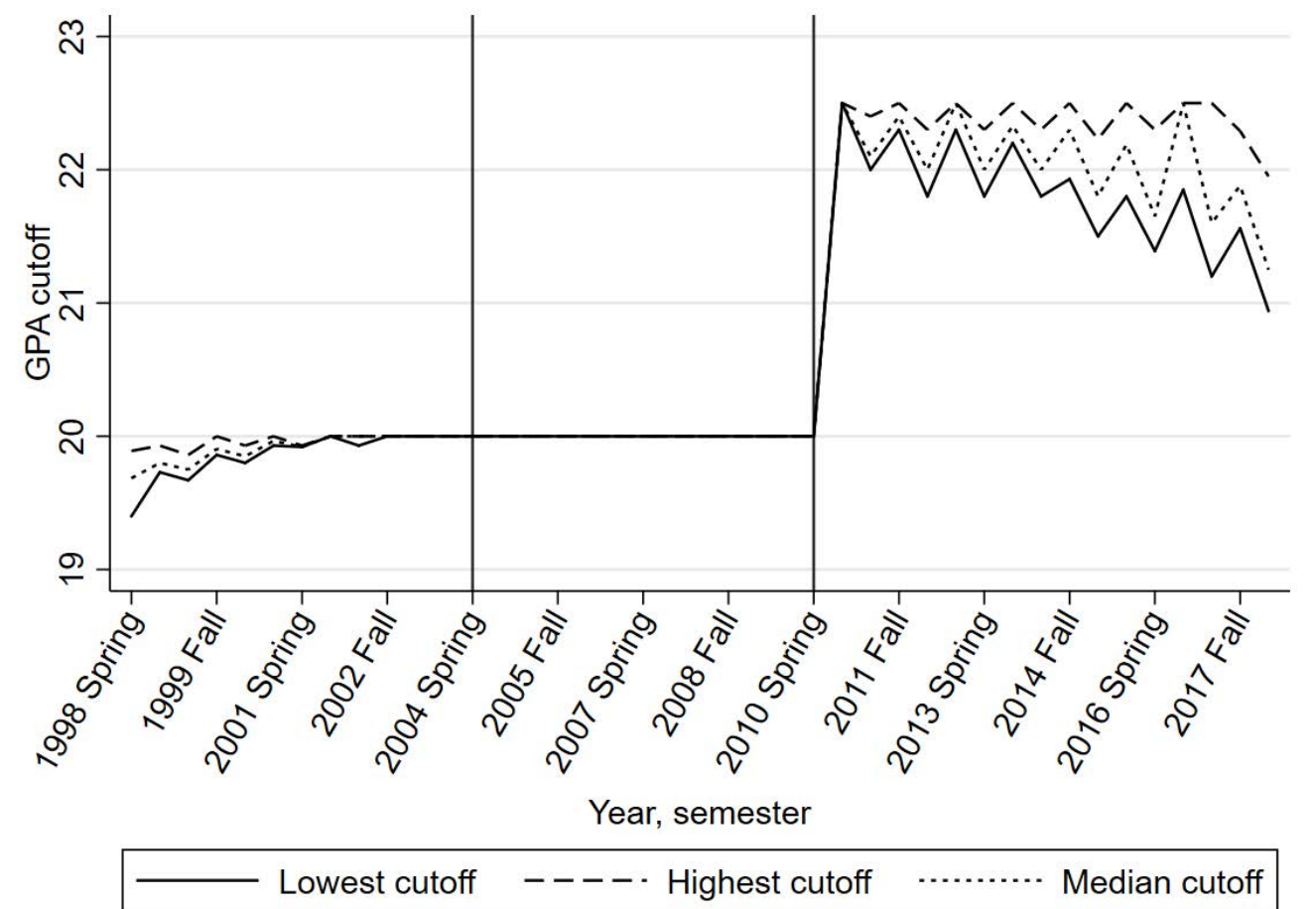

Figure plots the time series of the GPA cutoffs for undergraduate medical programs with the lowest, median, and highest cutoff. Each observation is a school and (semi-annual) application cycle, starting from 1998 to 2017. 
Figure 8: Doctor in the Family and Log-Run Health Bonus: Descriptive Evidence

A. Mortality

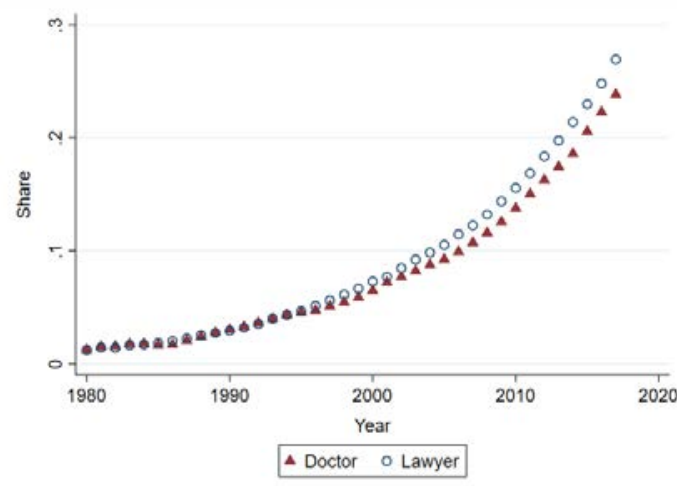

C. Heart Attack

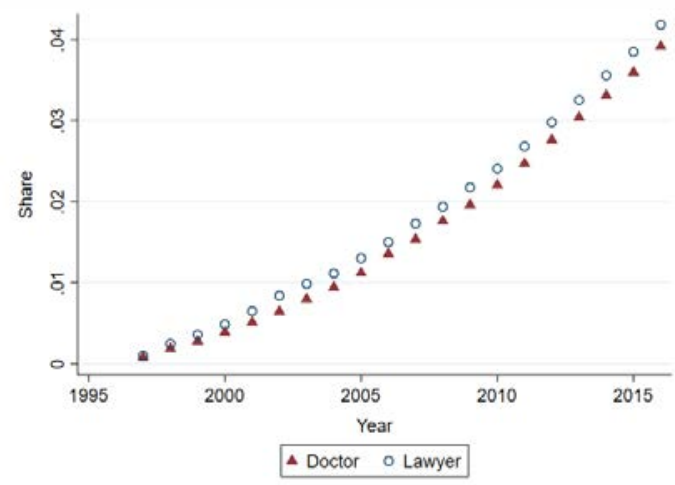

E. Type II Diabetes

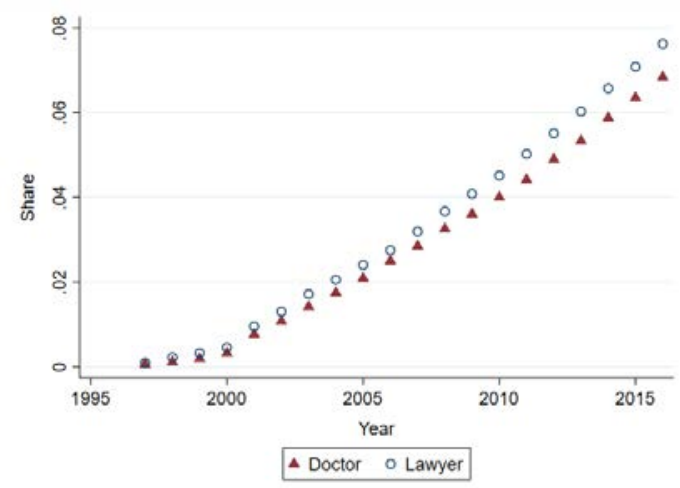

B. Age

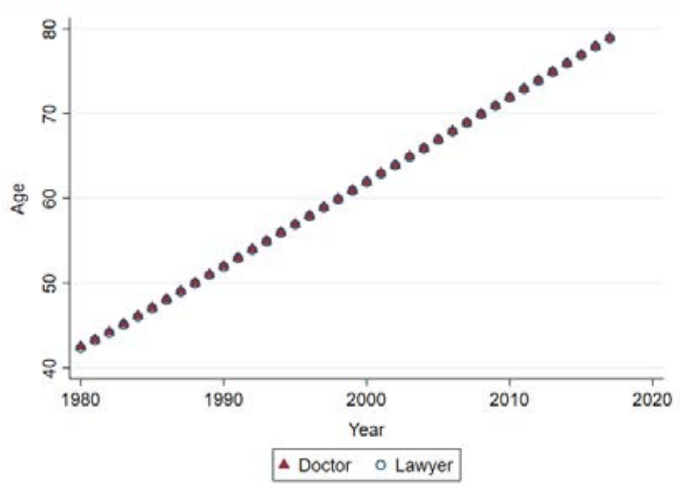

D. Heart Failure

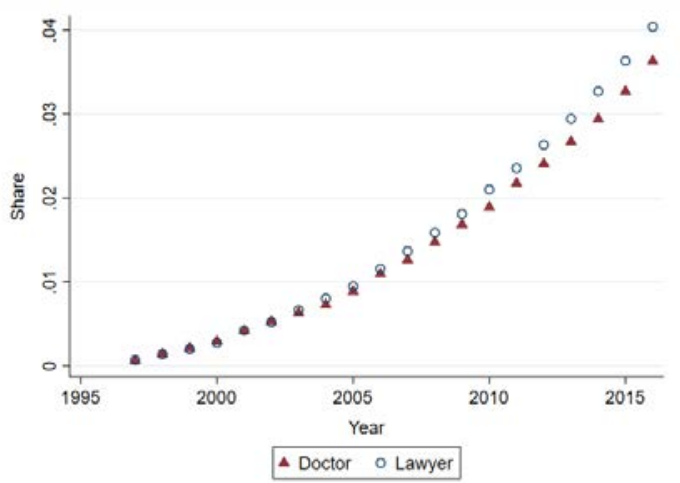

F. Lung Cancer

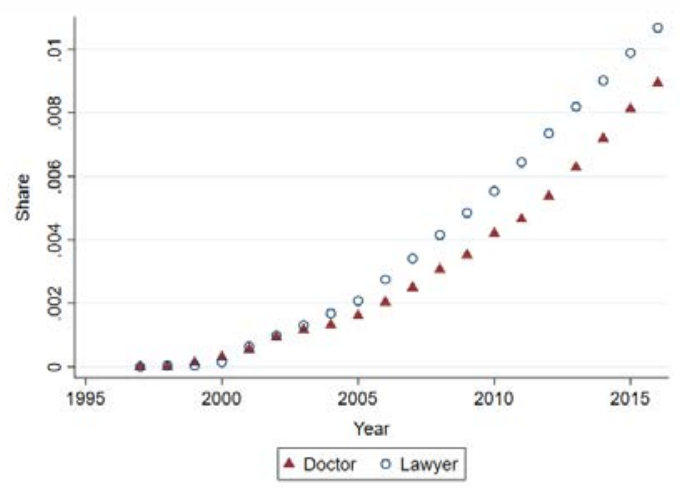

Panel A records the cumulative share (y-axis) of individuals born in Sweden in 1936-1940, who have died by a given calendar year (x-axis). Panel B records the average age of the same individuals by calendar year, keeping deceased individuals in the sample. Panels C to F record the share of individuals born in Sweden between 1936 and 1961, who have acquired the specified chronic condition by a given calendar year (x-axis). Deceased individuals are kept in the balanced sample. In all panels the sample is restricted to individuals who at some point in their lifetime had a child matriculated in the study of either law or medicine. The outcomes are shown separately for the group of individuals whose child matriculated into medical (filled triangles) or legal (hollow circles) studies. We exclude observations if at least one parent is a health professional (a physician or a nurse) herself or himself. Parents with a child who became a nurse before another child became a doctor are not included in the "doctor" sample; parents that have a child trained as a lawyer and another child trained as a doctor (or nurse) are excluded from the "lawyer" sample. 
Figure 9: Doctor in the Family and Long-Run Health Bonus: Event Studies

A. Mortality

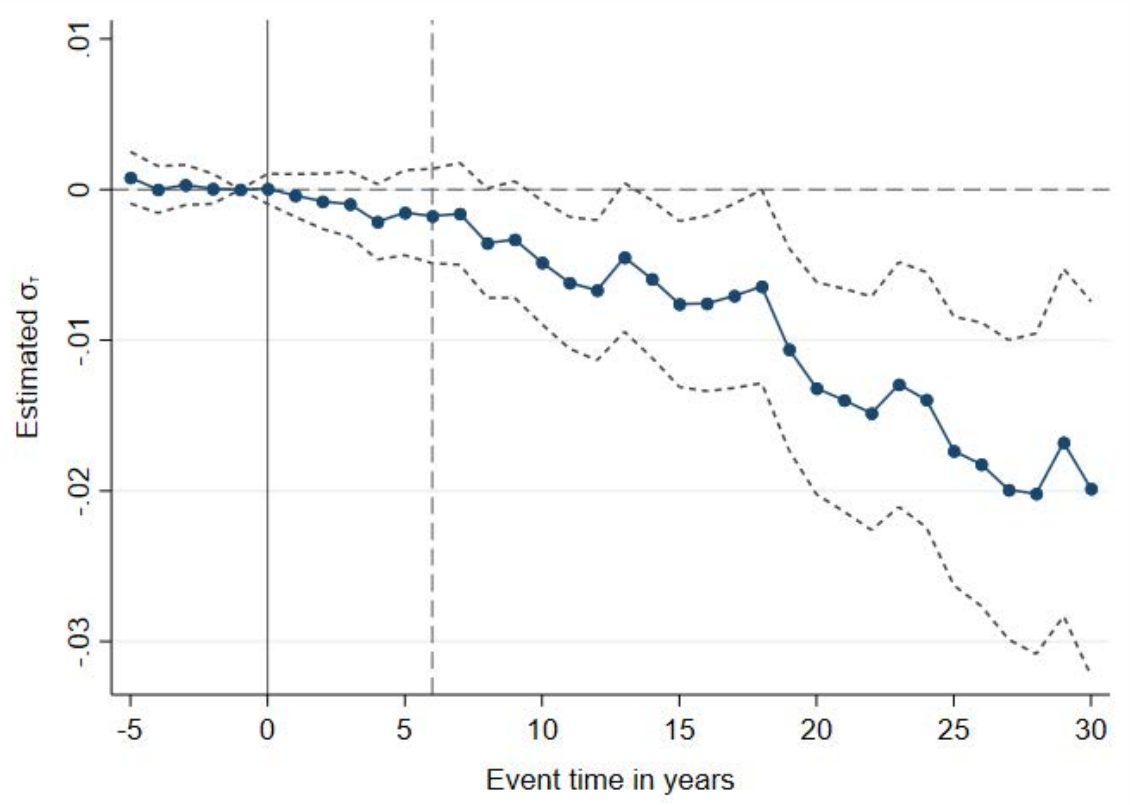

B. Lifestyle-Related Conditions

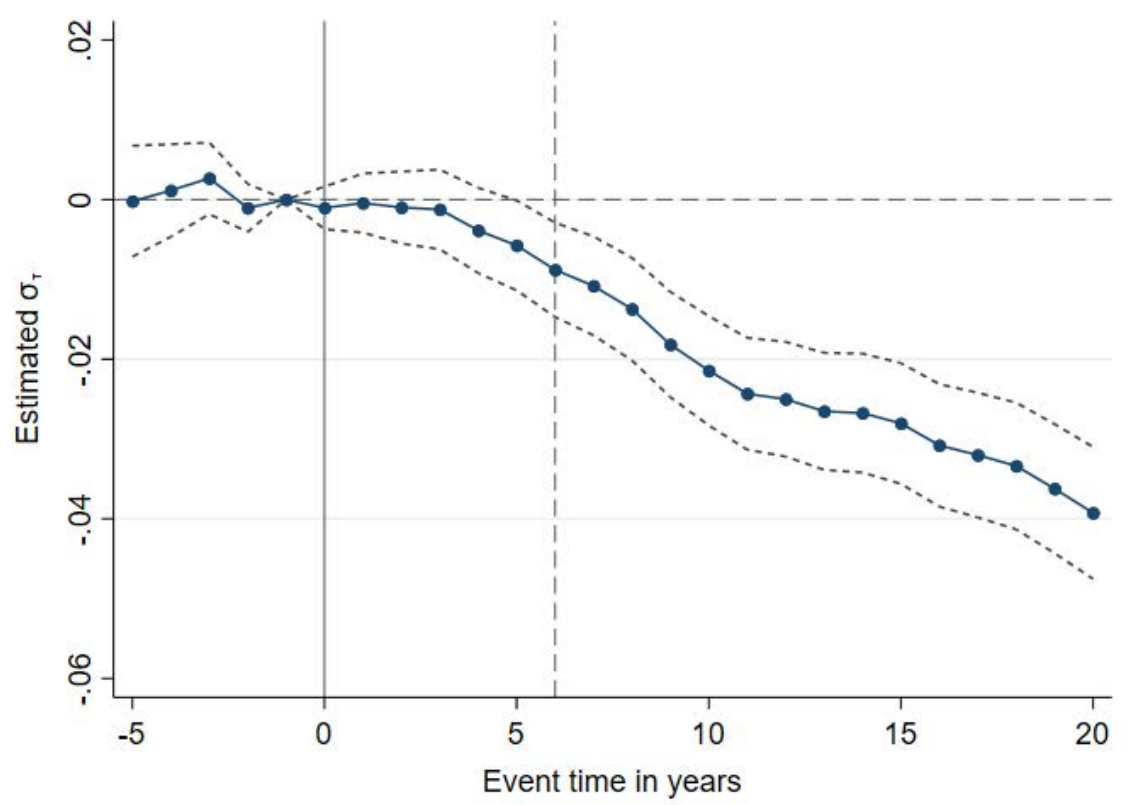

Figures plot coefficients $\sigma_{\tau}$ and $95 \%$ confidence intervals against relative time $\tau$ s from the event study specification in Equation (4). Panel A restricts the sample to family members born in Sweden between 1936 and 1940. Panel B restricts the sample to family members born in Sweden between 1936 and 1961. In both Panels, we exclude family members who are themsevles a health professional, or have a health professional spouse. Family members with a relative became a nurse before another relative became a doctor are dropped from the "doctor" sample; family members with both a lawyer and a health professional relative are dropped from the "lawyer" sample. Panel B excludes individuals that have died before the first year of clinical records-1997. The regressions are centered at event year -1, i.e., one year before the year of matriculation in a medical or legal degree. The dashed vertical line marks the average graduation time for physicians. Standard errors are clustered at the family level. 
Figure 10: Exposure to Expertise and Income-Mortality Gradient

A. Health-income gradient in "doctor-equivalents"

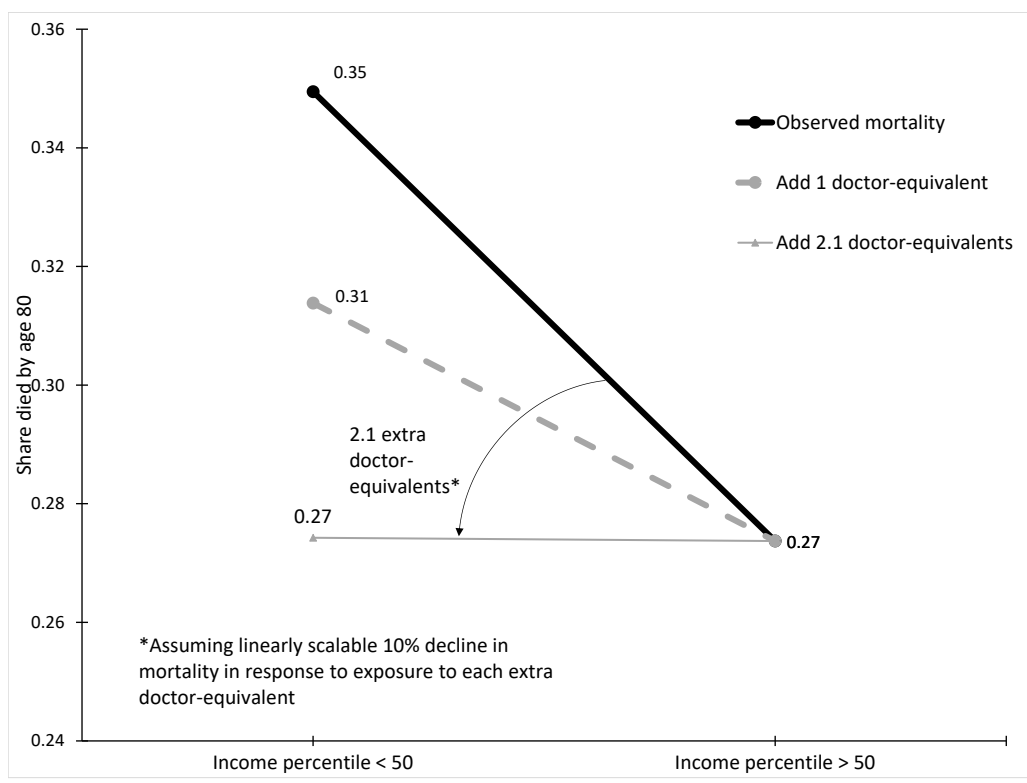

B. Universal access to expertise

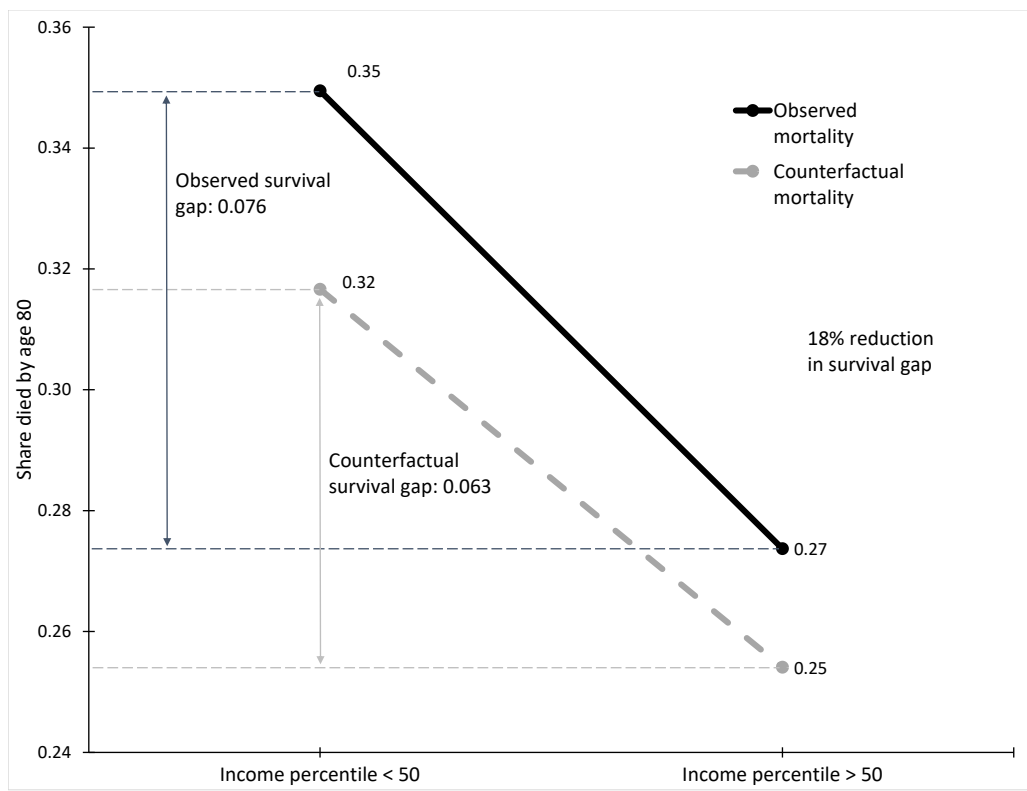

Both panels plot observed and counterfactual gradients in mortality. The sample is defined as in Panel A of Figure 1. In both panels, the solid line ("observed mortality") plots observed average probability of individuals surviving until age 80 conditional on being alive at age 55, across the first half and the second half of the income rank distribution at age 55 (among 1936-1937 cohorts). In Panel A, the points on the dashed and light grey line are computed by applying 10 percent estimate of mortality reduction for exposure to each additional doctor at the bottom half of the income distribution. In Panel B, the dashed line ("counterfactual mortality") is computed as follows. We multiply observed mortality within each income group by the treatment effect (1-T) and then re-scale the result by (1-T*s) to account for the differences in the underlying prevalence of access to expertise. $T$ is the treatment effect of access to expertise (estimated at 10 percent for mortality, following the non-parametric results in Table 1 and the event study estimates in Panel A of Figure 9); $\mathbf{s}$ is the share of individuals with health literacy at the baseline, proxied by the college completion rate (among 1936-1937 cohorts) of 7 percent and 31 percent percent at the bottom half and top half of the income distribution, respectively. 
Table 1: Health Professional in the Family and Health Outcomes

Panel A: Died, by Age 80

\begin{tabular}{|c|c|c|c|c|c|c|c|c|c|c|}
\hline & (1) & $(2)$ & $(3)$ & (4) & (5) & (6) & (7) & (8) & (9) & (10) \\
\hline Health Professional in Family & $\begin{array}{c}-0.030^{* * *} \\
(0.010)\end{array}$ & $\begin{array}{c}-0.034^{* * *} \\
(0.010)\end{array}$ & $\begin{array}{c}-0.044^{* * *} \\
(0.009)\end{array}$ & $\begin{array}{c}-0.019^{* *} \\
(0.009)\end{array}$ & $\begin{array}{c}-0.021^{* *} \\
(0.009)\end{array}$ & $\begin{array}{c}-0.027^{* * *} \\
(0.009)\end{array}$ & $\begin{array}{c}-0.023^{* * *} \\
(0.009)\end{array}$ & $\begin{array}{c}-0.018^{* *} \\
(0.009)\end{array}$ & $\begin{array}{c}-0.025^{* * *} \\
(0.008)\end{array}$ & $\begin{array}{c}-0.028^{* * *} \\
(0.008)\end{array}$ \\
\hline Mean of Dep. Var. & 0.41 & 0.36 & 0.34 & 0.31 & 0.30 & 0.30 & 0.29 & 0.27 & 0.26 & 0.23 \\
\hline Std. Dev. of Dep. Var. & 0.49 & 0.48 & 0.47 & 0.46 & 0.46 & 0.46 & 0.46 & 0.44 & 0.44 & 0.42 \\
\hline R-Squared & 0.051 & 0.042 & 0.053 & 0.043 & 0.039 & 0.029 & 0.034 & 0.022 & 0.030 & 0.026 \\
\hline No. of Obs. & 11,454 & 12,850 & 12,777 & 12,928 & 12,882 & 12,823 & 12,786 & 12,681 & 12,252 & 13,396 \\
\hline
\end{tabular}

Panel B: Index of Lifestyle-Related Conditions, Age 55+

\begin{tabular}{|c|c|c|c|c|c|c|c|c|c|c|}
\hline & (1) & (2) & (3) & (4) & (5) & (6) & (7) & (8) & (9) & (10) \\
\hline Health Professional in Family & $\begin{array}{c}-0.007^{* *} \\
(0.003)\end{array}$ & $\begin{array}{c}-0.020^{* * *} \\
(0.003)\end{array}$ & $\begin{array}{c}-0.013^{* * *} \\
(0.003)\end{array}$ & $\begin{array}{c}-0.010^{* * *} \\
(0.003)\end{array}$ & $\begin{array}{c}-0.013^{* * *} \\
(0.003)\end{array}$ & $\begin{array}{c}-0.006^{* *} \\
(0.003)\end{array}$ & $\begin{array}{c}-0.009^{* * *} \\
(0.002)\end{array}$ & $\begin{array}{c}-0.008^{* * *} \\
(0.002)\end{array}$ & $\begin{array}{c}-0.007^{* * *} \\
(0.002)\end{array}$ & $\begin{array}{c}-0.007^{* * *} \\
(0.002)\end{array}$ \\
\hline Mean of Dep. Var. & 0.07 & 0.04 & 0.02 & -0.00 & -0.01 & -0.02 & -0.02 & -0.03 & -0.04 & -0.06 \\
\hline Std. Dev. of Dep. Var. & 0.66 & 0.63 & 0.60 & 0.57 & 0.57 & 0.55 & 0.54 & 0.53 & 0.51 & 0.48 \\
\hline R-Squared & 0.081 & 0.080 & 0.083 & 0.079 & 0.081 & 0.078 & 0.078 & 0.076 & 0.076 & 0.069 \\
\hline No. of Obs. & 191,979 & 215,131 & 215,099 & 215,522 & 214,393 & 213,476 & 211,081 & 205,246 & 203,877 & 213,377 \\
\hline
\end{tabular}

Panel C: HPV Vaccine, by age 20

\begin{tabular}{|c|c|c|c|c|c|c|c|c|c|c|}
\hline & (1) & (2) & (3) & (4) & (5) & (6) & (7) & (8) & (9) & $(10)$ \\
\hline Health Professional in Family & $\begin{array}{c}0.047^{* * *} \\
(0.009)\end{array}$ & $\begin{array}{c}0.054^{* * *} \\
(0.008)\end{array}$ & $\begin{array}{c}0.048^{* * *} \\
(0.009)\end{array}$ & $\begin{array}{c}0.041^{* * *} \\
(0.009)\end{array}$ & $\begin{array}{c}0.053^{* * *} \\
(0.009)\end{array}$ & $\begin{array}{c}0.049^{* * *} \\
(0.009)\end{array}$ & $\begin{array}{c}0.048^{* * *} \\
(0.009)\end{array}$ & $\begin{array}{c}0.031^{* * *} \\
(0.009)\end{array}$ & $\begin{array}{c}0.017^{*} \\
(0.009)\end{array}$ & $\begin{array}{c}0.046^{* * *} \\
(0.008)\end{array}$ \\
\hline Mean of Dep. Var. & 0.11 & 0.16 & 0.20 & 0.21 & 0.24 & 0.26 & 0.27 & 0.28 & 0.30 & 0.37 \\
\hline Std. Dev. of Dep. Var. & 0.31 & 0.37 & 0.40 & 0.41 & 0.43 & 0.44 & 0.44 & 0.45 & 0.46 & 0.48 \\
\hline R-Squared & 0.054 & 0.052 & 0.059 & 0.059 & 0.062 & 0.074 & 0.073 & 0.086 & 0.088 & 0.113 \\
\hline No. of Obs. & 11,327 & 12,568 & 12,516 & 12,469 & 12,539 & 12,427 & 12,511 & 12,500 & 12,471 & 13,683 \\
\hline
\end{tabular}

Panel D: Tobacco Exposure, in utero

\begin{tabular}{lccccccccccc}
\hline & $(1)$ & $(2)$ & $(3)$ & $(4)$ & $(5)$ & $(6)$ & $(7)$ & $(8)$ & $(9)$ \\
\hline Health Professional in Family & $-0.046^{* * *}$ & $-0.033^{* * *}$ & $-0.025^{* * *}$ & $-0.022^{* * *}$ & $-0.012^{* * *}$ & $-0.012^{* * *}$ & $-0.007^{* * *}$ & $-0.003^{*}$ & -0.000 & 0.001 \\
& $(0.003)$ & $(0.003)$ & $(0.002)$ & $(0.002)$ & $(0.002)$ & $(0.002)$ & $(0.002)$ & $(0.002)$ & $(0.002)$ & $(0.001)$ \\
\hline Mean of Dep. Var. & 0.33 & 0.28 & 0.24 & 0.21 & 0.19 & 0.18 & 0.17 & 0.15 & 0.12 & 0.08 \\
Std. Dev. of Dep. Var. & 0.47 & 0.45 & 0.43 & 0.40 & 0.39 & 0.38 & 0.38 & 0.36 & 0.32 & 0.27 \\
R-Squared & 0.126 & 0.090 & 0.074 & 0.070 & 0.071 & 0.067 & 0.061 & 0.054 & 0.045 & 0.031 \\
No. of Obs. & 162,206 & 188,607 & 191,521 & 192,979 & 193,267 & 193,549 & 193,523 & 192,929 & 191,630 & 205,000 \\
\hline
\end{tabular}

Notes: Tables report the results of OLS regressions of the outcome of interest on an indicator for having a health professional in the family, estimated separately for each decile (reported in columns (1) to (10)) of the individual's (or parental) income rank. Each regression includes the full set of covariates. Health professional in the family is a indicator variable that equals one if the individual has at least one relative with a completed medical or nursing degree. In panels $\mathrm{A}$ and $\mathrm{B}$, the set of relatives includes spouse, sibling, cousin, child, child-in-law, niece/nephew, grandchild. In panels $\mathrm{C}$ and $\mathrm{D}$, the set of relatives includes sibling, cousin, parent, aunt/uncle, and grandparent. Panel A restricts the sample to individuals born in Sweden between 1936-1937. Panel B restricts the sample to individuals born in Sweden between 1936-1961 and alive at age 55. Panel C restricts the sample to females born in Sweden between 1995-1997 and alive at age 20. Panel D restricts the sample to children born in Sweden between 1995 and 2016. Covariates in Panels A and B include fixed effects for individual's own income rank percentile and income rank percentile of the highest-earning relative, year of birth fixed effects, gender dummy, fixed effects for discretized education levels, fixed effects for the county of residence at age 55. Covariates in panel $\mathrm{C}$ include fixed effects for parental income percentile at birth, highest-earning relative's income percentile, year of birth, gender, mother's county of residence in the year before child birth. Covariates in panel D include fixed effects for parental income percentile at birth, highest-earning relative's income percentile, year of birth, gender, mother's county of residence in the year before child birth, maternal birth order, mother's education, maternal age. Standard errors are clustered at the family level. *, **, and *** denote significance at $10 \%, 5 \%$, and $1 \%$ level, respectively. 
Table 2: Medical School Lotteries: Balance of Baseline Observables

\begin{tabular}{|c|c|c|c|}
\hline & $\begin{array}{l}\text { Admitted } \\
(1)\end{array}$ & $\begin{array}{c}\text { Not Admitted } \\
(2)\end{array}$ & $\begin{array}{c}p \text {-value } \\
(3)\end{array}$ \\
\hline Medical School Matriculation & $\begin{array}{c}0.96 \\
(0.19)\end{array}$ & $\begin{array}{c}0.59 \\
(0.49)\end{array}$ & 0.00 \\
\hline \multicolumn{4}{|l|}{ Demographics } \\
\hline Female & $\begin{array}{c}0.57 \\
(0.50)\end{array}$ & $\begin{array}{c}0.60 \\
(0.49)\end{array}$ & 0.41 \\
\hline Age & $\begin{array}{l}19.67 \\
(1.23)\end{array}$ & $\begin{array}{l}19.48 \\
(1.03)\end{array}$ & 0.03 \\
\hline Number of siblings & $\begin{array}{l}1.82 \\
(1.06)\end{array}$ & $\begin{array}{l}1.80 \\
(1.06)\end{array}$ & 0.84 \\
\hline Born in Sweden & $\begin{array}{c}0.97 \\
(0.18)\end{array}$ & $\begin{array}{c}0.95 \\
(0.21)\end{array}$ & 0.45 \\
\hline Father born in Sweden & $\begin{array}{c}0.87 \\
(0.33)\end{array}$ & $\begin{array}{c}0.85 \\
(0.36)\end{array}$ & 0.33 \\
\hline Mother born in Sweden & $\begin{array}{c}0.86 \\
(0.34)\end{array}$ & $\begin{array}{c}0.85 \\
(0.36)\end{array}$ & 0.64 \\
\hline \multicolumn{4}{|c|}{ Parental income (10k krona, inflation-adjusted) } \\
\hline Year before high school graduation & $\begin{array}{c}94.00 \\
(62.26)\end{array}$ & $\begin{array}{c}90.42 \\
(64.27)\end{array}$ & 0.52 \\
\hline Year before first application & $\begin{array}{c}93.65 \\
(63.63)\end{array}$ & $\begin{array}{c}90.91 \\
(64.89)\end{array}$ & 0.63 \\
\hline \multicolumn{4}{|c|}{ Father's income (10k krona, inflation-adjusted) } \\
\hline Year before high school graduation & $\begin{array}{c}55.25 \\
(53.93)\end{array}$ & $\begin{array}{c}54.04 \\
(56.86)\end{array}$ & 0.80 \\
\hline Year before first application & $\begin{array}{c}54.41 \\
(54.19)\end{array}$ & $\begin{array}{c}54.11 \\
(57.33)\end{array}$ & 0.95 \\
\hline \multicolumn{4}{|c|}{ Relative deceased by year of first application } \\
\hline Father & $\begin{array}{c}0.01 \\
(0.07)\end{array}$ & $\begin{array}{c}0.01 \\
(0.10)\end{array}$ & 0.63 \\
\hline Mother & $\begin{array}{c}0.01 \\
(0.07)\end{array}$ & $\begin{array}{c}0.01 \\
(0.10)\end{array}$ & 0.63 \\
\hline Paternal Grandfather & $\begin{array}{c}0.57 \\
(0.50)\end{array}$ & $\begin{array}{c}0.55 \\
(0.50)\end{array}$ & 0.69 \\
\hline Paternal Grandmother & $\begin{array}{c}0.32 \\
(0.47)\end{array}$ & $\begin{array}{c}0.35 \\
(0.48)\end{array}$ & 0.46 \\
\hline Maternal Grandfather & $\begin{array}{c}0.48 \\
(0.50)\end{array}$ & $\begin{array}{c}0.51 \\
(0.50)\end{array}$ & 0.52 \\
\hline Maternal Grandmother & $\begin{array}{c}0.30 \\
(0.46)\end{array}$ & $\begin{array}{c}0.28 \\
(0.45)\end{array}$ & 0.64 \\
\hline Number of Observations & 188 & 555 & \\
\hline
\end{tabular}

Notes: Table reports the probability of medical school matriculation and the sample mean (standard deviation in parentheses) of observable demographics for students who (i) have a high school GPA of 20.0 and (ii) applied to medical schools for the first time during application cycles fall 2007-spring 2010. The sample in Column 1 includes applicants who were admitted to a medical school on their first application attempt. Column 2 reports the same outcomes for applicants who lost their first application lottery. Column 3 reports the $p$-value of a two-sided $t$-test for the equivalence in means between Columns (1) and (2). 
Table 3: Doctor in the Family and Health at Older Ages: Medical School Lottery Evidence

\begin{tabular}{|c|c|c|c|c|c|c|}
\hline \multirow[b]{2}{*}{$\begin{array}{l}\text { Outcomes } \\
\text { per } 1,000 \text { Individuals }\end{array}$} & \multicolumn{2}{|c|}{ ITT } & \multirow[b]{2}{*}{$\begin{array}{c}\text { LATE } \\
(3)\end{array}$} & \multirow[b]{2}{*}{$\begin{array}{c}\text { Control } \\
\text { Mean } \\
(4)\end{array}$} & \multirow[b]{2}{*}{$\begin{array}{c}\text { Control } \\
\text { Complier } \\
\text { Mean } \\
(5)\end{array}$} & \multirow[b]{2}{*}{$\begin{array}{c}\text { Obs } \\
(6)\end{array}$} \\
\hline & $\begin{array}{c}\text { No } \\
\text { Covariates } \\
(1)\end{array}$ & $\begin{array}{c}\text { With } \\
\text { Covariates } \\
(2)\end{array}$ & & & & \\
\hline
\end{tabular}

\section{B. Physical Health}

\begin{tabular}{|c|c|c|c|c|c|c|}
\hline Heart Attack & $\begin{array}{c}-12 \\
(10)\end{array}$ & $\begin{array}{c}-19^{*} \\
(11)\end{array}$ & $\begin{array}{c}-40^{*} \\
(21)\end{array}$ & 42 & 48 & 1,532 \\
\hline Heart Failure & $\begin{array}{l}-21 \\
(13)\end{array}$ & $\begin{array}{c}-27^{*} \\
(14)\end{array}$ & $\begin{array}{c}-54^{*} \\
(29)\end{array}$ & 74 & 83 & 1,532 \\
\hline Lung Cancer & $\begin{array}{c}3 \\
(5)\end{array}$ & $\begin{array}{c}3 \\
(5)\end{array}$ & $\begin{array}{c}6 \\
(11)\end{array}$ & 6 & 6 & 1,532 \\
\hline Type II Diabetes & $\begin{array}{l}-11 \\
(14)\end{array}$ & $\begin{array}{c}8 \\
(15)\end{array}$ & $\begin{array}{c}15 \\
(29)\end{array}$ & 77 & 72 & 1,532 \\
\hline \multicolumn{7}{|l|}{ C. Preventive Health } \\
\hline Statins & $\begin{array}{c}23 \\
(17)\end{array}$ & $\begin{array}{c}37^{* *} \\
(18)\end{array}$ & $\begin{array}{c}93^{* *} \\
(45)\end{array}$ & 281 & 293 & 3,134 \\
\hline Blood Thinners & $\begin{array}{c}31^{* *} \\
(15)\end{array}$ & $\begin{array}{l}29^{*} \\
(15)\end{array}$ & $\begin{array}{c}73^{*} \\
(38)\end{array}$ & 247 & 273 & 3,134 \\
\hline Diabetes Drugs & $\begin{array}{c}8 \\
(8)\end{array}$ & $\begin{array}{l}15 \\
(9)\end{array}$ & $\begin{array}{c}36 \\
(22)\end{array}$ & 74 & 76 & 3,134 \\
\hline Beta Blockers & $\begin{array}{c}10 \\
(16)\end{array}$ & $\begin{array}{c}9 \\
(16)\end{array}$ & $\begin{array}{c}22 \\
(40)\end{array}$ & 302 & 309 & 3,134 \\
\hline Asthma Drugs & $\begin{array}{c}9 \\
(15)\end{array}$ & $\begin{array}{c}9 \\
(16)\end{array}$ & $\begin{array}{c}22 \\
(39)\end{array}$ & 179 & 187 & 3,134 \\
\hline Vitamin D & $\begin{array}{c}11 \\
(10)\end{array}$ & $\begin{array}{l}20^{*} \\
(11)\end{array}$ & $\begin{array}{l}49^{*} \\
(27)\end{array}$ & 32 & 27 & 1,642 \\
\hline Preventable Hospitalizations & $\begin{array}{l}-14 \\
(38)\end{array}$ & $\begin{array}{c}1 \\
(42)\end{array}$ & $\begin{array}{c}3 \\
(84)\end{array}$ & 197 & 235 & 1,532 \\
\hline Addiction & $\begin{array}{c}-8 \\
(8)\end{array}$ & $\begin{array}{l}-12 \\
(10)\end{array}$ & $\begin{array}{l}-25 \\
(19)\end{array}$ & 26 & 30 & 1,532 \\
\hline
\end{tabular}

Notes: Table reports the results of estimating Equation (2) for older (age 50 and above) family members of medical school "lottery" participants. Outcomes are tracked for 8 years after the applicant's matriculation into a medical school or the last medical school application. Sample size varies across outcomes due to differences in pharmaceutical and clinical data availability. Aggregate health index is an unweighted mean of z-scores of all individual outcomes. Column 2 and 3 report ITT and LATE estimates with a full set of covariates, including family member's birth year fixed effects, gender, educational attainment, family tie fixed effects (e.g., sibling, parent, etc.), whether the family member was born in Sweden, the applicant's birth year fixed effects and gender, whether the applicant was born in Sweden, whether the applicant took the Swedish SAT, and the number of medical schools that the applicant applied to in the first application cycle. In regressions using statins, blood thinners, diabetes drugs, beta blockers, and asthma drugs as the outcome, we also control for whether the family member has asthma, type II diabetes, heart failure, ischemic heart diseases, stroke, hyperlipidemia, or hypertension. Standard errors clustered by the applicant are reported in parentheses. Column 4 reports mean outcomes in the control group, i.e., among family members of applicants who lost the lottery on the first medical school application attempt. Column 5 reports mean outcomes among the "control compliers," i.e., family members of applicants who lost the lottery on the first medical school application attempt and did not subsequently re-apply to medical schools. ${ }^{*},{ }^{* *}$, and ${ }^{* * *}$ denote significance at $10 \%, 5 \%$, and $1 \%$ level, respectively. 
Table 4: Doctor in the Family and Health at Younger Ages: Medical School Lottery Evidence

\begin{tabular}{|c|c|c|c|c|c|c|}
\hline \multirow[b]{2}{*}{$\begin{array}{l}\text { Outcomes } \\
\text { per } 1,000 \text { individuals }\end{array}$} & \multicolumn{2}{|c|}{ ITT } & \multirow[b]{2}{*}{$\begin{array}{l}\text { LATE } \\
\quad(3)\end{array}$} & \multirow[b]{2}{*}{$\begin{array}{c}\text { Control } \\
\text { Mean } \\
(4)\end{array}$} & \multirow[b]{2}{*}{$\begin{array}{c}\text { Control } \\
\text { Complier } \\
\text { Mean } \\
(5)\end{array}$} & \multirow[b]{2}{*}{$\begin{array}{c}\text { Obs } \\
(6)\end{array}$} \\
\hline & $\begin{array}{c}\text { No } \\
\text { Covariates } \\
(1)\end{array}$ & $\begin{array}{c}\text { With } \\
\text { Covariates } \\
(2)\end{array}$ & & & & \\
\hline A. Health Index & $\begin{array}{l}31^{*} \\
(18)\end{array}$ & $\begin{array}{l}32^{*} \\
(18)\end{array}$ & $\begin{array}{l}118^{*} \\
(67)\end{array}$ & -1 & 37 & 4,113 \\
\hline \multicolumn{7}{|l|}{ B. Physical Health } \\
\hline Number Inpatient stays & $\begin{array}{l}-33^{*} \\
(20)\end{array}$ & $\begin{array}{l}-38^{*} \\
(21)\end{array}$ & $\begin{array}{c}-140^{*} \\
(80)\end{array}$ & 215 & 200 & 4,086 \\
\hline Respiratory Infection & $\begin{array}{l}-5 \\
(7)\end{array}$ & $\begin{array}{l}-4 \\
(7)\end{array}$ & $\begin{array}{l}-13 \\
(26)\end{array}$ & 38 & 30 & 4,113 \\
\hline Intestinal Infection & $\begin{array}{l}-3 \\
(4)\end{array}$ & $\begin{array}{l}-2 \\
(4)\end{array}$ & $\begin{array}{c}-9 \\
(16)\end{array}$ & 18 & 14 & 4,113 \\
\hline Chronic Tonsil Diseases & $\begin{array}{c}4 \\
(6)\end{array}$ & $\begin{array}{c}5 \\
(6)\end{array}$ & $\begin{array}{c}17 \\
(22)\end{array}$ & 21 & 13 & 4,113 \\
\hline \multicolumn{7}{|l|}{ C. Preventive Health } \\
\hline HPV Vaccination & $\begin{array}{c}42 \\
(26)\end{array}$ & $\begin{array}{l}56^{* *} \\
(26)\end{array}$ & $\begin{array}{c}218^{* *} \\
(108)\end{array}$ & 119 & 174 & 1,192 \\
\hline No Hormonal Contraceptives & $\begin{array}{c}55 \\
(48)\end{array}$ & $\begin{array}{c}135^{* * *} \\
(50)\end{array}$ & $\begin{array}{c}562^{* *} \\
(227)\end{array}$ & 644 & 594 & 514 \\
\hline Addiction & $\begin{array}{c}-12^{* * *} \\
(4)\end{array}$ & $\begin{array}{c}-11^{* * * *} \\
(4)\end{array}$ & $\begin{array}{c}-42^{* * *} \\
(16)\end{array}$ & 19 & 15 & 4,113 \\
\hline Injury/Poison & $\begin{array}{c}2 \\
(16)\end{array}$ & $\begin{array}{c}-2 \\
(17)\end{array}$ & $\begin{array}{c}-7 \\
(61)\end{array}$ & 265 & 251 & 4,113 \\
\hline
\end{tabular}

Notes: Table reports the results of estimating Equation (2) for younger family members (younger than 30) of medical school "lottery" participants. Outcomes are tracked for 6 years after the applicant's matriculation into a medical school or the last medical school application. In Row 2 (number of inpatient stays), we drop observations above the 99th percentile of the distribution in inpatient stays. Row 6 (HPV vaccination) and Row 7 (no hormonal contraceptives) restrict the sample to females aged between 10 and 25 and females aged between 10 and 20, respectively. Aggregate health index is an unweighted mean of z-scores of all individual outcomes. Column 2 and 3 report ITT and LATE estimates with a full set of covariates, including family member's birth year fixed effects, gender, educational attainment, family tie fixed effects (e.g., sibling, parent, etc.), whether the family member was born in Sweden, the applicant's birth year fixed effects and gender, whether the applicant was born in Sweden, whether the applicant took the Swedish SAT, and the number of medical schools that the applicant applied to in the first application cycle. Standard errors clustered by the applicant are reported in parentheses. Column 4 reports mean outcomes in the control group, i.e., among family members of applicants who lost the lottery on the first medical school application attempt. Column 5 reports mean outcomes among the "control compliers," i.e., family members of applicants who lost the lottery on the first medical school application attempt and did not subsequently re-apply to medical schools. ${ }^{*}, * *$, and ${ }^{* * *}$ denote significance at $10 \%, 5 \%$, and $1 \%$ level, respectively. 
Table 5: Doctor in the Family and Health: Event Study Evidence

\begin{tabular}{|c|c|c|c|c|c|c|c|}
\hline \multirow[b]{3}{*}{ Outcomes } & \multirow[b]{3}{*}{$\begin{array}{c}\text { Pooled } \\
\text { (1) }\end{array}$} & \multicolumn{6}{|c|}{ Heterogeneity by } \\
\hline & & \multicolumn{2}{|c|}{ Income } & \multicolumn{2}{|c|}{ Family Tie } & \multicolumn{2}{|c|}{ Geographic Proximity } \\
\hline & & $\begin{array}{l}\text { Below } \\
\text { Median } \\
(2)\end{array}$ & $\begin{array}{c}\text { Above } \\
\text { Median } \\
(3)\end{array}$ & $\begin{array}{c}\text { Close } \\
(4)\end{array}$ & $\begin{array}{l}\text { Far } \\
(5)\end{array}$ & $\begin{array}{c}\text { Close } \\
(6)\end{array}$ & $\begin{array}{l}\text { Far } \\
(7)\end{array}$ \\
\hline
\end{tabular}

\section{A. Mortality}

\begin{tabular}{|c|c|c|c|c|c|c|c|}
\hline$\tau=-5$ & $\begin{array}{c}0.001 \\
(0.001)\end{array}$ & $\begin{array}{c}0.001 \\
(0.001)\end{array}$ & $\begin{array}{c}0.000 \\
(0.000)\end{array}$ & $\begin{array}{c}0.000 \\
(0.002)\end{array}$ & $\begin{array}{l}-0.001 \\
(0.001)\end{array}$ & $\begin{array}{c}0.000 \\
(0.000)\end{array}$ & $\begin{array}{c}0.000^{* * *} \\
(0.000)\end{array}$ \\
\hline$\tau=+15$ & $\begin{array}{c}-0.008^{* *} \\
(0.003)\end{array}$ & $\begin{array}{c}-0.008^{* * *} \\
(0.002)\end{array}$ & $\begin{array}{c}-0.004^{* *} \\
(0.001)\end{array}$ & $\begin{array}{l}-0.006 \\
(0.005)\end{array}$ & $\begin{array}{l}-0.007 \\
(0.005)\end{array}$ & $\begin{array}{c}-0.010^{* * *} \\
(0.002)\end{array}$ & $\begin{array}{c}-0.004^{* *} \\
(0.002)\end{array}$ \\
\hline$\tau=+25$ & $\begin{array}{c}-0.017^{* * *} \\
(0.005)\end{array}$ & & & $\begin{array}{c}-0.020^{* *} \\
(0.007)\end{array}$ & $\begin{array}{c}-0.019 * \\
(0.008)\end{array}$ & & \\
\hline Mean of Dep. Var. $(\text { at } \tau=+15 / 25)^{a}$ & 0.166 & 0.043 & 0.029 & 0.177 & 0.167 & 0.032 & 0.032 \\
\hline$\%$ Effect (at $\tau=+15 / 25)$ & 10.2 & 18.6 & 13.8 & 11.3 & 11.4 & 31.3 & 12.5 \\
\hline No. of Obs. & $1,222,675$ & $1,132,787$ & $1,652,427$ & 461,996 & 474,659 & $1,338,214$ & $1,603,283$ \\
\hline
\end{tabular}

\section{B. Lifestyle Conditions Index}

\begin{tabular}{|c|c|c|c|c|c|c|c|}
\hline$\tau=-5$ & $\begin{array}{l}-0.000 \\
(0.004)\end{array}$ & $\begin{array}{c}0.006 \\
(0.006)\end{array}$ & $\begin{array}{l}-0.007 \\
(0.005)\end{array}$ & $\begin{array}{c}0.007 \\
(0.006)\end{array}$ & $\begin{array}{c}0.002 \\
(0.005)\end{array}$ & $\begin{array}{l}-0.001 \\
(0.006)\end{array}$ & $\begin{array}{c}0.002 \\
(0.005)\end{array}$ \\
\hline$\tau=+10$ & $\begin{array}{c}-0.021^{* * *} \\
(0.003)\end{array}$ & $\begin{array}{c}-0.023^{* * *} \\
(0.006)\end{array}$ & $\begin{array}{c}-0.019 * * * \\
(0.005)\end{array}$ & $\begin{array}{c}-0.020 * * * \\
(0.005)\end{array}$ & $\begin{array}{c}-0.015^{* *} \\
(0.005)\end{array}$ & $\begin{array}{c}-0.028^{* * *} \\
(0.005)\end{array}$ & $\begin{array}{c}-0.022^{* * *} \\
(0.005)\end{array}$ \\
\hline$\tau=+15$ & $\begin{array}{c}-0.028^{* * *} \\
(0.004)\end{array}$ & $\begin{array}{c}-0.026^{* * *} \\
(0.006)\end{array}$ & $\begin{array}{c}-0.025^{* * *} \\
(0.005)\end{array}$ & $\begin{array}{c}-0.028^{* * *} \\
(0.006)\end{array}$ & $\begin{array}{c}-0.022^{* * *} \\
(0.006)\end{array}$ & $\begin{array}{c}-0.035^{* * *} \\
(0.006)\end{array}$ & $\begin{array}{c}-0.026^{* * *} \\
(0.005)\end{array}$ \\
\hline Mean of Dep. Var. $(\text { at } \tau=+15)^{a}$ & 0.000 & 0.000 & 0.000 & 0.000 & 0.000 & 0.000 & 0.000 \\
\hline$\%$ Effect (at $\tau=+15)$ & NA & NA & NA & NA & NA & NA & NA \\
\hline No. of Obs. & $5,077,267$ & $1,843,234$ & $2,670,101$ & $2,034,144$ & $2,319,347$ & $2,282,660$ & $2,699,245$ \\
\hline
\end{tabular}

${ }^{a}$ Among family members of lawyers

${ }^{b}$ z-score index includes four conditions: heart attack, heart failure, type II diabetes, and lung cancer

Notes: Table reports coefficients $\sigma_{\tau}$ from the event study specification in Equation (4). The event time, sample restriction, and the set of family members included in the analysis are described in Section 3.4. Column (1) reports pooled results for 1936-1940 cohorts (mortality) and 1936-1961 cohorts (lifestyle conditions index). Columns 2 and 3 split the sample by whether the individual's income rank within his/her gender-birth cohort is below or above the 50th percentile, with income measured at age 55 in Panel B and at age 45 in Panel A. Earlier age of income measurement reduces selection on survival when analyzing the mortality of "high" and "low" income groups separately. To be able to observe income at a younger age, we adjust the set of cohorts to individuals born between 1946-1955 in Columns 2 and 3. Individuals with a zero or negative income are dropped from analyses in Columns 2-3. Columns 4 and 5 split the full sample by the type of family tie: parents-children in "close" family tie and aunts/uncles vs. nieces/nephews in "far." Individuals with both ties are excluded from analyses in Column 5 . Columns 6 and 7 split the sample by geographic distance. Family members are classified as living "close" if their place of residence is recorded to be in the same county for more than 50 percent of the years between matriculation (into law or medicine) and the last year of data (2016). Given data restrictions, the geographic split is performed on the same sample of 1946 -1955 cohorts as the income split in Columns 2 and 3 (income and geography are recorded in the same data; the records do not go far enough for older generations). We observe these cohorts for a shorter period of time, estimating the regression up to event time 15. When available, coefficients are reported for event years -5, 10, 15 and 25 (i.e. 5 years before, and 10 , 15 and 25 years after matriculation into the study of medicine or law). The lifestyle conditions index in Panel B is constructed as the mean of the z-scores of indicators for a heart attack, heart failure, type II diabetes, and lung cancer; by construction the index is normalized to zero for the "control" group of lawyer family members. All regressions include the main effects and the interactions between event year dummies and the dummy for having a doctor in the (broad) family. The regressions further include the following covariates: age fixed effects, calendar year fixed effects, and individual fixed effects. Standard errors clustered by family are in parentheses. $* * *$, and $* * *$ denote significance at $10 \%, 5 \%$, and $1 \%$ level, respectively. 


\section{FOR ONLINE PUBLICATION}

\section{A Figures and tables}

Figure A1: Early Emergence of the Health-SES Gradient

A. Asthma, by Age 5

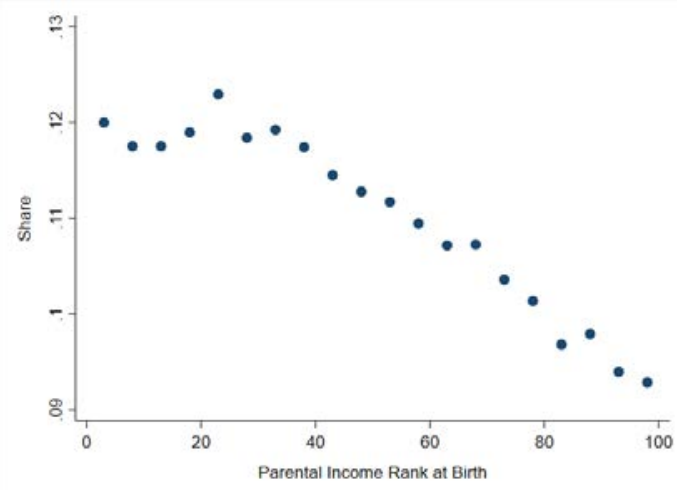

C. Number of Inpatient Stays, by Age 5

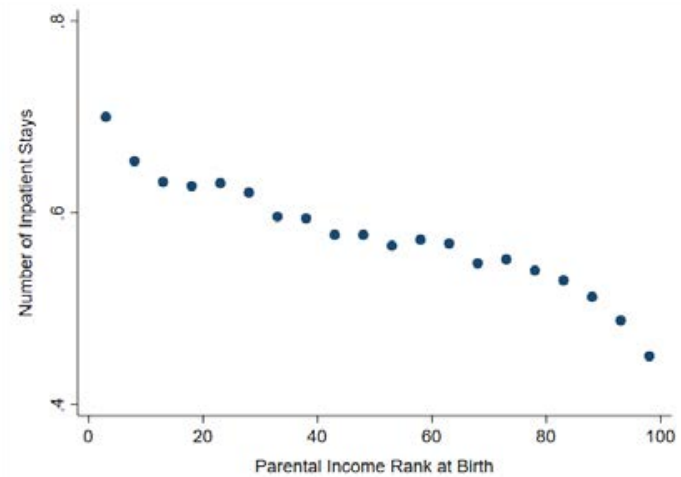

B. Maternal Age/High-Risk Births

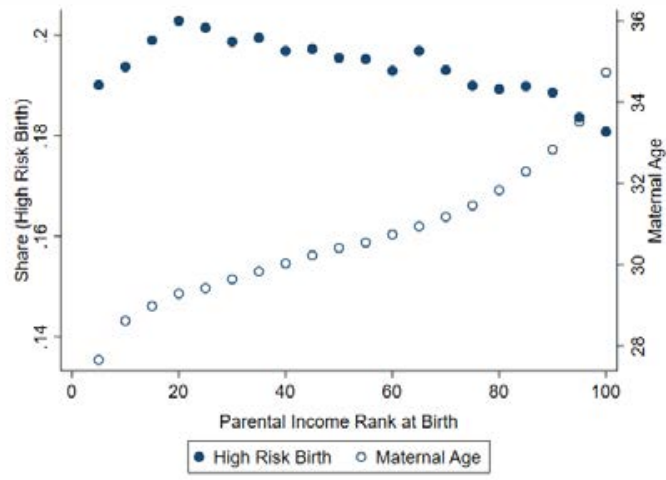

D. Number of Inpatient Stays over Life Cycle

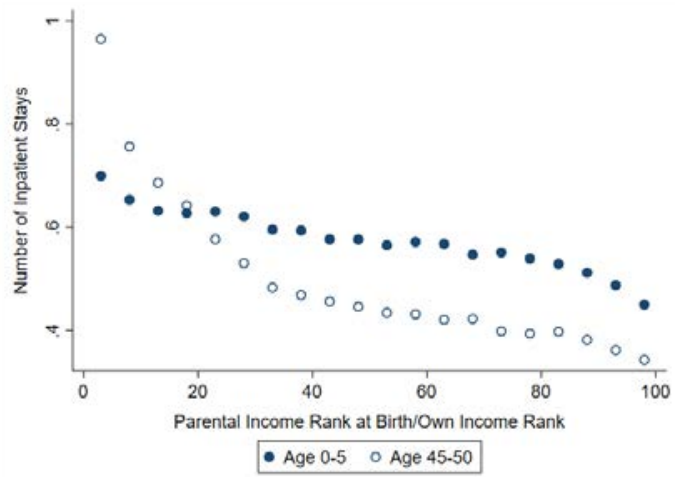

Figures plot the share of individuals with relevant outcomes for each ventile of income rank. Parental income rank at birth is assigned based on the average of parental incomes in the two years before the child was born relative to other parents with children in the same birth cohort. Income rank for adults aged 45-50 in Panel D are assigned based on each individual's own income at age 40 relative to other individuals in the same gender-birth cohort. Births in Panel B are defined as high risk if the mother has any of the following conditions during pregnancy: chronic kidney diseases, diabetes, epilepsy, lung diseases, systemic lupus erythematosus, ulcerative colitis, hypertension, or urinary tract infections. Inpatient stays due to pregnancy, childbirth and the puerperium are excluded from the count of inpatient stays in Panels C and D. 
Figure A2: Tobacco Exposure, in utero

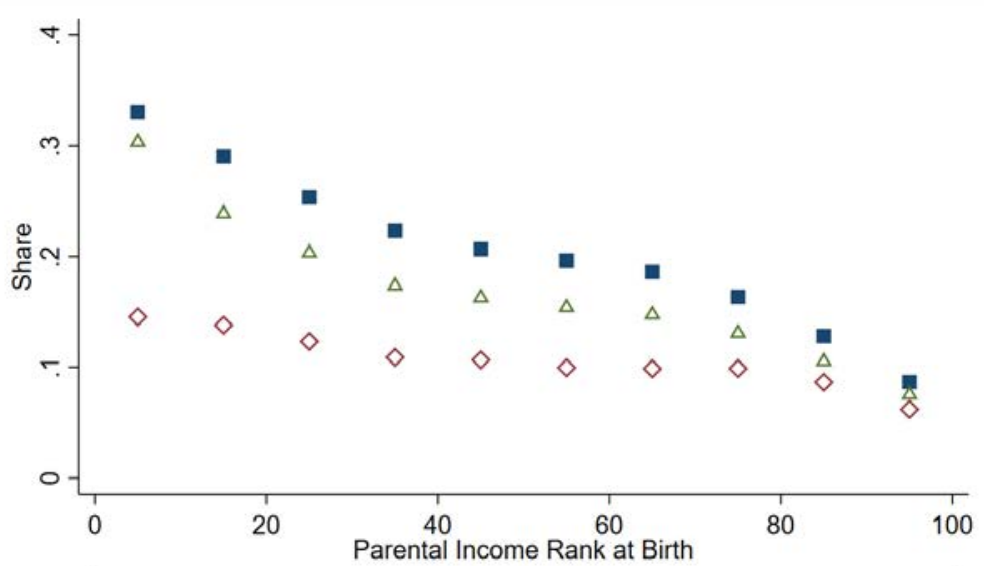

- No Health Professional in Family

$\triangle$ Health Professional Sibling, Cousin, Father, Aunt/Uncle, Grandparent

$\diamond$ Health Professional Mother

Figure plots the share of children exposed to tobacco in utero by decile of parental income rank at birth. Parental income rank at birth is assigned based on the average of parental incomes in the two years before the child was born relative to other parents with children in the same birth cohort. We start with the same data sample as defined in Panel C of Figure 4 . The sample is split by whether an individual has a health professional relative or a health professional mother. Individuals are assigned to the sample "with a health professional" if at least one member of their broad family (sibling, cousin, father, aunt/uncle, grandparent) has a university degree in medicine or nursing. Individuals are assigned to the sample "with a health professional mother" if the mother has a university degree in medicine or nursing.

Figure A3: Share of population with a doctor or a nurse in the family

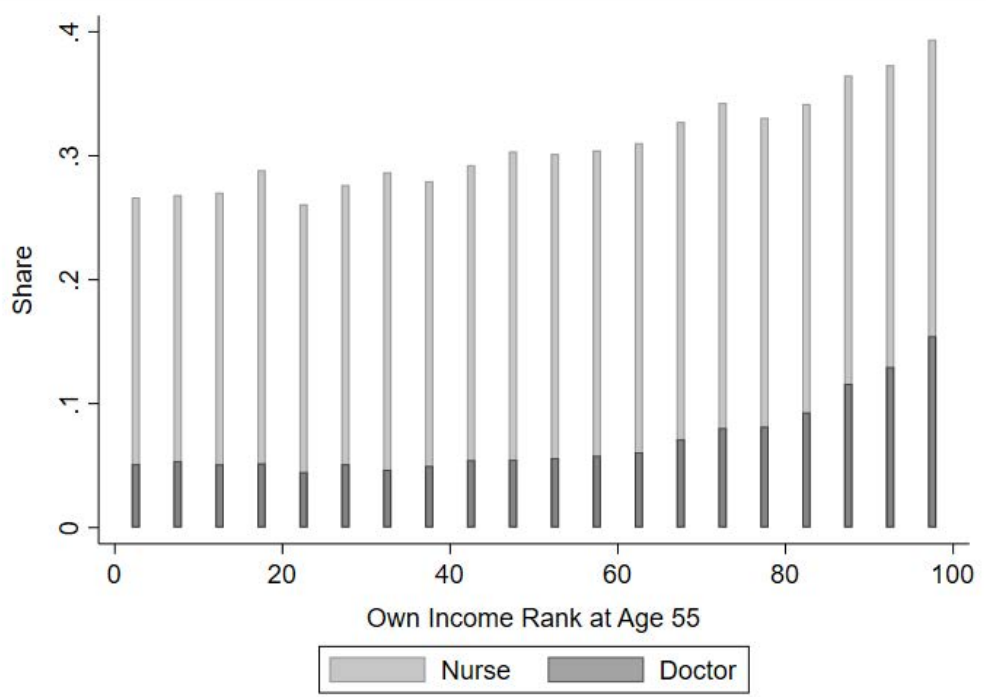

Figure plots the share of inviduals with a nurse or a doctor in the family by income ventile. The sample of individuals is defined as in Panel A of Figure 3. 
Figure A4: Income Distribution of the Medical School Lottery and the Event Study Analysis Sample

A. Medical School Lottery Sample

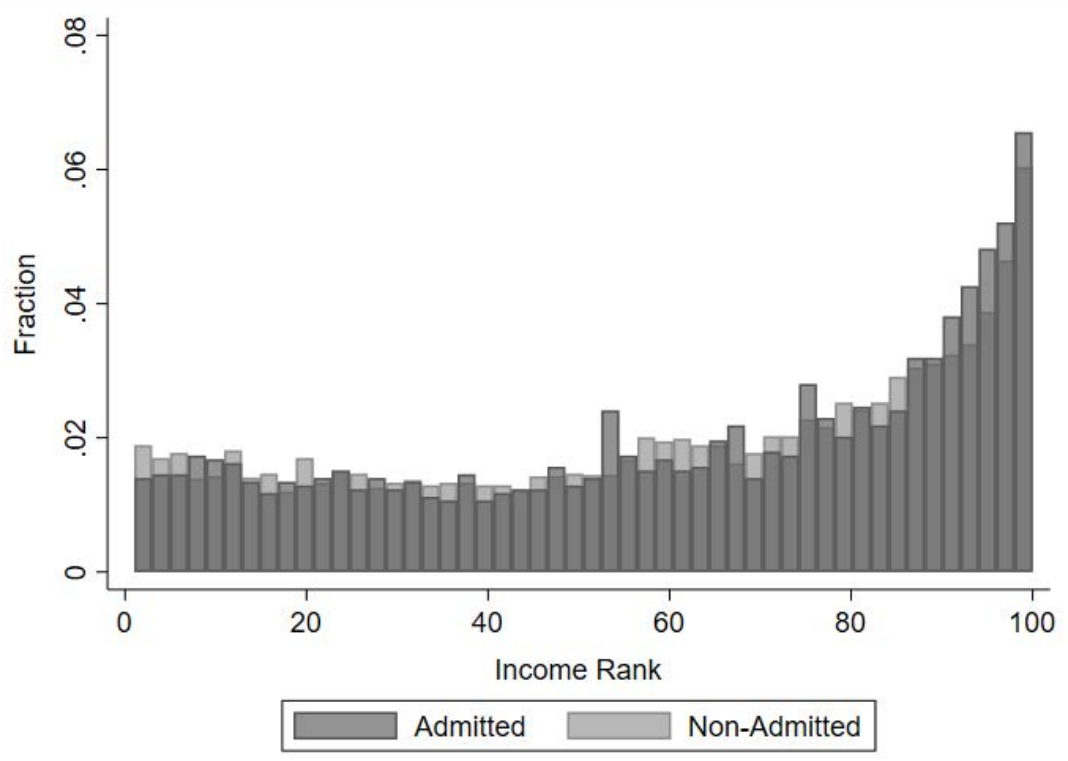

B. Event Study Sample

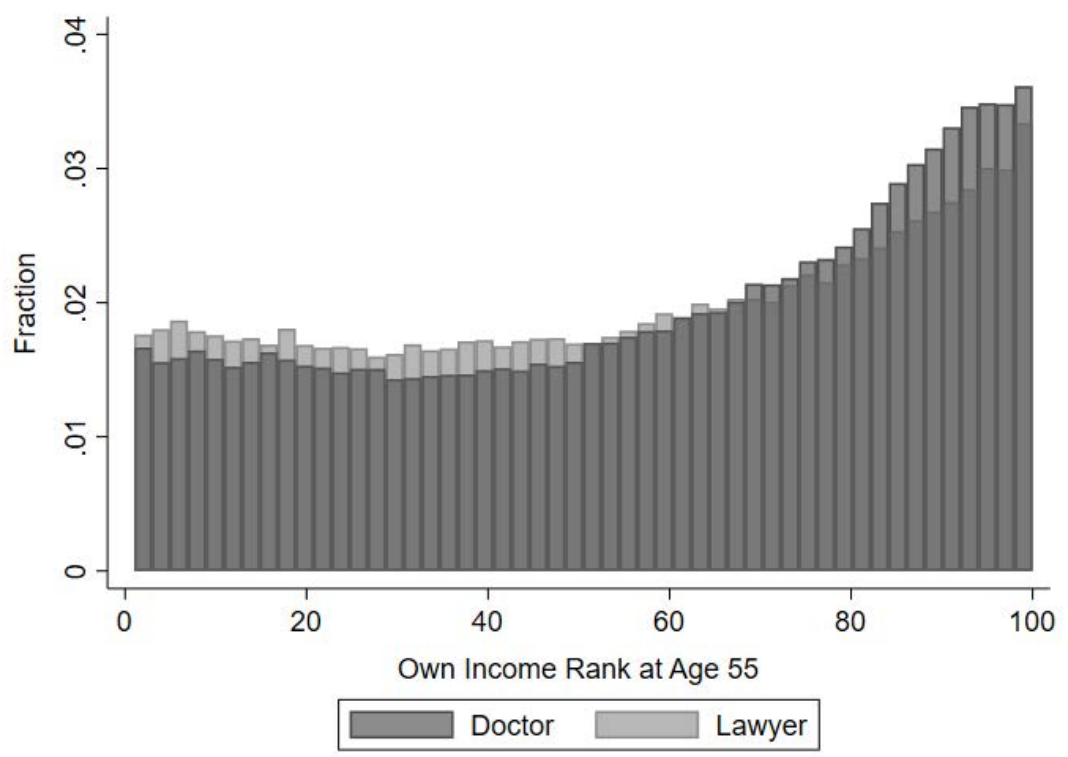

Panel A plots own income rank at age 30, 40, or 55 for the sample used in the medical school lottery analyses, individuals that are too young or too old to be observed income are not included in Panel A. Panel B plots own income rank at age 55 for the sample used in the lifestyle-related conditions index event study analyses (i.e., Panel B of Figure 9). 
Figure A5: Doctor in the Family and Long-Run Health Bonus: Event Studies

A. Heart Attack

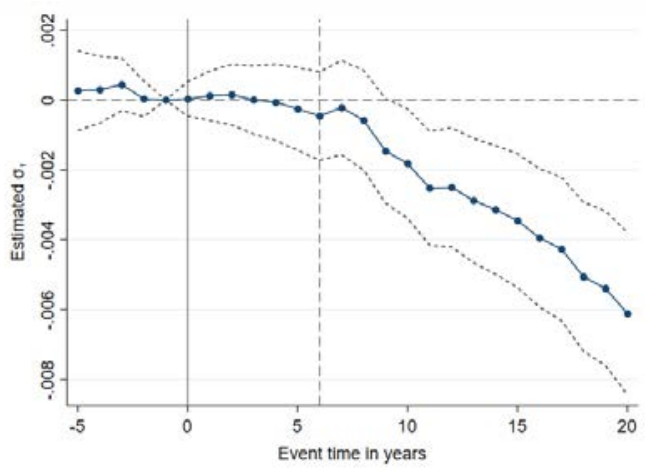

C. Diabetes

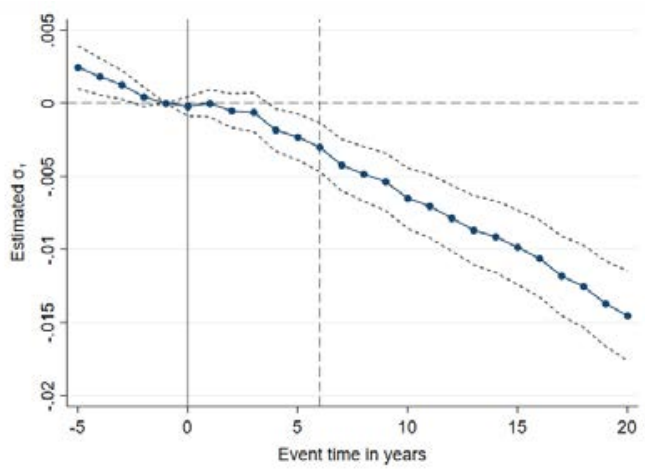

B. Heart Failure

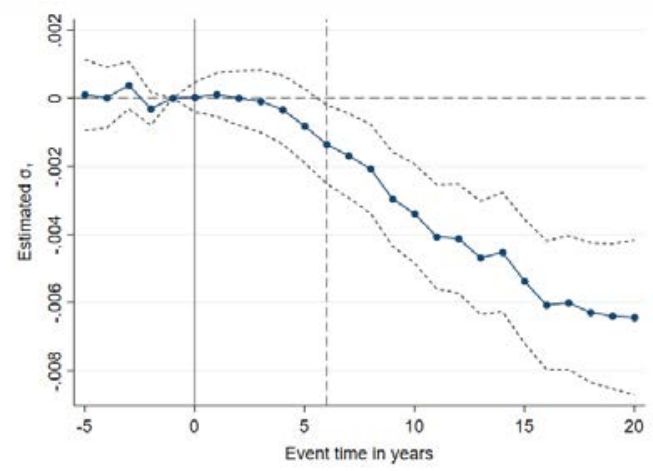

D. Lung Cancer

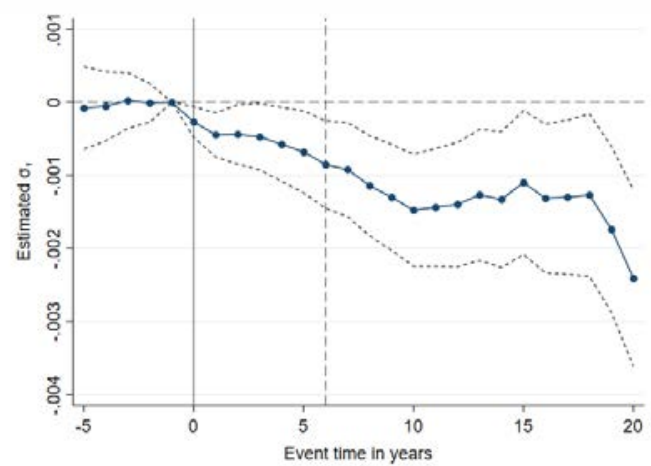

Figures plot coefficients $\sigma_{\tau}$ and $95 \%$ confidence intervals against relative time $\tau$ s from the event study specification in Equation (4). The sample is restricted to family members born in Sweden between 1936 and 1961. In both Panels, we exclude family members who are themsevles a health professional, or have a health professional spouse. Family members with a relative became a nurse before another relative became a doctor are dropped from the "doctor" sample; family members with both a lawyer and a health professional relative are dropped from the "lawyer" sample. All panels exclude individuals that have died before the first year of clinical records (i.e., 1997). The regressions are centered at event year -1, i.e., one year before the year of matriculation in a medical or legal degree. The dashed vertical line marks the average graduation time for physicians. Standard errors are clustered at the family level. 
Table A1: Doctor in the Family and Health: Event Study Evidence

\begin{tabular}{|c|c|c|c|c|c|c|c|}
\hline \multirow[b]{3}{*}{ Outcomes } & \multirow[b]{3}{*}{$\begin{array}{c}\text { Pooled } \\
(1)\end{array}$} & \multicolumn{6}{|c|}{ Heterogeneity by } \\
\hline & & \multicolumn{2}{|c|}{ Income } & \multicolumn{2}{|c|}{ Family Tie } & \multicolumn{2}{|c|}{ Geographic Proximity } \\
\hline & & $\begin{array}{c}\text { Below } \\
\text { Median } \\
(2)\end{array}$ & $\begin{array}{c}\text { Above } \\
\text { Median } \\
(3)\end{array}$ & $\begin{array}{c}\text { Close } \\
(4)\end{array}$ & $\begin{array}{l}\text { Far } \\
(5)\end{array}$ & $\begin{array}{c}\text { Close } \\
(6)\end{array}$ & $\begin{array}{l}\text { Far } \\
(7)\end{array}$ \\
\hline \multicolumn{8}{|l|}{ A. Heart Attack } \\
\hline \multirow[t]{2}{*}{$\tau=-5$} & 0.000 & 0.002 & -0.001 & 0.001 & 0.001 & 0.000 & -0.000 \\
\hline & $(0.001)$ & $(0.001)$ & $(0.001)$ & $(0.001)$ & $(0.001)$ & $(0.001)$ & $(0.001)$ \\
\hline \multirow[t]{2}{*}{$\tau=+10$} & $-0.002^{*}$ & $-0.003^{*}$ & -0.001 & -0.002 & -0.001 & -0.002 & $-0.003^{* *}$ \\
\hline & $(0.001)$ & $(0.001)$ & $(0.001)$ & $(0.001)$ & $(0.001)$ & $(0.001)$ & $(0.001)$ \\
\hline \multirow{2}{*}{$\tau=+15$} & $-0.003^{* * *}$ & $-0.005^{* *}$ & -0.002 & $-0.003^{*}$ & $-0.003^{*}$ & $-0.003^{*}$ & $-0.005^{* * *}$ \\
\hline & $(0.001)$ & $(0.002)$ & $(0.001)$ & $(0.002)$ & $(0.001)$ & $(0.001)$ & $(0.001)$ \\
\hline Mean of Dep. Var. $(\text { at } \tau=+15)^{a}$ & 0.025 & 0.028 & 0.020 & 0.024 & 0.027 & 0.024 & 0.025 \\
\hline$\%$ Effect $($ at $\tau=+15)$ & 12.0 & 17.9 & 10.0 & 12.5 & 11.1 & 12.5 & 20.0 \\
\hline No. of Obs. & $5,077,361$ & $1,843,430$ & $2,670,133$ & $2,034,144$ & $2,319,387$ & $2,282,723$ & $2,699,291$ \\
\hline \multicolumn{8}{|l|}{ B. Heart Failure } \\
\hline \multirow[t]{2}{*}{$\tau=-5$} & 0.000 & -0.000 & 0.000 & -0.000 & -0.000 & -0.001 & 0.000 \\
\hline & $(0.001)$ & $(0.001)$ & $(0.001)$ & $(0.001)$ & $(0.001)$ & $(0.001)$ & $(0.001)$ \\
\hline \multirow[t]{2}{*}{$\tau=+10$} & $-0.003^{* * *}$ & $-0.004^{* *}$ & $-0.002^{*}$ & $-0.004^{* * *}$ & $-0.003^{*}$ & $-0.005^{* * *}$ & $-0.003^{* *}$ \\
\hline & $(0.001)$ & $(0.001)$ & $(0.001)$ & $(0.001)$ & $(0.001)$ & $(0.001)$ & $(0.001)$ \\
\hline \multirow[t]{2}{*}{$\tau=+15$} & $-0.005^{* * *}$ & $-0.005^{* *}$ & $-0.003^{* *}$ & $-0.005^{* * *}$ & $-0.005^{* * *}$ & $-0.006^{* * *}$ & $-0.005^{* * *}$ \\
\hline & $(0.001)$ & $(0.002)$ & $(0.001)$ & $(0.001)$ & $(0.001)$ & $(0.001)$ & $(0.001)$ \\
\hline Mean of Dep. Var. $(\text { at } \tau=+15)^{a}$ & 0.022 & 0.025 & 0.015 & 0.020 & 0.025 & 0.022 & 0.021 \\
\hline$\%$ Effect (at $\tau=+15)$ & 22.7 & 20.0 & 20.0 & 25.0 & 20.0 & 27.3 & 23.8 \\
\hline No. of Obs. & $5,077,361$ & $1,843,430$ & $2,670,133$ & $2,034,144$ & $2,319,387$ & $2,282,723$ & $2,699,291$ \\
\hline \multicolumn{8}{|l|}{ C. Type II Diabetes } \\
\hline \multirow[t]{2}{*}{$\tau=-5$} & $0.002^{* *}$ & 0.002 & 0.001 & 0.001 & $0.003^{*}$ & $0.002^{*}$ & $0.002^{*}$ \\
\hline & $(0.001)$ & $(0.001)$ & $(0.001)$ & $(0.001)$ & $(0.001)$ & $(0.001)$ & $(0.001)$ \\
\hline \multirow[t]{2}{*}{$\tau=+10$} & $-0.007^{* * *}$ & $-0.005^{* *}$ & $-0.006^{* * *}$ & $-0.006^{* * *}$ & $-0.005^{* *}$ & $-0.008^{* * *}$ & $-0.006^{* * *}$ \\
\hline & $(0.001)$ & $(0.002)$ & $(0.001)$ & $(0.002)$ & $(0.002)$ & $(0.002)$ & $(0.001)$ \\
\hline \multirow[t]{2}{*}{$\tau=+15$} & $-0.010^{* * *}$ & $-0.006^{* *}$ & $-0.010^{* * *}$ & $-0.008 * * *$ & $-0.008^{* * *}$ & $-0.013^{* * *}$ & $-0.008 * * *$ \\
\hline & $(0.001)$ & $(0.002)$ & $(0.002)$ & $(0.002)$ & $(0.002)$ & $(0.002)$ & $(0.002)$ \\
\hline Mean of Dep. Var. $(\text { at } \tau=+15)^{a}$ & 0.044 & 0.048 & 0.034 & 0.043 & 0.048 & 0.045 & 0.042 \\
\hline$\%$ Effect (at $\tau=+15)$ & 22.7 & 12.5 & 29.4 & 18.6 & 16.7 & 28.9 & 19.0 \\
\hline No. of Obs. & $5,077,361$ & $1,843,430$ & $2,670,133$ & $2,034,144$ & $2,319,387$ & $2,282,723$ & $2,699,291$ \\
\hline
\end{tabular}


Table A1: Doctor in the Family and Health: Event Study Evidence (Continued)

\begin{tabular}{|c|c|c|c|c|c|c|c|}
\hline \multirow[b]{3}{*}{ Outcomes } & \multirow[b]{3}{*}{$\begin{array}{l}\text { Pooled } \\
\text { (1) }\end{array}$} & \multicolumn{6}{|c|}{ Heterogeneity by } \\
\hline & & \multicolumn{2}{|c|}{ Income } & \multicolumn{2}{|c|}{ Family Tie } & \multicolumn{2}{|c|}{ Geographic Proximity } \\
\hline & & $\begin{array}{c}\text { Below } \\
\text { Median } \\
(2)\end{array}$ & $\begin{array}{c}\text { Above } \\
\text { Median } \\
(3)\end{array}$ & $\begin{array}{c}\text { Close } \\
(4)\end{array}$ & $\begin{array}{l}\text { Far } \\
(5)\end{array}$ & $\begin{array}{c}\text { Close } \\
(6)\end{array}$ & $\begin{array}{l}\text { Far } \\
(7)\end{array}$ \\
\hline \multicolumn{8}{|l|}{ D. Lung Cancer } \\
\hline$\tau=-5$ & $\begin{array}{l}-0.000 \\
(0.000)\end{array}$ & $\begin{array}{c}0.000 \\
(0.000)\end{array}$ & $\begin{array}{l}-0.000 \\
(0.000)\end{array}$ & $\begin{array}{c}0.000 \\
(0.000)\end{array}$ & $\begin{array}{c}0.000 \\
(0.000)\end{array}$ & $\begin{array}{l}-0.000 \\
(0.000)\end{array}$ & $\begin{array}{c}0.000 \\
(0.000)\end{array}$ \\
\hline$\tau=+10$ & $\begin{array}{c}-0.001^{* * *} \\
(0.000)\end{array}$ & $\begin{array}{c}-0.002^{* * *} \\
(0.001)\end{array}$ & $\begin{array}{l}-0.001 \\
(0.000)\end{array}$ & $\begin{array}{c}-0.002^{* *} \\
(0.001)\end{array}$ & $\begin{array}{l}-0.001 \\
(0.001)\end{array}$ & $\begin{array}{c}-0.002^{* * *} \\
(0.000)\end{array}$ & $\begin{array}{c}-0.001^{* *} \\
(0.000)\end{array}$ \\
\hline$\tau=+15$ & $\begin{array}{l}-0.001^{*} \\
(0.001)\end{array}$ & $\begin{array}{l}-0.002 \\
(0.001)\end{array}$ & $\begin{array}{l}-0.001 \\
(0.001)\end{array}$ & $\begin{array}{c}-0.002^{* *} \\
(0.001)\end{array}$ & $\begin{array}{l}-0.000 \\
(0.001)\end{array}$ & $\begin{array}{c}-0.002^{* *} \\
(0.001)\end{array}$ & $\begin{array}{l}-0.000 \\
(0.001)\end{array}$ \\
\hline Mean of Dep. Var. (at $\tau=+15)^{a}$ & 0.005 & 0.006 & 0.004 & 0.005 & 0.006 & 0.005 & 0.004 \\
\hline$\%$ Effect (at $\tau=+15$ ) & 20.0 & 33.3 & 25.0 & 40.0 & 0.0 & 40.0 & 0.0 \\
\hline No. of Obs. & $5,077,361$ & $1,843,430$ & $2,670,133$ & $2,034,144$ & $2,319,387$ & $2,282,723$ & $2,699,291$ \\
\hline
\end{tabular}

${ }^{a}$ Among family members of lawyers

Table reports coefficients $\sigma_{\tau}$ from the event study specification in Equation (4). The event time, sample restriction, and the set of family members included in the analysis are described in Section 3.4. Column (1) reports pooled results for 1936-1961 cohorts. Columns 2 and 3 split the sample by whether the individual's income rank within his/her gender-birth cohort is below or above the 50th percentile, with income measured at age 55 . Individuals with a zero or negative income at age 55 are dropped from analyses. Columns 4 and 5 split the full sample by the type of family tie: parents-children in "close" family tie and aunts/uncles vs. nieces/nephews in "far." Individuals with both ties are excluded from analyses in Column 5 . Columns 6 and 7 split the sample by geographic distance. Family members are classified as living "close" if their place of residence is recorded to be in the same county for more than 50 percent of the years between matriculation (into law or medicine) and the last year of data (2016). Coefficients are reported for event years -5 , 10, and 15 (i.e. 5 years before, and 10 , and 15 years after matriculation into the study of medicine or law). All regressions include the main effects and the interactions between event year dummies and the dummy for having a doctor in the (broad) family. The regressions further include the following covariates: age fixed effects, calendar year fixed effects, and individual fixed effects. Standard errors clustered by family are in parentheses. $* * *$, and $* * *$ denote significance at $10 \%, 5 \%$, and $1 \%$ level, respectively. 
Table A2: Survey Evidence on Health Literacy and Education

\begin{tabular}{|c|c|c|c|c|c|c|c|}
\hline & $\begin{array}{c}\text { Prefer } \\
\text { Seeing } \\
\text { Same } \\
\text { Doctor } \\
\quad(1)\end{array}$ & $\begin{array}{c}\text { Believe } \\
\text { Doctor } \\
\text { Always } \\
\text { Tells Truth } \\
\text { (2) }\end{array}$ & $\begin{array}{c}\text { Regular } \\
\text { Vegetables } \\
(3)\end{array}$ & $\begin{array}{c}\text { Regular } \\
\text { Fruit } \\
(4)\end{array}$ & $\begin{array}{c}\text { Regular } \\
\text { Sport } \\
(5)\end{array}$ & $\begin{array}{c}\text { Not } \\
\text { Smoking } \\
(6)\end{array}$ & $\begin{array}{c}\text { Good } \\
\text { Health } \\
(7)\end{array}$ \\
\hline No College Degree & $\begin{array}{c}0.06 \\
(0.03)\end{array}$ & $\begin{array}{c}-0.07^{*} \\
(0.03)\end{array}$ & $\begin{array}{c}-0.19 * * * \\
(0.03)\end{array}$ & $\begin{array}{c}-0.16^{* * *} \\
(0.04)\end{array}$ & $\begin{array}{l}-0.06 \\
(0.04)\end{array}$ & $\begin{array}{c}-0.14^{* * *} \\
(0.03)\end{array}$ & $\begin{array}{c}-0.06^{*} \\
(0.03)\end{array}$ \\
\hline No. of Obs. & 927 & 927 & 738 & 738 & 738 & 738 & 927 \\
\hline $\begin{array}{l}\text { Mean of Dep. Var. } \\
\text { Std. Dev. of Dep. Var. }\end{array}$ & $\begin{array}{l}0.70 \\
0.46\end{array}$ & $\begin{array}{l}0.28 \\
0.45\end{array}$ & $\begin{array}{l}0.77 \\
0.42\end{array}$ & $\begin{array}{l}0.55 \\
0.50\end{array}$ & $\begin{array}{l}0.56 \\
0.50\end{array}$ & $\begin{array}{l}0.84 \\
0.36\end{array}$ & $\begin{array}{l}0.76 \\
0.43\end{array}$ \\
\hline Age Fixed Effects & Yes & Yes & Yes & Yes & Yes & Yes & Yes \\
\hline $\begin{array}{l}\text { Survey Weights Used } \\
\text { Survey Year }\end{array}$ & $\begin{array}{l}\text { Yes } \\
2004\end{array}$ & $\begin{array}{c}\text { Yes } \\
2004\end{array}$ & $\begin{array}{c}\text { Yes } \\
2014\end{array}$ & $\begin{array}{l}\text { Yes } \\
2014\end{array}$ & $\begin{array}{c}\text { Yes } \\
2014\end{array}$ & $\begin{array}{c}\text { Yes } \\
2014\end{array}$ & $\begin{array}{c}\text { Yes } \\
2004\end{array}$ \\
\hline
\end{tabular}

Table reports OLS relationship between the level of education and health-related behaviors. The analysis is based on 2004 and 2014 waves of European Social Survey for Sweden. The sample is restricted to working age individuals between age 30 and 60 . We regress the outcome of interest on an indicator for having no college education (defined as not having a "completed tertiary education"). The OLS regression uses post-stratification survey weights and controls for age fixed effects. Binary outcome variables were constructed from underlying categorical survey responses to the following 7 questions or statements: 1) "Prefer same doctor for all everyday health problems"; 2) "Doctors keep whole truth from patients"; 3) "How often eat vegetables or salad, excluding potatoes"; 4) "How often eat fruit, excluding drinking juice"; 5 ) "Do sports or other physical activity, how many of last 7 days"; 6) "Cigarettes smoking behavior"; 7) "Subjective general health". For example, "Prefer seeing the same doctor" takes the value of 1 if individuals answered "Same for all health problems" in response to the question of whether they "Prefer same doctor for all everyday health problems." *,**, and *** denote significance at $10 \%, 5 \%$, and $1 \%$ level, respectively. 


\section{B Identification codes for diseases and drug use}

Diseases We identify diseases using the following ICD-10 diagnosis codes:

Table B1: ICD-10 Codes

\begin{tabular}{ll}
\hline Conditions & ICD10 Codes \\
\hline Heart Attack & I21, I22, I23 \\
Heart Failure & I11, I13, I50 \\
Type II Diabetes & E11, E13, E14 \\
Lung Cancer & $\mathrm{C} 34$ \\
Addiction & F10-F19 \\
Injury/Poisoning & S0-S9, T0-T9 \\
Respiratory Infection & J00-J06, J20-J22 \\
Intestinal Infection & A00-A09 \\
Chronic Tonsil Diseases & J35 \\
Asthma & J45 \\
Hypertension & I10 \\
Hyperlipidemia & E78, I70 \\
Ischemic Heart Diseases & I20-I25 \\
Stroke & I60, I61, I63, I66, G45, G46 \\
Pregnancy, Childbirth and the Puerperium & O00-O99 \\
\hline
\end{tabular}

Drug use Drug use is identified based on the following Anatomical Therapeutic Chemical (ATC) codes:

Table B2: ATC Codes

\begin{tabular}{ll}
\hline Drugs & ATC Codes \\
\hline Statins & C10AA \\
Blood Thinners & B01AC \\
Diabetes Drugs & A10B \\
Beta Blockers & C07 \\
Asthma Drugs & R03 \\
Vitamin D & A11CB, A11CC \\
Hormonal Contraceptives & G03A excluding G03AD \\
HPV Vaccine & J07BM \\
\hline
\end{tabular}




\section{Further related literature}

\section{C.1 Health literacy}

\section{C.2 Early childhood interventions}

A growing literature has documented that early life interventions have a positive effect on infant mortality and can promote health in the long-run, suggesting that conditions in infancy are a relevant source of health and socioeconomic disparities in later life. A Nurse-Family Partnership program in the US that provides regular home visits by certified nurses to low-income mothers from early pregnancy until the child reaches the age of two, has been found to have positive effects on birth outcomes and health in childhood (Agency for Healthcare Research and Quality 2014). For a universal home visiting program implemented in Denmark, Wüst (2012) show that the intervention had a positive and significant effect on the infant first-year survival rate in Danish towns and was most effective in the majority of small and medium-sized municipalities. The authors suggests that the main driver of the program's impact was the promotion of breastfeeding and appropriate infant nutrition by visiting nurses. In a related study, Hjort et al. (2017) examine the long-term impact of the Danish home visiting program. They find that treated individuals that were visited by nurses in infancy experience better health mid-life: they have lower mortality rates, spend fewer nights at hospital, and are less likely to be diagnosed with cardiovascular diseases. Similarly, Butikofer et al. (2015) investigate the long-term impact of mother and child health care centers in Norway and find that the increasing access to well-child visits had a positive effect on health, education and earning of treated infants when they reach age 30 to 40. Moreover, the authors find a stronger impact for children from lower socioeconomic background. Similarly, Sweden saw the introduction of a nurse home visiting program in the early 1930's and Bhalotra et al. (2017) find that, in the long-run, the infant care provided by nurse home visits reduced the probability of dying by age 75 by seven percent.

\section{C.3 Community health workers and access to primary care}

Community health workers (CHWs) have been employed in many countries to provide health-related services to their fellow community members. Although there has not been many rigorous evaluations, most existing evidence suggests that CHWs increase takeup rates of a wide variety of healthy behaviors and improve disease management in the community, notably for health behaviors such as cancer screening and immunization, and management of diseases such as asthma, hypertension, and diabetes (see e.g., Norris et al. 2006, Haines et al. 2007, and Najafizada et al. 2015). In addition, by assisting individuals in navigating the health care system, CHWs have been shown to improve access to medical services, especially for marginalized populations (Felix et al. 2011, Najafizada et al. 2015).

Access to primary care in the community setting has also been found to be an effective way to improve patients' health. Bailey and Goodman-Bacon (2015) use the rollout of community health centers (CHCs) in the U.S. from 1965 to 1974 to study the long-term health benefits of increased access to primary health care for the poor. The paper finds that, in one decade after CHCs were established, CHCs reduced age-adjusted all-cause 
mortality rates by 7 to 13 percent among the poor aged 50 and older, with the reduction primarily driven by the decline in cardiovascular-related deaths. The authors argue that having access to a regular source of care, lower medication cost, and improved compliance with prescription drugs were the main mechanisms for the effects of CHCs on mortality.

Moreover, a growing body of evidence suggests that the ease of access to nurses improves the health of patients with chronic conditions. Fergenbaum et al. (2015) present a systematic review of six randomized control trials that study the effects of home visits with nurse-led guidance in disease self-care management. Home visiting programs result in fewer hospitalizations, fewer emergency department visits, and better patient quality of life. Studies on nurse-led clinics that provide disease knowledge and support for disease self-care management report similar health effects: these clinics significantly reduce patient emergency department visits, hospital readmissions, and mortality rates, and improve patient medication adherence (Agvall et al. 2013, Gandhi et al. 2017, and Liljeroos and Strömberg 2019).

\section{C.4 Patient education}

An extensive body of work has evaluated the effectiveness of patient education interventions, finding such programs to be generally effective in promoting population health. For chronic diseases, Stenberg et al. (2018) review existing studies - 56 face-to-face intervention among patients living with chronic illess - on the impact of education programs that target chronic obstructive pulmonary disease (COPD), asthma, chronic pain, heart disease, and diabetes patients. The authors find that, regardless of study design and time horizon, interventions that promote patient education are beneficial in terms of decreased hospital admissions, fewer visits to emergency departments or general practitioners, and in terms of increased quality-adjusted life-years

Similarly, Wang et al. (2017) review randomized control trials that investigate effects of self-management education among patients with COPD. The paper highlights that such education programs improve patient disease-specific knowledge and quality of life, and reduce respiratory-related hospital admissions and emergency department visits. Anderson et al. (2017) focus on the educational component of cardiac rehabilitation for patients with coronary heart diseases. The study reviews 22 randomized control trials that assigned patients to different educational interventions that ranged from face-to-face counseling to residential stays with follow-up sessions. Patients in control groups received usual medical care in cardiac rehab that comprises exercise counseling and training and psychological support. The paper finds that, although there is limited evidence that educationbased interventions reduce total mortality, the risk of a heart attack, or the number of hospitalizations, these interventions result in lower risks of cardiovascular events and better quality of life. Similarly, Menichetti et al. (2018) review randomized control trials that promote patient engagement among older adults with osteoporosis, diabetes or cardiovascular-related health problems. The authors find that such interventions often demonstrate positive effects on patient compliance with treatment regimens.

In the context of health behaviors, Aveyard et al. (2012) and Stead et al. (2013) show that medical advice and provision of behavioral or pharmaceutical assistance on smoking cessation increase the frequency and success of smoking cessation attempts. Kaner et al. (2018) review the literature on alcohol interventions provided by health 
professionals and conclude positive effects of these interventions on reducing excessive alcohol consumption. For weight control, Aveyard et al. (2016) show that a randomized trial that provides interventions delivered by trained general practitioners improves body weight control among obese patients.

Another strand of literature examines the effects of public health education campaigns promoted by social media. A comprehensive summary of this literature can be found in Giustini et al. (2018). Many topics have been included in these social-media education campaigns, including health behaviors such as smoking cessation, healthy diet and physical activity (see, e.g., Chang et al. 2013, Williams et al. 2014, Swanton et al. 2015, and Chakraborty et al. 2018), and prevention and management of diseases such as diabetes and cancer (Gabarron et al. 2018, Han et al. 2018). Existing studies generally suggest positive effects of these campaigns on population health.

\section{Appendix references}

Agency for Healthcare Research and Quality, "Nurse Home Visits Improve Birth Outcomes, Other Health and Social Indicators for Low-Income, First-Time Mothers and their Children," 2014. Accessed February 22, 2019. https://innovations.ahrq.gov/profiles/ nurse-home-visits-improve-birth-outcomes-other-health-and-social-indicators-low-income.

Agvall, Björn, Urban Alehagen, and Ulf Dahlström, "The Benefits of Using a Heart Failure Management Programme in Swedish Primary Healthcare," European Journal of Heart Failure, 2013, 15 (2), 228-236.

Anderson, Lindsey, James Pr Brown, Alexander M Clark, Hasnain Dalal, Henriette K Rossau, Charlene Bridges, and Rod S Taylor, "Patient Education in the Management of Coronary Heart Disease," Cochrane Database of Systematic Reviews, June 2017, 6, No. CD008895.

Aveyard, Paul, Amanda Lewis, Sarah Tearne, Kathryn Hood, Anna Christian-Brown, Peymane Adab, Rachna Begh, Kate Jolly, Amanda Daley, Amanda Farley, Deborah Lycett, Alecia Nickless, Ly-Mee Yu, Lise Retat, Laura Webber, Laura Pimpin, and Susan Jebb, "Screening and Brief Intervention for Obesity in Primary Care: A Parallel, Two-Arm, Randomised Trial," The Lancet, 2016, 388 (10059), 2492-2500.

_ , Rachna Begh, Amanda Parsons, and Robert West, "Brief Opportunistic Smoking Cessation Interventions: A Systematic Review and Meta-Analysis to Compare Advice to Quit and Offer of Assistance," Addiction, 2012, 107 (6), 1066-1073.

Bailey, Martha J and Andrew Goodman-Bacon, "The War on Poverty's Experiment in Public Medicine: Community Health Centers and the Mortality of Older Americans," American Economic Review, 2015, 105 (3), 1067-1104.

Bhalotra, Sonia, Martin Karlsson, and Therese Nilsson, "Infant Health and Longevity: Evidence from a Historical Intervention in Sweden," Journal of the European Economic Association, 2017, 15 (5), 1101-1157. 
Butikofer, Aline, Katrine Løken, and Kjell Salvanes, "Long-Term Consequences of Access to Well-Child Visits," 2015. Accessed February 23, 2019. http://ftp.iza.org/dp9546.pdf.

Chakraborty, Bibhas, Raju Maiti, and Victor J Strecher, "The Effectiveness of Web-Based Tailored Smoking Cessation Interventions on the Quitting Process (Project Quit): Secondary Analysis of a Randomized Controlled Trial," Journal of Medical Internet Research, 2018, 20 (6), e213.

Chang, Tammy, Vineet Chopra, Catherine Zhang, and Susan J Woolford, "The Role of Social Media in Online Weight Management: Systematic Review," Journal of Medical Internet Research, 2013, 15 (11), e262.

Felix, Holly C, Glen P Mays, M Kathryn Stewart, Naomi Cottoms, and Mary Olson, "Medicaid Savings Resulted When Community Health Workers Matched those with Needs to Home and Community Care," Health Affairs, 2011, 30 (7), 1366-1374.

Fergenbaum, Jennifer, Sarah Bermingham, Murray Krahn, David Alter, and Catherine Demers, "Care in the Home for the Management of Chronic Heart Failure: Systematic Review and Cost-Effectiveness Analysis," Journal of Cardiovascular Nursing, 2015, 30 (4S), S44-S51.

Gabarron, Elia, Eirik Årsand, and Rolf Wynn, "Social Media Use in Interventions for Diabetes: Rapid Evidence-Based Review," Journal of Medical Internet Research, 2018, 20 (8), e10303.

Gandhi, Sumeet, Wassim Mosleh, Umesh C Sharma, Catherine Demers, Michael E Farkouh, and Jon-David Schwalm, "Multidisciplinary Heart Failure Clinics are Associated with Lower Heart Failure Hospitalization and Mortality: Systematic Review and Meta-Analysis," Canadian Journal of Cardiology, 2017, 33 (10), 1237-1244.

Giustini, Dean, Syed Mustafa Ali, Matthew Fraser, and Maged N Kamel Boulos, "Effective Uses of Social Media in Public Health and Medicine: A Systematic Review of Systematic Reviews," Online Journal of Public Health Informatics, 2018, 10 (2), e215.

Haines, Andy, David Sanders, Uta Lehmann, Alexander K Rowe, Joy E Lawn, Steve Jan, Damian G Walker, and Zulfiqar Bhutta, "Achieving Child Survival Goals: Potential Contribution of Community Health Workers," The Lancet, 2007, 369 (9579), 2121-2131.

Han, Claire Jungyoun, Young Ji Lee, and George Demiris, "Interventions Using Social Media for Cancer Prevention and Management: A Systematic Review," Cancer Nursing, 2018, 41 (6), E19-E31.

Hjort, Jonas, Mikkel Sølvsten, and Miriam Wüst, "Universal Investment in Infants and Long-Run Health: Evidence from Denmark's 1937 Home Visiting Program," American Economic Journal: Applied Economics, 2017, $9(4), 78-104$.

Kaner, Eileen FS, Fiona R Beyer, Colin Muirhead, Fiona Campbell, Elizabeth D Pienaar, Nicolas Bertholet, Jean B Daeppen, John B Saunders, and Bernard Burnand, "Effectiveness of Brief Alcohol Interventions in Primary Care Populations," Cochrane Database of Systematic Reviews, 2018, 2, No. CD004148. 
Liljeroos, Maria and Anna Strömberg, "Introducing Nurse-Led Heart Failure Clinics in Swedish Primary Care Settings," European Journal of Heart Failure, 2019, 21 (1), 103-109.

Menichetti, Julia, Guendalina Graffigna, and Aslak Steinsbekk, "What are the Contents of Patient Engagement Interventions for Older Adults? A Systematic Review of Randomized Controlled Trials," Patient Education and Counseling, 2018, 101 (6), 995-1005.

Najafizada, Said Ahmad Maisam, Ivy Lynn Bourgeault, Ronald Labonte, Corinne Packer, and Sara Torres, "Community Health Workers in Canada and other High-Income Countries: A Scoping Review and Research Gaps," Canadian Journal of Public Health, 2015, 106 (3), 157-164.

Norris, Susan L, Farah M Chowdhury, K Van Le, Tanya Horsley, J Nell Brownstein, Xuanping Zhang, Leonard Jack Jr, and Dawn W Satterfield, "Effectiveness of Community Health Workers in the Care of Persons with Diabetes," Diabetic Medicine, 2006, 23 (5), 544-556.

Stead, Lindsay F, Diana Buitrago, Nataly Preciado, Guillermo Sanchez, Jamie Hartmann-Boyce, and Tim Lancaster, "Physician Advice for Smoking Cessation," Cochrane Database of Systematic Reviews, 2013, 5, No. CD000165.

Stenberg, Una, Andre Vågan, Maria Flink, Vibeke Lynggaard, Kari Fredriksen, Karl Fredrik Westermann, and Frode Gallefoss, "Health Economic Evaluations of Patient Education Interventions: A Scoping Review of the Literature," Patient Education and Counseling, 2018, 101 (6), 1006-1035.

Swanton, Rosie, Vanessa Allom, and Barbara Mullan, "A Meta-Analysis of the Effect of New-Media Interventions on Sexual-Health Behaviours," Sexually Transmitted Infections, 2015, 91 (1), 14-20.

Wang, Tao, Jing-Yu Tan, Lily Dongxia Xiao, and Renli Deng, "Effectiveness of Disease-Specific SelfManagement Education on Health Outcomes in Patients with Chronic Obstructive Pulmonary Disease: An Updated Systematic Review and Meta-Analysis," Patient Education and Counseling, 2017, 100 (8), 1432-1446.

Williams, Gillian, Michele P Hamm, Jocelyn Shulhan, Ben Vandermeer, and Lisa Hartling, "Social Media Interventions for Diet and Exercise Behaviours: A Systematic Review and Meta-Analysis of Randomised Controlled Trials," BMJ Open, 2014, 4 (2), e003926.

Wüst, Miriam, "Early Interventions and Infant Health: Evidence from the Danish Home Visiting Program," Labour Economics, 2012, 19 (4), 484-495. 